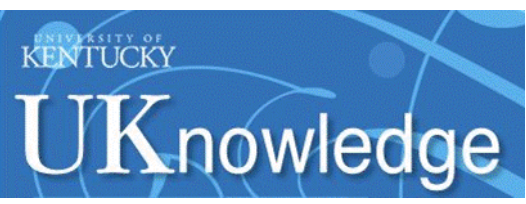

University of Kentucky

UKnowledge

\title{
THE EFFECTIVENESS OF USING COMMUNICATION-CENTERED INTERVENTION TO FACILITATE PHONOLOGICAL LEARNING IN YOUNG CHILDREN
}

Sharon Blodgett Hart

University of Kentucky, harts@murray-ky.net

Right click to open a feedback form in a new tab to let us know how this document benefits you.

\section{Recommended Citation}

Hart, Sharon Blodgett, "THE EFFECTIVENESS OF USING COMMUNICATION-CENTERED INTERVENTION TO FACILITATE PHONOLOGICAL LEARNING IN YOUNG CHILDREN" (2007). University of Kentucky Doctoral Dissertations. 518.

https://uknowledge.uky.edu/gradschool_diss/518

This Dissertation is brought to you for free and open access by the Graduate School at UKnowledge. It has been accepted for inclusion in University of Kentucky Doctoral Dissertations by an authorized administrator of UKnowledge. For more information, please contact UKnowledge@lsv.uky.edu. 


\section{ABSTRACT OF DISSERTATION}

Sharon Blodgett Hart

The Graduate School

University of Kentucky

2007 
THE EFFECTIVENESS OF USING COMMUNICATION-CENTERED INTERVENTION TO FACILITATE PHONOLOGICAL LEARNING IN YOUNG CHILDREN

\author{
ABSTRACT OF DISSERTATION \\ A dissertation submitted in partial fulfillment of the \\ requirements for the degree of Doctor of Philosophy in the \\ College of Health Sciences \\ at the University of Kentucky \\ By \\ Sharon Blodgett Hart \\ Lexington, Kentucky \\ Director: Dr. Lori Gonzalez, Professor and Dean of the College of Health Sciences \\ Lexington, Kentucky \\ 2007
} and Dr. Colleen Schneck, Professor of Occupational Therapy

Copyright@ Sharon Blodgett Hart 2007 


\section{ABSTRACT OF DISSERTATION}

\section{THE EFFECTIVENESS OF USING COMMUNICATION-CENTERED INTERVENTION TO FACILITATE PHONOLOGICAL LEARNING IN YOUNG CHILDREN}

A phonological disorder is a communication disorder of the speech sound system characterized by an impaired ability to use developmentally expected speech sounds and sound patterns to communicate with others (Bauman-Waengler, 2004). This impairment affects the clarity of a child's speech and how easily a child's speech can be understood. As stated in the Diagnostic and Statistical Manual of Mental Disorders (DSM-IV) (American Psychiatric Association, 1994), difficulties with speech sound production may interfere with academic achievement, social communication, or future occupational achievement. Children with phonological impairments are generally viewed as being at risk for reading difficulties (American Speech-Language-Hearing Association, 2001).

Clinicians and researchers in speech-language pathology agree that efficient treatment of children who have moderate to severe phonological disorders is critical. Although imitation and structured practice are primary strategies employed by speechlanguage pathologists for practicing speech production, using communicative tasks to facilitate generalization during phonological intervention has been suggested in the literature.

The purpose of this study was to determine if communication-centered phonological intervention would be effective in improving speech production in preschool children with moderate to severe phonological disorders. A single subject multiple probe across subjects research design (Horner \& Baer, 1978) was used to assess the effectiveness of communication-centered phonological intervention with three preschool children. The communication-centered phonological intervention in this investigation consisted of the combined application of focused stimulation of key words during joint storybook reading and interactive practice of key words using communicative feedback.

All three subjects demonstrated some type of phonological improvement following the communication-centered intervention. Two out of the three subjects demonstrated improvement in the use of the target phonological patterns during the 
intervention sessions with one of these participants demonstrating generalization of the target phonological pattern to conversational speech. Although the third subject did not demonstrate improvement during the intervention period, follow-up testing revealed some system-wide changes in his phonology that may be attributed to the intervention. Further investigation of communication-centered phonological intervention is warranted.

KEYWORDS: Phonological Disorders, Phonological Intervention, Speech Sound Disorders, Minimal Pairs, Generalization

Sharon Blodgett Hart 
THE EFFECTIVENESS OF USING COMMUNICATION-CENTERED INTERVENTION TO FACILITATE PHONOLOGICAL LEARNING IN YOUNG CHILDREN

\author{
By \\ Sharon Blodgett Hart
}

Lori Gonzalez, Ph.D.

Director of Dissertation

Co-Chair of Doctoral Committee

Colleen Schneck, Sc.D.

Co-Chair of Doctoral Committee

Jodelle Deem, Ph.D.

Director of Graduate Studies

May 5, 2007 


\section{RULES FOR THE USE OF DISSERTATIONS}

Unpublished dissertations submitted for the Doctor's degree and deposited in the University of Kentucky Library are as a rule open for inspection, but are to be used only with due regard to the rights of the authors. Bibliographical references may be noted, but quotations or summaries of parts may be published only with the permission of the author, and with the usual scholarly acknowledgments.

Extensive copying or publication of the dissertation in whole or part also requires the consent of the Dean of the Graduate School of the University of Kentucky.

A library that borrows this dissertation for use by its patrons is expected to secure the signature of each user.

Name

$\underline{\text { Date }}$ 


\section{DISSERTATION}

Sharon Blodgett Hart

The Graduate School

University of Kentucky

2007 
THE EFFECTIVENESS OF USING COMMUNICATION-CENTERED INTERVENTION TO FACILITATE PHONOLOGICAL LEARNING IN YOUNG CHILDREN

\section{DISSERTATION}

A dissertation submitted in partial fulfillment of the requirements for the degree of Doctor of Philosophy in the College of Health Sciences at the University of Kentucky

By

Sharon Blodgett Hart

Lexington, Kentucky

Director: Dr. Lori Gonzalez, Professor and Dean of the College of Health Sciences and Dr. Colleen Schneck, Professor of Occupational Therapy

Lexington, Kentucky

2007

Copyright@ Sharon Blodgett Hart 2007 


\section{DEDICATION}

This work is dedicated to the individuals who are my constant source of support: John, my husband, Betty, my mother, and my two wonderful children, Benjamin and Steven. 


\section{ACKNOWLEDGEMENTS}

I wish to thank my committee members who shared their expertise and time. Thank you to Dr. Schneck, Dr. Stewart, Dr. Hammons, and Dr. Bosch for serving on my committee. I would like to thank Dr. Schuster for joining my committee and helping guide my dissertation research. A special thanks to Dr. Lori Gonzalez for her guidance through every step of the process.

I would like to thank my colleagues from Murray State University who have been generous with their encouragement and their time throughout this process. Thank you Corky Broughton, Pearl Payne, Mick Miller, Jo-Ann Hammons, and Susan Brown. I would especially like to thank Kelly Kleinhans for her positive attitude and support during all phases of my dissertation research, especially for the hours she spent reviewing intervention tapes to assist me with reliability measures.

I would like to thank my mother for the time she spent listening and transcribing during this project. We always have fun talking about children’s interesting speech patterns, don’t we?

I would like to thank Stephanie Schaaf, not only for helping me implement the procedures and data collection process during this project, but also for our discussions about creating activities to facilitate meaningful, communicative, interactions for children. I would like to thank Rachel Hopper for her hours of patient work completing the computerized transcription reliability. I would also like to thank Haley Siler for her insight into the kinds of activities that would interest and engage young children.

I extend my appreciation to the parents who allowed me to include their children in this project. Your willingness to try new interventions for the benefit of your child and others is admirable.

Finally, I would like to thank my fellow doctoral students, especially those in the first cohort of this program. We have supported each other during this adventure while having full-time professional careers, family responsibilities, and a desire learn and grow as individuals. 


\section{TABLE OF CONTENTS}

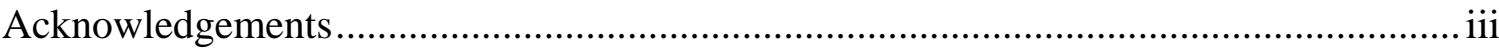

List of Tables ........................................................................................................... vii

List of Figures ....................................................................................................... ix

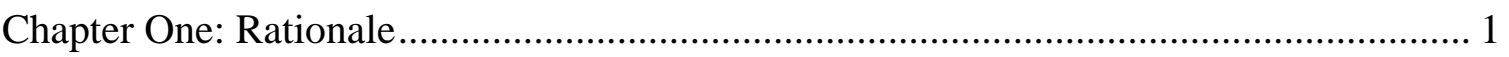

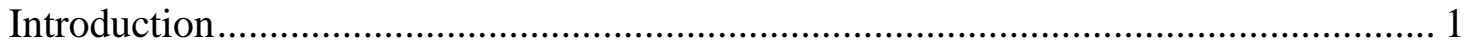

Impact of Phonological Disorders ......................................................................1

Phonological Disorders and Literacy Development .................................................2

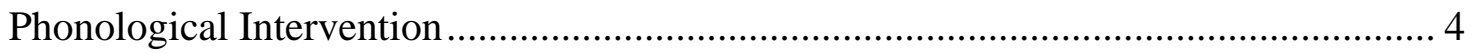

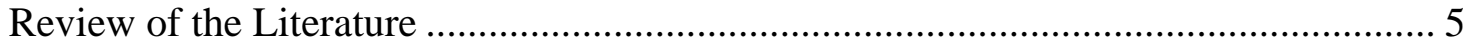

Principles of Phonological Intervention............................................................. 5

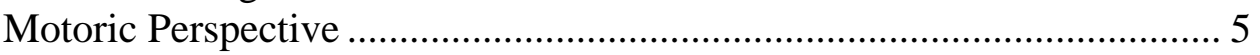

Linguistic Perspective............................................................................. 6

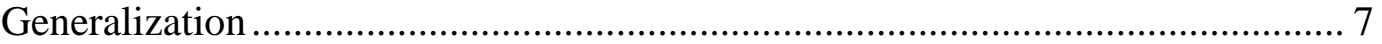

Generalization to Untreated Words …………………….......................... 7

Generalization Across Word Positions ..................................................... 8

Generalization Across Linguistic Units ................................................. 8

Generalization Within Sound Classes....................................................... 8

Facilitating Generalization..................................................................... 9

Phonological Treatment Principles ……….................................................... 9

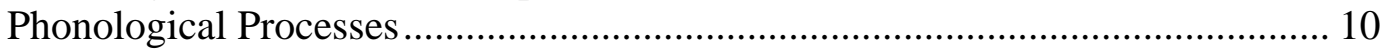

Syllable Structure Processes .................................................................... 10

Developmental Substitution Processes ....................................................... 12

Atypical Substitution Processes ............................................................ 12

Assimilatory Processes ........................................................................... 12

Phonological Processes in Children with Phonological Disorders ......................... 13

Natural Phonology Theory............................................................................. 14

Phonological Intervention Methods.................................................................. 14

Standard Procedures............................................................................. 14

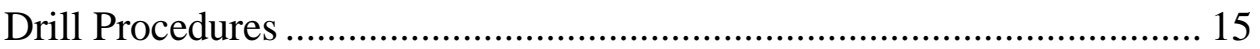

Drill-Play Procedures............................................................................... 15

Structured Play and Play Formats............................................................. 16

Therapeutic Feedback ........................................................................... 16

Minimal Pairs ..................................................................................... 16

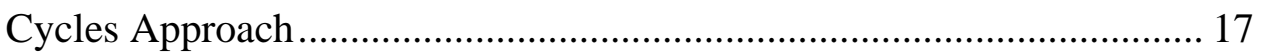

Communicative Intervention Methods ………………..................................... 18

Social Interactionist Theory ............................................................................ 19

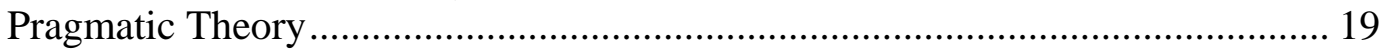

Communicative Approaches and Language Intervention..................................... 20

Naturalistic Procedures ....................................................................... 20

Shared Storybook Reading .................................................................... 21

Communicative Phonological Intervention ....................................................... 22 


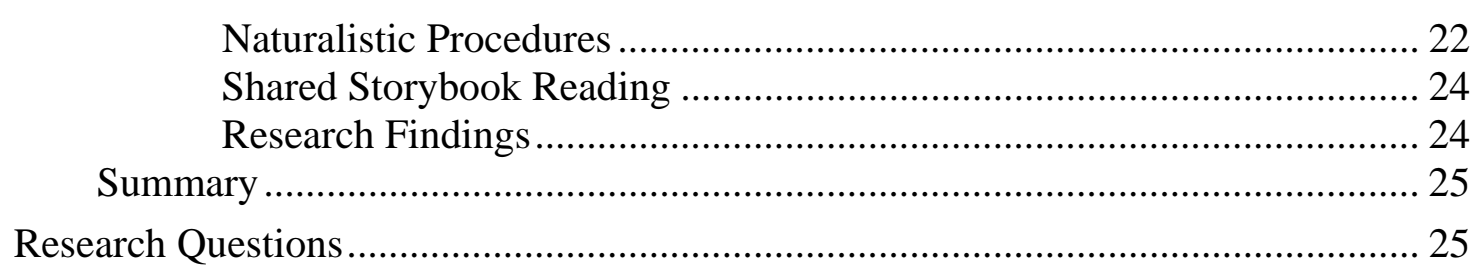

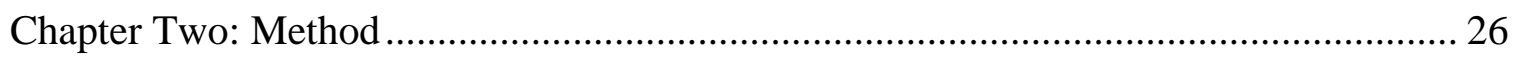

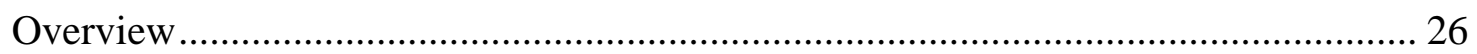

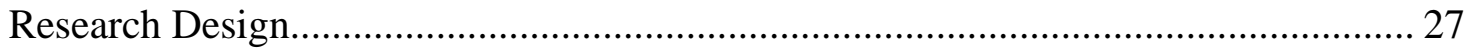

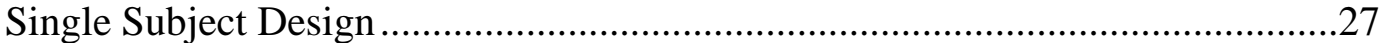

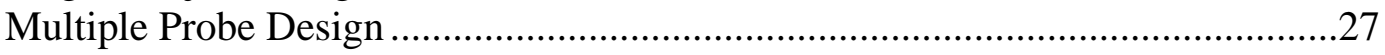

Independent Variables ..........................................................................28

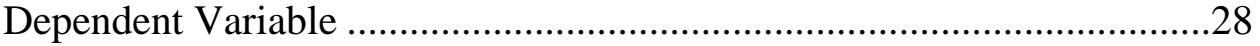

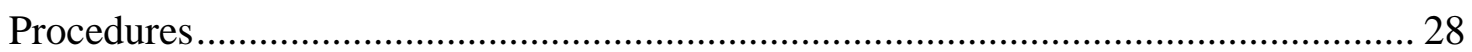

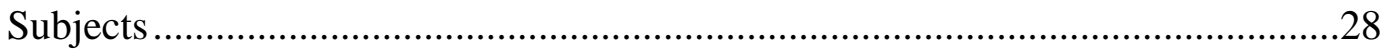

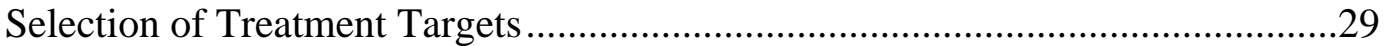

Standardized Testing............................................................................29

Phonological Process Selection ..............................................................29

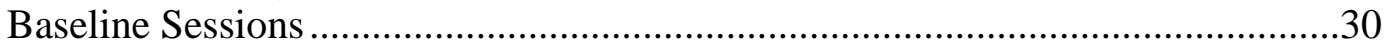

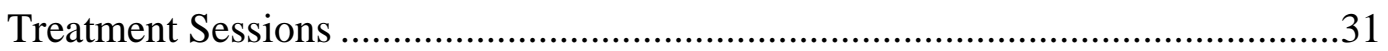

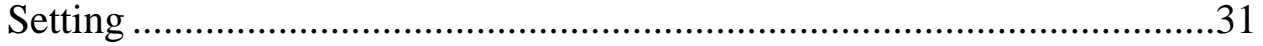

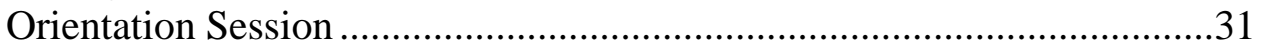

General Procedures ..................................................................................31

Development of General Procedures ............................................................33

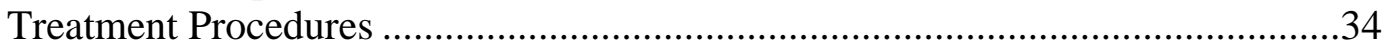

Focused Stimulation of Key Words ............................................................34

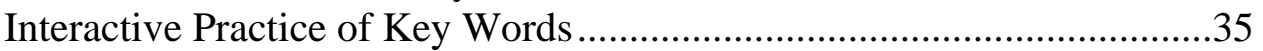

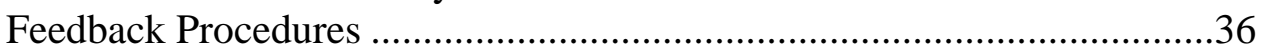

Materials and Equipment ...........................................................................37

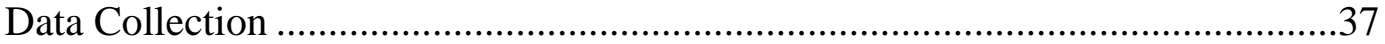

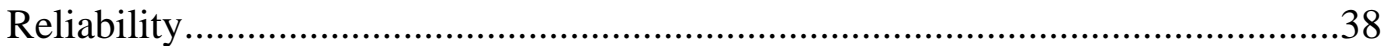

Transcription Reliability ………………………………………….......38

Procedural Reliability for Independent Variable .......................................39

Dependent Variable Reliability................................................................39

Analysis of Results ...........................................................................................

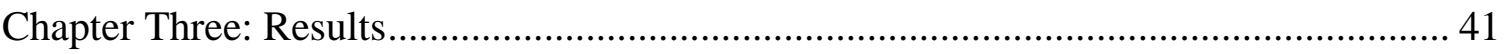

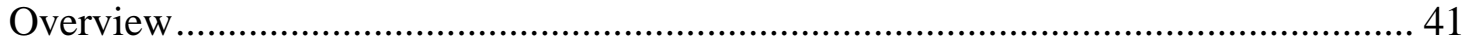

Results for Subject 1: Adam ................................................................................... 41

Background Information..............................................................................4

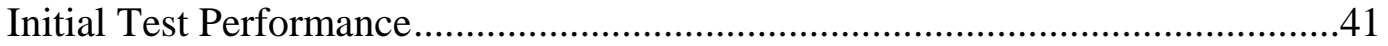

Target Selection …………………….............................................................43

Intervention Effectiveness ..............................................................................43 


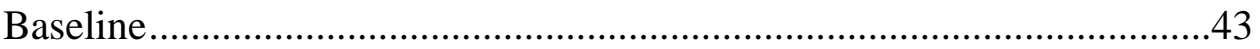

Intervention Sessions .............................................................................43

Within Class Generalization Following Intervention ...................................43

Within Class Generalization to Conversational Speech Following

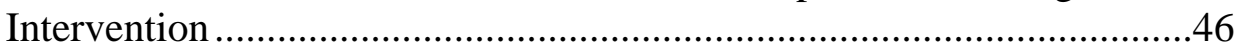

Maintenance and Within Class Generalization at One Month

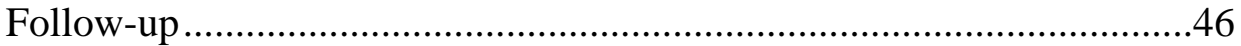

Maintenance and Generalization to Conversational Speech at One

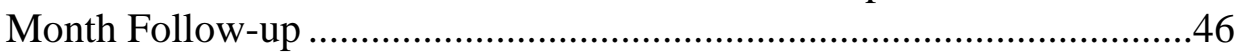

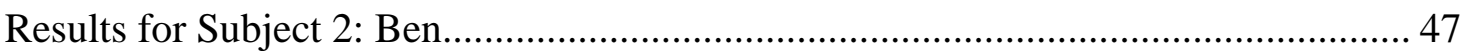

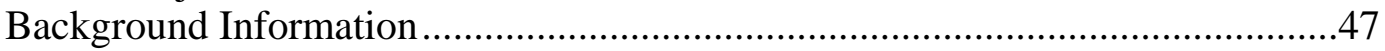

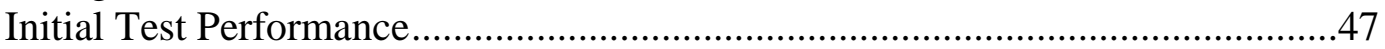

Target Selection .........................................................................................48

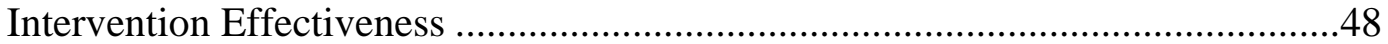

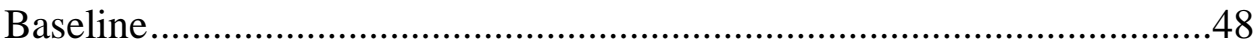

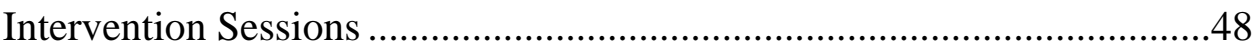

Within Class Generalization Following Intervention ..................................48

Within Class Generalization to Conversational Speech Following

Intervention

Maintenance and Within Class Generalization at One Month

Follow-up

Maintenance and Generalization to Conversational Speech at One

Month Follow-up ...............................................................................49

Results for Subject 3: Steven .............................................................................. 50

Background Information...............................................................................50

Initial Test Performance...................................................................................

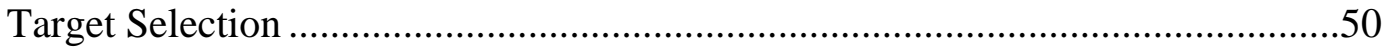

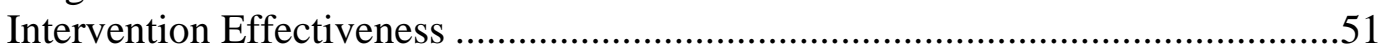

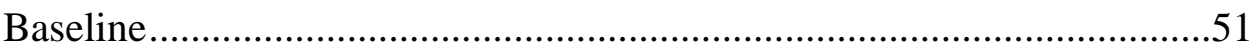

Intervention Sessions ……………………..........................................51

Within Class Generalization Following Intervention ...................................51

Within Class Generalization to Conversational Speech Following

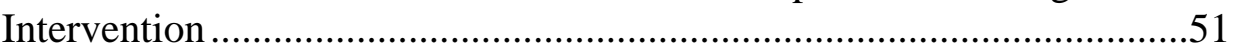

Maintenance and Within Class Generalization at One Month

Follow-up ...........................................................................................52

Maintenance and Generalization to Conversational Speech at One

Month Follow-up ...................................................................................52

System-wide Changes ...........................................................................52

Summary of Results for All 3 Subjects...................................................................... 53

Multiple Probe Single Subject Design..................................................................53

Intervention Effectiveness ………………....................................................53

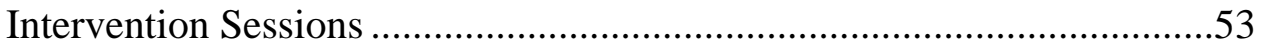

Within Class Generalization Following Intervention .................................54

Within Class Generalization to Conversational Speech Following

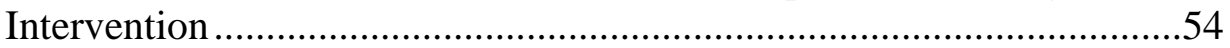

Maintenance and Generalization at One Month Follow-up.........................54 


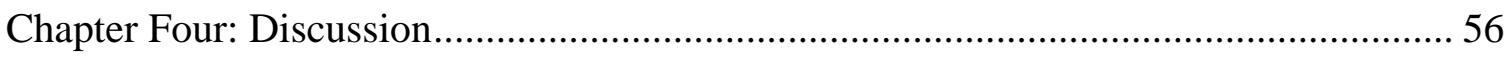

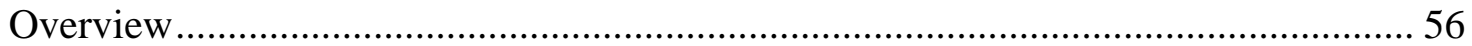

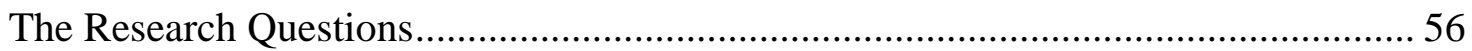

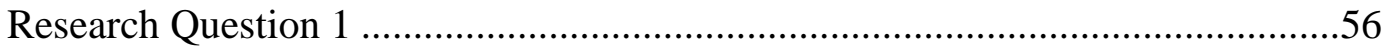

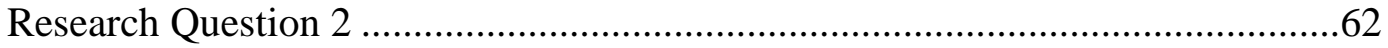

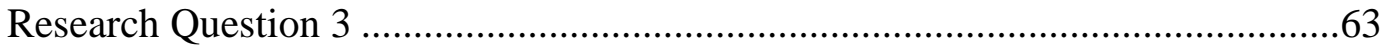

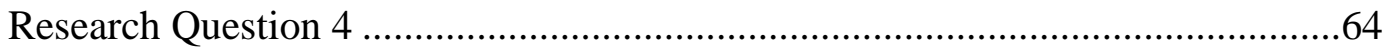

Research Question 5 ........................................................................65

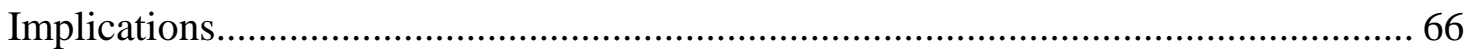

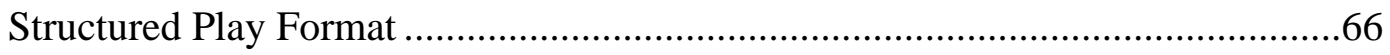

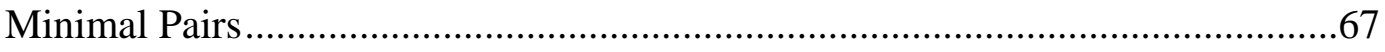

Books as Therapeutic Tools.......................................................................67

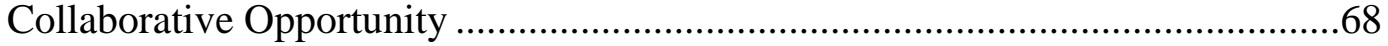

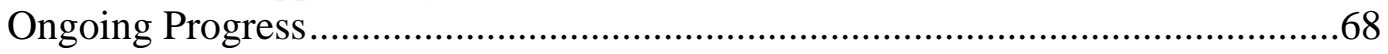

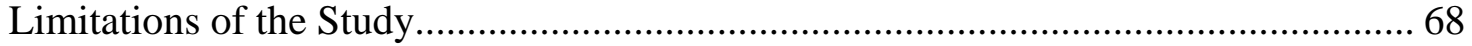

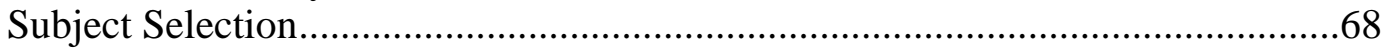

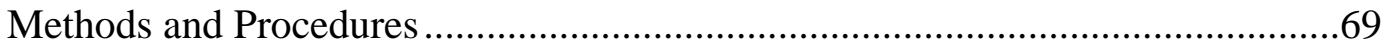

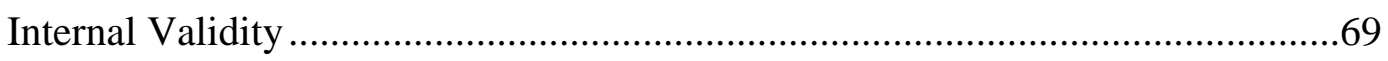

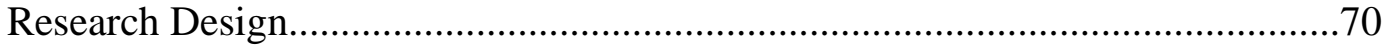

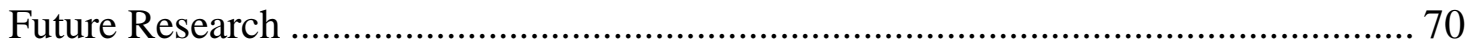

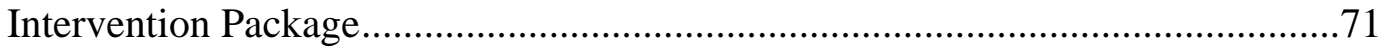

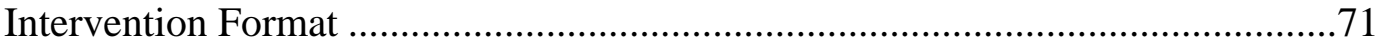

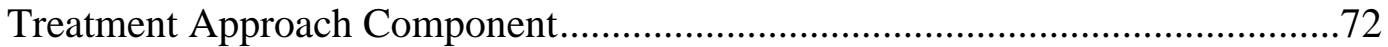

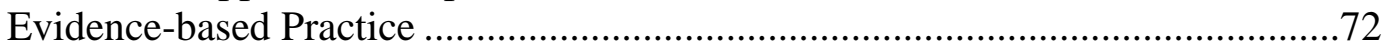

Appendices

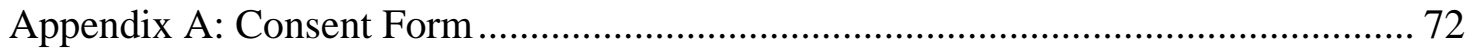

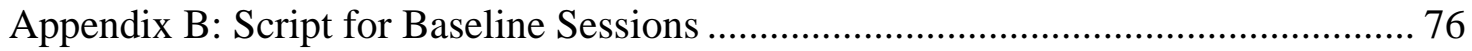

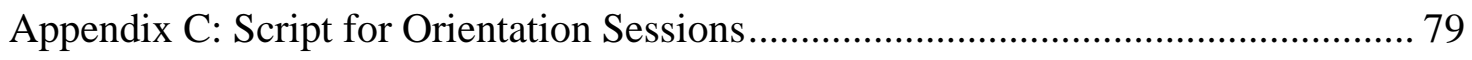

Appendix D: Parent Questionnaire ..................................................................... 80

Appendix E: Text of Clinician Made Books......................................................... 81

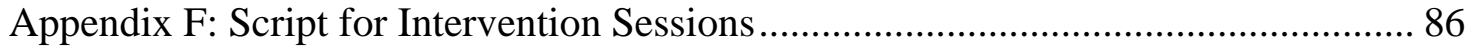

Appendix G: Reliability Datasheet for Baseline Sessions ....................................... 89

Appendix H: Reliability Datasheet for Intervention Sessions, Phase I ...................... 91

Appendix I: Reliability Datasheet for Intervention Sessions, Phase II....................... 92

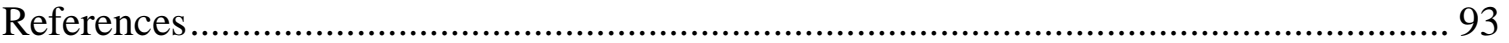

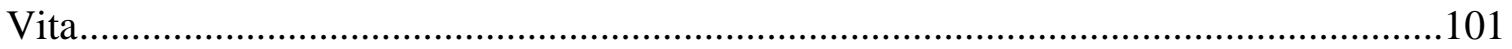




\section{LIST OF TABLES}

Table 1 Categorization of Phonological Processes .....................................................11

Table 2.1 Description of Substitution Processes............................................................30

Table 2.2 Description of Clinician Made Books ..........................................................33

Table 2.3 Examples of Cues for Phonological Target Sounds .......................................35

Table 3.1 Summary of Initial Assessments for All Subjects .......................................42

Table 3.2 Summary of Assessments for All Subjects......................................................45

Table 4.1 Changes During Intervention for Subject 2 ................................................58

Table 4.2 Changes During Intervention for Subject 1 ...............................................59

Table 4.3 Changes During Intervention for Subject 3 .............................................61 


\section{LIST OF FIGURES}

Figure 2 Communication-Centered Intervention Procedure........................................32

Figure 3 Baseline and Intervention Sessions for Adam, Ben, and Steven.....................44 


\section{CHAPTER ONE: RATIONALE}

Introduction

A phonological disorder is a communication disorder of the speech sound system characterized by an impaired ability to use developmentally expected speech sounds and sound patterns to communicate with others (Bauman-Waengler, 2004). This impairment affects the clarity of a child's speech and how easily a child's speech can be understood. Children with speech disorders may leave out sounds in words such as saying "un” for the word "sun". They may substitute one sound for another as in "tup" for "cup," or they may have a speech pattern that affects the syllable structure of words such as final consonant deletion. A child with this pattern would omit the last sound in most words (i.e., "boo" for "boot”). Children with moderate to severe speech sound disorders may use a limited number of speech sounds or have atypical speech patterns that make their speech very difficult to understand.

Phonological disorders are the most prevalent communication difficulty seen in young children (Lewis, Freebairn, \& Taylor, 2000). These disorders affect approximately eight to nine percent of the preschool and school age population (National Institute on Deafness and Other Communication Disorders, 2005). According to the American Speech-Language-Hearing Association’s recent School Survey (2004), the most common area of intervention was with children who have speech disorders. A small percentage of children with phonological disorders have physical factors such as hearing loss, major structural variations of the speech mechanism, or neuromotor disorders that impact phonological development. However, for most children with phonological disorders, the cause is unknown (Bernthal \& Bankson, 1998).

Impact of Phonological Disorders

Clinicians and researchers in speech-language pathology agree that efficient treatment of children who have moderate to severe phonological disorders is critical. For these children, treatment can often be a slow and gradual process (Rvachew \& Nowak, 2001) with many sounds and sound patterns requiring intervention. As stated in the Diagnostic and Statistical Manual of Mental Disorders (DSM-IV) (American Psychiatric Association, 1994), difficulties with speech sound production may interfere with academic achievement, social communication, or future occupational achievement. 


\section{Phonological Disorders and Literacy Development}

Children with phonological impairments have a disturbance in the speech sound system and are generally viewed as being at risk for reading difficulties (American Speech-Language-Hearing Association, 2001). A body of research is forming that appears to confirm this assumption (Bird, Bishop, \& Freeman, 1995; Hesketh, Adams, Nightingale, \& Hall, 2000; Nathan, Stackhouse, Goulandris, \& Snowling, 2004; Webster, Plante, \& Couvillion, 1997). Longitudinal and comparison studies of early literacy development in children with phonological disorders indicate that these children, especially children with moderate to severe disorders, are at risk for difficulty with literacy skills. In a longitudinal investigation (Webster et al., 1997), 45 children were assessed every three months on measures of phonological awareness, verbal working memory, and pre-reading skills from age 3:6 to 6:0. Twenty nine children had moderate to severe phonological impairments and 16 children had no speech impairments. The children with phonological impairments performed poorer on verbal working memory, phoneme segmentation, and letter identification indicating that children with moderate to severe phonological impairments during preschool are at risk for later difficulties with phonological awareness and letter knowledge.

Hesketh (2004) identified 35 children with a history of moderate to severe speech disorders between the ages of 3:6 and 5:0 and conducted follow-up assessments of phonological awareness, speech, and early literacy skills. Overall, the children with phonological disorders scored within normal limits on tasks of phonological awareness and literacy; however, a small number of children were identified with literacy delays. Phonological awareness assessment is recommended following speech intervention to identify this subgroup of children who may need literacy support.

Children who have phonological disorders often have concomitant impairments in other areas of language. Several researchers have examined the literacy skills of children with phonological disorders and additional language impairments. An investigation of 19 children with expressive phonological impairments, 12 children with phonological impairments plus additional language problems along with a matched control group, examined phonological awareness abilities at 5:7 and phonological awareness and outcome literacy measures for two subsequent years (Bird et al., 1995). Wide variation in 
performance was found; however, the majority of children with phonological impairments demonstrated significant literacy problems two years after the initial assessment with poorer performance in the group with additional language problems.

Another study compared the literacy skills of children with isolated phonological disorders and children with speech and language impairments (Nathan et al., 2004) and was designed to test language, phonology, and literacy skills of 47 children at 4:7, 5:8, and 6:9 years of age. Nineteen children had speech disorders; 19 had speech and language impairments; and 19 served as a typically developing control group. The children with speech and language impairment performed less well on the literacy measures than the children with phonological disorders or the control group. The children with more severe and persistent speech disorders were more likely to struggle with literacy development. Having a persistent speech disorder at seven years of age was seen as a risk factor for literacy problems. It was proposed that literacy development of children with preschool phonological disorders will be normal if the speech impairment has resolved before the initiation of formal literacy instruction.

Lewis, Freebairn, and Taylor (2000) assessed articulation, phonological processing, oral motor skills, and language skills of 52 children with moderate to severe expressive phonological disorders who were 4:6. They also divided the children into two groups based on initial testing: phonological disorder in isolation and phonological disorder plus other language problems. During the third grade and fourth grade, the children received follow-up measures of articulation, phonological processing, language, reading, and spelling. The group with phonological and other language problems performed more poorly on phoneme awareness, language, reading decoding, reading comprehension, and spelling. The isolated phonological disorder group demonstrated poor spelling skills relative to their reading and language abilities.

Although the precise link between reading acquisition and phonological disorders is not established, children with phonological disorders appear to be vulnerable to reading difficulties. Additional evidence is needed to clarify this relationship (Carroll \& Snowling, 2004). 


\section{Phonological Intervention}

Although imitation and structured practice are primary strategies employed by speech-language pathologists for practicing speech production, using communicative tasks to facilitate generalization during phonological intervention has been suggested in the literature. Elbert (1989) suggested that "the clinician give the child an opportunity to manipulate sounds actively and to recognize that sounds can and should be used in different communicative situations" (p.40). Winitz (1975) recommended "that the clinician contrive circumstances in which the child is eager to talk. Then the clinician should respond appropriately to correct productions and inappropriately to incorrect productions” (p.68). Kamhi (2000) pointed out that structured practice during speech intervention sessions is different from purposeful communication and may affect generalization of speech sounds and speech patterns. He used the example of a child who participated during structured speech therapy sessions but had difficulty generalizing new speech patterns to other settings.

Naturalistic intervention strategies are standard practice to facilitate generalization of language skills in young children (Bradshaw, Hoffman, \& Norris, 1998; Camarata \& Nelson, 1994; Crowe, Norris, \& Hoffman, 2003; Fey, 1986; Hoffman, 1997; Kaderavek \& Justice, 2002). The environment is arranged to provide opportunities for a child to learn through interaction. The therapist follows the child's lead and offers the child control over the communicative interaction. "Naturalistic approaches tend to rely more on language use and meaningful practice than in repetition or formal rehersal. It is believed that this contextual approach facilitates generalization” (Vilaseca \& Del Rio, 2004, p.165).

There is limited research addressing the clinical variable of using communicative interactions to impact the effectiveness of phonological intervention. Children who have moderate to severe phonological disorders have difficulty communicating with others in their environment. Conversational partners may understand part or none of the child's message. For a preschool child, having a phonological disorder may interfere with participation in daily activities at home and preschool. Gierut (1998) concluded that "treatment of functional phonological disorders in children is an established, welldocumented form of clinical intervention. To date the available research has clearly 
demonstrated the positive effects of such treatment" (p.94). Although treatment of phonological disorders is effective, it remains unclear which treatment variables are critical for efficient treatment especially for children with more severe phonological disorders. Systematic investigation of phonological intervention treatment variables is necessary in order to design efficient and effective treatment for children with moderate to severe phonological disorders (Baker \& Bernhardt, 2004).

The purpose of this study is to determine if communication-centered intervention will be effective in improving speech production in preschool children with moderate to severe phonological disorders. This investigation will use a single subject multiple probe across subjects research design to evaluate the effectiveness of communication-centered intervention on phonological patterns. The communication-centered intervention will consist of the combined application of focused stimulation of key words during joint storybook reading and interactive practice of key words.

Review of the Literature

The following review will begin with an overview of the principles of phonological intervention. A summary of standard phonological intervention methods and emerging communicative intervention procedures will be included.

Principles of Phonological Intervention

Many researchers and practitioners in speech-language pathology have shifted from an individual sound focus to a pattern-based focus regarding the assessment and treatment of children who have phonological disorders. This change has involved adopting a linguistic perspective by viewing speech production as rule-based behavior (Ingram, 1976; Stampe, 1969, 1979) rather than simply motor-based problems.

Motoric perspective. Historically, speech sound intervention has primarily been viewed as teaching a motor behavior. Articulation is a specific type of motor learning and includes "the processes involved in the planning and execution of smooth sequences of highly overlapping gestures of the speech organs” (Fey, 1992b, p. 225) Speech production errors were considered to be a result of defective oral anatomical structure, auditory processing difficulty, or difficulty with oral motor coordination (Hoffman \& Daniloff, 1990). Treatment focused on speed, mobility, and precision of the articulators (Fey, 1992b). 
The traditional motoric approach was developed in the early decades of the $1900 \mathrm{~s}$ by pioneers in the field of speech pathology. In the late 1930s, Charles Van Riper presented the first comprehensive theory and treatment techniques for articulation disorders. Van Riper modified and refined these principles over the years and today there are numerous versions of the traditional articulation approach in use (Bernthal \& Bankson, 1998; Secord, 1989). The therapy sequence begins with discrimination training followed by production of the sound in isolation. Intervention progresses through production of the sound in syllables, words, phrases, sentences, and spontaneous speech (Van Riper, 1978). Speech production is seen as a learned motor skill necessitating repetitive practice until the skill becomes automatic with individual phonemes targeted in a sequential manner (Bernthal \& Bankson, 1998).

During discrimination training, children are asked to make judgments of same or different for two words such as "rake" and "wake”. Bernthal and Bankson (1998) point out that, "there is a lack of evidence about the precise nature of the relationship between sound discrimination and the establishment of correct productions” (p. 310). A correlation between speech production errors seen in children and measures of speech perception has not been found, thus the assumption that discrimination should precede production is not universally accepted. Because most children can discriminate between correct and incorrect productions, auditory discrimination is not a strong variable related to production problems in most children (Pena-Brooks \& Hegde, 2000).

Linguistic perspective. The shift in viewing speech production in the context of the broader language system was influenced by the work of several linguists. Noam Chomsky and Morris Halle (1968) published The Sound Pattern of English which described speech patterns in terms of distinctive features. Each phoneme was attributed with a set of binary features such as nasal/nonnasal or voiced/nonvoiced. David Stampe proposed the Natural Phonology Theory (1969) which described an innate system of phonological processes that serve to revise a child's speech production until it matches the adult model. Lastly, David Ingram (1976) published Phonological Disability in Children which detailed a clinically-based application of phonological processes for clinicians. 
Application of rule-based analysis to the assessment and treatment of children with phonological disorders became established in the 1980s (Stoel-Gammon, StoneGoldman, \& Glaspey, 2002). Phonology was seen as a broader concept referring to the language component governing the patterns of speech sounds and how phonemes in a language function to signal a change in meaning. In a phonological approach to speech disorders, articulation is seen as part of the broader phonological system (Fey, 1992a).

In linguistic approaches to intervention, the primary focus of intervention is the relationship among sounds and facilitation of phonological rules. The goal of treatment is to facilitate sound contrasts, sequences, and sound classes or to establish new syllable shapes. Individual sounds or exemplars are selected for intervention with the assumption that generalization within the sound class or sound positions will occur (Bernthal \& Bankson, 1998).

\section{Generalization}

The goal of phonological intervention is to facilitate system-wide improvement or generalization in the child's speech sound system in order for the child to be more easily understood by others (Gierut, 2001). Intervention focusing on particular speech sounds or speech patterns often results in improvement in speech sounds or patterns that were not specifically targeted during speech therapy sessions. Rockman and Elbert (1984) explain "that by evaluating generalization routinely during clinical training, we afford ourselves a window into the client's changing articulation/phonological system and into the effectiveness of our own procedures as well” (p. 133). Many investigations of generalization following phonological intervention were conducted the the late 1960s, 1970s, and in the 1980s.

Generalization to untreated words. One type of generalization involves the correct production of target sounds in words not used in treatment sessions. "It seems clear that children are able to extend their correct use of a sound taught in only a few exemplars to a larger set of untrained items containing the same sound" (Elbert, 1989, p. 34). McReynolds (1972) found that most children transferred correct articulation to untrained probe words following training using a small set of nonsense syllables in a study of 4 children from 6:1 to 8:3. In a study of 19 children with a mean age of 4:7, a minimal pair contrast procedure was used targeting phonemes in the initial position of 
words (Elbert, Powell, \& Swartzlander, 1991). The production accuracy of target sounds was probed in the initial position of non-treated words. A small number of exemplars facilitated generalization in most of the subjects. For $80 \%$ of the children, generalization occurred using five or less exemplars during treatment sessions.

Generalization across word positions. Generalization from a word position that is trained to a word position that has not been trained has also been documented in the literature (Bernthal \& Bankson, 1998). Elbert and McReynolds (1975) taught 12 children from 6:5 to 11:3 to produce one specific [r] allophone or varient in the initial, medial, or final position of nonsense syllables. They found that most subjects generalized correct production to untrained allophones in different word positions. In an additional investigation of generalization, the [s] was targeted for five subjects between 5:6 and 6:4 using three basic syllables with the [s] first in the initial position, followed by the final position, then the medial position. Generalization probes using untrained syllables and words were conducted during each intervention session. All subjects demonstrated generalization of correct [s] responses to additional contexts as each training syllable was introduced. Two subjects demonstrated generalization of [s] to one or more probe syllable categories after intervention on the first target syllable (Elbert \& McReynolds, 1978).

Generalization across linguistic units. In this type of generalization, treatment occurs at one linguistic level such as syllables or words with generalization to more complex linguistic levels such as sentences or conversational speech. Generalization of target sounds and patterns to conversational speech is typically the goal of phonological intervention (Elbert \& Gierut, 1986). An investigation of 10 children from 3:7 to 5:9 with multiple phonological errors was designed to examine changes in the phonological system by analyzing spontaneous speech samples following minimal pair contrast training at the word level. Most of the children increased their percentage of correct consonant productions in conversational speech demonstrating generalization of correct sound productions to conversational speech without a direct focus on that linguistic level (Elbert, Dinnsen, Swartzlander, \& Chin, 1990).

Generalization within sound classes. Generalization within a sound class is expected when targets are based on phonological process analysis and manner, place, and 
voicing analysis (Bernthal \& Bankson, 1998). Weiner (1981) used a minimal contrast method to target three phonological process in two children ages 4:10 and 4:4. Deletion of final consonants, stopping, and fronting were addressed using four minimal pairs as stimuli for each phonological process. Gradual generalization of the treatment effect to probe words representing each targeted phonological process was seen for each subject. McReynolds and Elbert (1981) taught six children with a mean age of 5:9 [s], [r], or [1] clusters in nonsense syllables and tested generalization. Within class generalization was found for each cluster class with generalization most predictable to [s] clusters.

Facilitating generalization. Generalization is "an integral component in a child's acquisition of speech sounds and in the reorganization of the phonological system" (Elbert \& Gierut, 1986, p. 149) and is the ultimate goal of phonological intervention (Tyler, 2005b). Elbert and Gierut (1986) state that to facilitate generalization during phonological intervention, target items should be meaningful to the child and target sounds should be used in different communicative situations during intervention sessions. Phonological Treatment Principles

Numerous approaches to phonological intervention have been reported in the literature. Phonological treatment approaches share a common set of principles including a comprehensive evaluation of the child's phonological system with a detailed description of the child's phonological patterns (Forrest, Elbert, \& Dinnsen, 2000; Hodson \& Paden, 1991; Morrisette \& Gierut, 2002; Rvachew \& Nowak, 2001). The goal of clinical intervention is to increase a child's overall intelligibility through generalization of specific treatment targets (Elbert et al., 1990; T. Powell, Miccio, Elbert, Brasseur, \& Strike-Roussos, 1999; Williams, 1991). Phonological patterns are generally selected for intervention objectives and key phonemes are selected for treatment targets (Gierut \& Champion, 2001; Hodson, 2004; Saben, Costello, \& Ingham, 1991). Stimulable phonemes are usually chosen for targets (Bernthal \& Bankson, 1998; Dyson \& Robinson, 1987; Hodson \& Paden, 1991) meaning that the child can correctly imitate the sound following examiner modeling and cueing (Miccio, Elbert, \& Forrest, 1999).

Treatment variables differ among phonological treatment approaches. Traditional methods of intervention using behavioral techniques and a hierarchial progression focusing on the phoneme, syllable, word, phrase, sentence and conversation levels are 
commonly used in phonological intervention (Almost \& Rosenbaum, 1998; Forrest \& Elbert, 2001; Tyler \& Figurski, 1994). However, other researchers employ whole word practice using a drill-play format (Forrest \& Elbert, 2001; Hodson, 2004; McCauley, 1993; Morrisette \& Gierut, 2002). Contrastive pairs of words (words differing by one or more articulatory elements) (Dean, Howell, Walters, \& Reid, 1995; T. Powell, Elbert, \& Dinnsen, 1991; Weiner, 1981) and specific cueing strategies are often employed as components on phonological intervention (Blodgett \& Miller, 1989; Hodson \& Paden, 1991; Stone \& Stoel-Gammon, 1990).

\section{Phonological Processes}

The use of phonological processes as an assessment and treatment framework has become widely applied in speech-language pathology. Phonological process procedures are accepted for analyzing the speech of children with multiple articulation errors and reduced intelligibility (Edwards, 1997). Phonological processes are usually described as processes that modify the syllable structure of a target word (syllable structure processes), processes that substitute one sound for another sound (substitution processes), and processes that involve one sound becoming more similar to another sound (assimilation processes) (Ingram, 1976; Stoel-Gammon \& Dunn, 1985).

An example of the categorization of phonological processes is found on Table 1. The phonological processes on the left side of the chart represent phonological processes seen during typical language development. In general, phonological processes found in the speech of children with typical development also occur in children with phonological disorders. A few phonological patterns are rare in typical development and frequent in children with phonological disorders (Stoel-Gammon \& Dunn, 1985). Atypical patterns are located on the right of the phonological process chart.

Syllable structure processes. Developmental syllable structure processes usually include deletion of final consonants, deletion of unstressed syllables, reduplication (repeating a syllable), diminuitization (adding [I] to a word), and cluster reduction (simplifying a consonant cluster). Phonological processes not usually seen in typical development include backing, initial consonant deletion and atypical cluster reduction. In atypical cluster reduction the deleted consonant is the consonant that is usually 
Table 1

Categorization of Phonological Processes

Developmental Processes (Typical)

Non-Developmental Processes (Atypical)

\begin{tabular}{|c|c|c|c|c|c|}
\hline \multicolumn{6}{|c|}{ Syllable Structure Processes } \\
\hline Deletion of Final Consonants & $\begin{array}{l}\text { Target } \\
\text { cat }\end{array}$ & $\begin{array}{l}\text { Child } \\
{[k æ]}\end{array}$ & Initial consonant deletion & $\begin{array}{l}\text { Target } \\
\text { sun }\end{array}$ & $\begin{array}{l}\text { Child } \\
{[\wedge n]}\end{array}$ \\
\hline Deletion of Unstressed Syllables & telephone & [tefon] & & & \\
\hline Reduplication & bottle & {$[\mathrm{baba}]$} & & & \\
\hline Diminuitization & blanket & [bænki] & & & \\
\hline Cluster Reduction & stick & [ttk] & Atypical cluster reduction & stop & [sap] \\
\hline \multicolumn{6}{|c|}{ Assimilatory Processes } \\
\hline Labial Assimilation & zip & [bip] & & & \\
\hline \multirow[t]{2}{*}{ Velar Assimilation } & coat & [kok] & & & \\
\hline & rock & [gak] & & & \\
\hline Nasal Assimilation & bunny & {$[\mathrm{m} \wedge \mathrm{ni}]$} & & & \\
\hline \multicolumn{6}{|c|}{ Substitution Processes } \\
\hline Stopping & house & [haut] & Fricatives substituted for stops & candle & [sændl] \\
\hline Deaffrication & watch & [was] & Backing & pat & [pæk] \\
\hline Velar Fronting & cow & [tau] & Glottal Replacement & baby & [bePi] \\
\hline Depalatization & shoe & [su] & Sound Preference & sun & {$[\mathrm{h} \wedge \mathrm{n}]$} \\
\hline \multirow[t]{2}{*}{ Voicing } & pie & [bar] & & foot & [hut] \\
\hline & bag & [bæk] & & shoe & [hu] \\
\hline Gliding & look & [wuk] & & & \\
\hline Vowelization & hammer & [hæmo] & Stops substituted for glides & will & [bIl] \\
\hline
\end{tabular}

Adapted from (Hodson, 2004; Ingram, 1976; Stoel-Gammon \& Dunn, 1985) 
maintained. For example, in the typical substitution for the word "stop" the [s] is deleted as in [tap]. An atypical substitution would be to delete the [t] as in [sap] (Stoel-Gammon \& Dunn, 1985).

Developmental substitution processes. Substitution processes occurring during typical phonological development include stopping, velar fronting, depalatization, voicing, gliding, and vowelization. For the process of stopping, a stop consonant $[p, b, t, d, k, g]$ is substituted for a fricative consonant $\left[f, v, s, z, \int, 3, \theta, \partial, h\right]$. An anterior consonant $[t, d]$ is substituted for a posterior consonant $[k, g]$ for velar fronting. Depalatization occurs when an alveolar fricative [s] is substituted for a palatal fricative [J]. The phonological process of voicing or changing the voicing of a consonant can be further divided into prevocalic voicing as in [brg] for pig, prevocalic devoicing as in [k^m] for gum, and postvocalic devoicing as in [bæk] for bag. Gliding usually denotes the substitution of a glide [ $w, j]$ for a liquid $[l, r]$. Vowelization (sometimes referred to as vocalization) indicates that a vowel is substituted for a vocalic liquid as in [zipu] for zipper (Hodson, 2004; Stoel-Gammon \& Dunn, 1985).

Atypical substitution processes. Examples of atypical substitution processes reported include the phonological processes of backing, glottal replacement, fricatives substituted for stops, stops substituted for glides, and sound preference patterns. The process of backing occurs when posterior consonants are substituted for anterior consonants. This frequently involves the substitution of velars $[k, g]$ for alveolars $[t, d]$. However, other backing patterns are seen such as [h^m] for "thumb", or [hup] for "soup". In the phonological process of glottal replacement, a glottal stop is substituted systematically for another phoneme as in [bæ?] for black. When children have sound preference patterns they may substitute one consonant for numerous other consonants. In the example from Table 1 the child substitutes [h] for [s, $\left.f, \int\right]$. Children also demonstrate unique atypical phonological processes such as substituting fricatives for stops (Hodson, 2004; Stoel-Gammon \& Dunn, 1985).

Assimilatory processes. A final category of phonological processes is assimilatory processes. Assimilation involves a sound changing due to the influence of another sound 
in a word. The sound is altered by taking on a characteristic of another sound (Hodson, 2007). This category represents a group of processes commonly divided into labial assimilation, velar assimilation, and nasal assimilation. In labial assimilation a nonlabial target becomes labial in the presence of another labial sound, in velar assimilation, a velar is substituted for a nonvelar consonant when a velar is present, and in nasal assimilation a nasal is substituted for a nonnasal consonant when a nasal sound is in the word (Hodson, 2004). Assimilatory processes represent sound changes due to sounds preceding each other (progressive assimilation) or following each other (regressive assimilation) in a word (Stoel-Gammon \& Dunn, 1985). In Table 1, [kok] for “coat” is an example of progressive assimilation and [gak] for "rock" represents a regressive assimilation process. Phonological Processes in Children with Phonological Disorders

In addition to the individual categories of phonological processes presented, words can be impacted by more than one phonological process especially in the speech of young children with phonological disorders (Stoel-Gammon et al., 2002). For example a child may pronounce the word "sister" as [di?ə] which can be described by the phonological processes of stopping, glottal replacement, and vowelization.

Numerous descriptions of phonological processes are found in the literature (Edwards \& Shriberg, 1983; Grunwell, 1997; Hodson, 2004; Hodson \& Paden, 1991; Ingram, 1976; Shriberg \& Kwiatkowski, 1980; Stoel-Gammon \& Dunn, 1985). There is also considerable variation in the occurrence of phonological processes in the speech of young children. Some children may not exhibit all of the patterns categorized as developmental processes. Most children will demonstrate weak syllable deletion, final consonant deletion, gliding, and cluster reduction during phonological development with gradual suppression of processes (Stoel-Gammon \& Dunn, 1985).

Children who continue to use these simplification processes beyond the typical time frame or use atypical processes in addition to developmental phonological processes are identified as having a phonological disorder. The speech sound patterns used by a child with a phonological disorder may be unique and may interfere with communication In some children, intelligibility may be reduced while in other children their speech may be unintelligible. 


\section{Natural Phonology Theory}

Stampe's Natural Phonology Theory (1979) forms the theoretical basis for using phonological processes in the assessment and treatment of young children with phonological disorders. He defined a phonological process as a "mental operation that applies in speech to substitute, for a class of sounds or sound sequences presenting a specific common difficulty to the speech capacity of the individual, an alternative class identical but lacking the difficult property” (p. 1). During development when children are confronted with sounds they cannot pronounce, they use regular substitutions or simplifications. According to Stampe, these substitutions involve a mental operation motivated by the innate physical constraints of the speech mechanism and serve to minimize articulatory difficulties. Children are seen as having a set of innate processes that serve to simplify adult word forms (Ingram, 1989).

Stampe maintains that phonological processes provide "interim pronunciations" children can use to communicate with others until they can master mature pronunciation. During language development, the child suppresses these natural substitutions and gradually acquires conventional patterns. Each phonological process applies to a natural class of sounds sharing a common articulatory, perceptual, or prosodic difficulty. Each process involves a substitution changing one phonetic property or feature "to remedy the difficulty” (Donegan \& Stampe, 1979, p. 137). Natural Phonology Theory has been adopted by many child phonology researchers. The proposal that phonological processes describe systematic errors in children’s speech production has been widely accepted (Stoel-Gammon \& Dunn, 1985).

\section{Phonological Intervention Methods}

Standard procedures. Following a phonological process analysis, key sounds affected by the targeted error pattern are chosen to serve as "vehicles for elimination of the entire error pattern” (Tyler, 2005a, p. 69). The goal is to decrease the child's use of the phonological process and facilitate the emergence of new patterns by using specific phonemes as examples of the target pattern (Hodson \& Paden, 1991). For example, if the child demonstrates the phonological process of stopping, by consistently substituting stop consonants for fricatives, the new target pattern is production of fricatives. One or more phonemes from the fricative category are chosen as exemplars for the new pattern. 
The process of phonological acquisition is gradual (Ingram, 1976). During phonological intervention, children are expected to demonstrate improved intelligibility over time. It is standard practice during the early stages of phonological intervention to note a child's correct use of the target pattern rather than correct production of the exact phoneme. For example, if the target pattern is correct production of fricatives, the child may say [f^n] for the word [s^n]. If the child usually substitutes a stop consonant and says

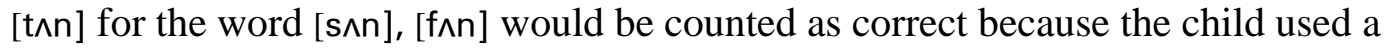
fricative to begin the word and the target pattern was used correctly. Ingram (1976) points out that, "a change in the child's speech can be considered correct if it results in a closer approximation to the adult model” (p.150).

Routine procedures found in most descriptions of phonological research include clinician-directed interaction using a drill or drill-play format. The child is in a responding role usually imitating the clinician or naming pictures, and token or verbal reinforcement is provided to the child based on production accuracy. The customary framework for phonological intervention consists of four modes: drill, drill-play, structured play, and play (Shriberg \& Kwiatkowski, 1982).

Drill procedures. Drill procedures involve rapid presentation of the stimulus. The child does not have control over the selection or rate of presentation of the stimuli. Drill procedures are commonly seen in phonological intervention research (Elbert et al., 1991; Forrest \& Elbert, 2001; Forrest et al., 2000; Gierut, Morrisette, \& Champion, 1999; Hesketh et al., 2000; Miccio et al., 1999; Rvachew \& Nowak, 2001; Williams, 1993). During drill procedures, the child is typically imitating phonemes in isolation (Forrest et al., 2000; Tyler \& Figurski, 1994), or in words (Elbert et al., 1991; Morrisette \& Gierut, 2002).

Drill-play procedures. Drill-play procedures are also widely used in phonological intervention (Gierut, 1990, 1992, 1999, 2005; Hodson \& Paden, 1991; T. Powell, 1991) and are structured in different ways. Examples include imitating or naming a picture before taking a turn during a game (Rvachew \& Nowak, 2001) or naming picture cards as they are found buried in box of sand (Hodson \& Paden, 1991).

Structured play and play formats. Structured play is a similar format to drill-play with the training stimuli embedded more in a play activity (Shriberg \& Kwiatkowski, 
1982). In the play structure, the clinician designs activities so the child's target responses occur as a natural part of the activity. Descriptions of structured play and play frameworks are infrequent in the phonological intervention literature. Hoffman (1992) emphasizes using functional play activities during phonological intervention. Common routines can be used such as feeding a doll. Steps in the play routine (putting food on a plate, feeding the doll, talking to the doll about the food, etc...) create a communicative intervention context. Camarata (1993) structured a play format for an investigation of naturalistic conversation training. Numerous toys and books containing specific speech targets were used during intervention. Tyler (2005a) employs drill-play procedures and naturalistic procedures for production practice during phonological intervention. Naturalistic procedures are centered on themes and the daily routines of art, snack, and dramatic play.

Therapeutic feedback. Token reinforcement and verbal praise are the primary methods of feedback given to children during phonological intervention. An example of token reinforcement (T. Powell, 1991) is giving a child a chip for each correct response with chips exchanged for stickers. Providing verbal feedback usually entails using praise for correct responses and corrective feedback or modeling for incorrect responses (Forrest \& Elbert, 2001; Forrest et al., 2000; Gierut, 2005; Gierut \& Champion, 1999, 2001; Morrisette \& Gierut, 2002).

Minimal pairs. An additional procedure commonly found in phonological intervention research is the use of minimal pairs. Minimal pairs are sets of words differing by a single phoneme that causes a change in meaning (Barlow \& Gierut, 2002). For example in the words "bike" and "bite", the first and second phoneme are the same and the differing final phonemes signal a change in meaning. Weiner (1981) explains the procedure:

In this treatment technique, pairs of words are selected for which the child's mispronunciation of one member of the pair (the target word) renders it identical to the second member of the pair. The child is then confronted with the homonymous word pairs and is requested to eliminate the ambiguity by changing the pronunciation of the target word (p. 98).

In conventional minimal pair treatment, the child's production and the correct production form a pictured contrast pair. The child identifies members of the pair by pointing to the 
picture that is named then the roles are reversed and the child tells the clinician which picture to point to. A communication breakdown is created when the child is obviously intending to say one of the words and actually says the contrast pair instead. The clinician provides feedback relating to the miscommunication creating an opportunity for the child to modify his production to correct the confusion (Barlow \& Gierut, 2002; Blache, Parsons, \& Humphreys, 1981; Lowe \& Weitz, 1994).

Minimal pair stimuli have also been used with drill and drill-play activities (Elbert et al., 1990; Elbert \& McReynolds, 1985; Elbert et al., 1991; Gierut, 1990; Gierut, Elbert, \& Dinnsen, 1987; T. Powell, 1991; T. Powell \& Elbert, 1984; T. Powell et al., 1991; Williams, 1993). During these activities, the minimal pair pictures are imitated or named by the child using token reinforcement or praise rather than communicative feedback.

Cycles approach. The Cycles Phonological Remediation Approach "is the most fully articulated treatment program based on phonological processes" (Stoel-Gammon et al., 2002, p. 7). The approach consists of a detailed phonological analysis, guidelines for determining target speech patterns, and a structure for treatment sessions. The purpose of the approach is to facilitate overall intelligibility by targeting primary error patterns in a cyclical fashion (Hodson, 1997; Hodson \& Paden, 1991). Intervention procedures include using a small number of words for production practice during drill-play activities; using auditory, visual, and tactile cues; and focusing on facilitating phonological pattern emergence rather than on a high response rate to perfect individual phonemes. Hodson and Paden (1991) explain the concept of a cycle:

Cycles are time periods during which all primary phonological patterns that need remediation are facilitated in succession - approximately two to six hours for each target pattern and 60 minutes per target phoneme(s) for each cycle. The patterns are recycled (i.e., re-presented) during ensuing cycles until each of the targeted patterns begins to emerge in spontaneous utterances (p. 22).

The Cycles Approach (Hodson \& Paden, 1991) is based on more than 15 years of intervention with several hundred children between the ages of 2 and 14 years old. The majority of these children were judged to be less than $15 \%$ intelligible before intervention. Most preschool children required less than 12 months of intervention to become intelligible. Effectiveness of the Cycles Approach has been documented through 
a series of case studies. Hodson (1984) provides case examples of a six year old child who was judged to be $10 \%$ to $15 \%$ intelligible and a four year old child who was judged to be completely unintelligible. By facilitating target phonological patterns in cycles, each of these children demonstrated a gradual emergence of target patterns in conversational speech with notably increased intelligibility. Hodson \& Paden (1991) presented additional case examples demonstrating this approach. One subject began phonological intervention at age 3:1 and was in the profound range of severity. Following intervention, the child was judged to be $85 \%$ intelligible during post testing at age 4:4. Another child, age 4:6, who was also in the profound range of severity, was dismissed after nine months of intervention and was judged by unfamiliar listeners to be $90 \%$ intelligible. Stoel-Gammon, Stone-Goldman, and Glaspey (2002) outline phonological treatment outcomes for a four year old child with a severe phonological disorder using the Cycles Approach. Phonological process chosen for remediation included: final consonant deletion, cluster reduction, velar fronting, gliding, and stopping. Performance during therapy activities, generalization probes of unpracticed words, and standardized testing were used to assess progress. Improvement was documented throughout each intervention cycle. By the end of the second year of treatment, the child scored in the mild range of severity on a standardized assessment and communicated easily with others.

\section{Communicative Intervention Methods}

The use of naturalistic, communicative methods is a standard procedure for intervention with children who have language disorders (Bradshaw et al., 1998; Camarata \& Nelson, 1994; Fey, 1986; Kaderavek \& Justice, 2002; Kirshner, 1991; Norris \& Hoffman, 1990). Communication-centered methods have also been proposed as intervention methods for children with phonological disorders (Norris \& Hoffman, 2005). In the following section, the theoretical basis underlying communicative intervention methods will be discussed with an overview of social interactionist theory and pragmatic theory. Communicative approaches to language intervention along with communicative approaches to phonological intervention will be reviewed with a focus on naturalistic procedures and the use of shared storybook reading as an intervention context. 


\section{Social Interactionist Theory}

One underlying basis for using communication-centered intervention methods is social interactionist theory. According to this theory, language is primarily learned through social interactions with the child as an active participant in the process (Loeb, 1997). Children and their language environments are seen as a dynamic system dependent upon each other for efficient social communication during development. The functions of language in social communication are seen as important throughout development (Bohannon \& Warren-Leubaker, 1985). Fey (1986) discusses the impact of interactionist theory:

Within interactionist theory, language can be neither conceived nor understood without consideration of 1) the social functions that language serves and 2) the influences of the social context on the topics that are discussed and on the forms that are selected by the speaker in a particular speaking situation (p. 17).

Fey proposes that intervention procedures congruent with an interactionist perspective should include modeling targets frequently in a meaningful context, and creating reasons for the child to produce the target during communicative interactions.

\section{Pragmatic Theory}

A related theoretical construct is pragmatic theory. In the late 1970s and early 1980s, there was a shift in the field of speech-language pathology toward pragmatic models of language acquisition. According to pragmatic models, communicative functions and purposes are the motivation and framework for language development. In pragmatic approaches to language intervention, the child perceives the clinician as an interactive conversational partner, the child engages in joint actions and events with the clinician, and play is seen as the appropriate framework for intervention activities (Craig, 1983). Successful communicative interaction as well as communication failure may have implications for phonological intervention. Gallagher (1977) examined the response to communicative failure by repeatedly pretending not to understand what children said during collection of a spontaneous language sample for each child. She found that typically developing children consistently revised the linguistic form of their message when they perceived that they were misunderstood. In a typical communication situation during conversational speech, the speaker endeavors to be understood by the listener and makes adjustments to the message if it is misunderstood. 
Weiner and Ostrowski (1979) used a picture naming task with 15 children from 3:0 to 5:0 years old to examine if listener uncertainty had an effect on sound production. During the first condition, the children named pictures and during the second condition the examiner provided one of three types of feedback (“Did you say?”....followed by the correct pronunciation of the picture; “Did you say?”...followed by a model of the child's error production of the picture, and “Did you say?”...followed by a misarticulated production different from the child's production of the picture). The third feedback condition resulted in the fewest misarticulations by the children. The researchers concluded that during typical drill activities the pictures are known to the child and the clinician, therefore the need for successful communication is not established. They suggest that use of a communication failure strategy may be useful in speech intervention.

Communicative Approaches and Language Intervention

Naturalistic procedures. Naturalistic, communicative methods of language intervention are commonly used as standard procedures for children with language disorders. In Fey’s (1986) seminal book, Language intervention with young children, he outlined intervention strategies based on interactionist and pragmatic theory. He emphasized the significance of a child-oriented approach. The clinician creates an accepting, responsive environment motivating the child to communicate spontaneously. The clinician responds to the child's initiations and manipulates the environment to create opportunities for the child to need to communicate.

Norris and Hoffman’s (1990) procedures for naturalistic/communicative language intervention are consistent with Fey's language intervention model. The child is seen as an active participant and is given opportunities to participate in real conversations in the context of ongoing themes or topics. The clinician orchestrates communicative opportunities for the child to use language to regulate the behavior of others. The clinician scaffolds the child's active participation by using strategies such as cloze procedures, preparatory sets, and questioning techniques. A cloze procedure involves pausing to indicate the need to fill in information. For example, after retelling part of a story the clinician may say "and then they saw the ____ pausing to encourage the child to say the next word or phrase. Preparatory sets highlight and suggest an 
appropriate communication act such as, "You need to wake up the dolls." Specific questions ("Who has the muffin?"), open ended questions ("What should we do next?), or binary choices (“Is it the green frog or the blue frog?”) are also used to facilitate verbal interaction in context. Communicative reinforcement is used with feedback from the clinician related to the child's communicative effectiveness.

Camarata and Nelson (1994) compared conversational recasting and imitative procedures for training grammatical structures in 21 children with specific language impairments. In the imitation procedure, the children imitated the target grammatical structure after the clinician's model paired with a picture or object stimulus followed by verbal or token reinforcement. In the naturalistic procedure, play activities were used to elicit grammatical structures. Feedback involved the clinician using a recast or rephrasing of the child's utterance incorporating the correct use of the target structure. Imitative procedures generated more elicited productions; however, there were a greater number of spontaneous productions under the conversational treatment. The transition from elicited to spontaneous production was more rapid with the conversational treatment procedures.

Shared storybook reading. Speech-language pathologists are increasingly incorporating joint storybook reading as an interactive context for language intervention. Child-adult interactions during shared storybook reading are reciprocal and create a dynamic context that can be adjusted to address the child's intervention goals (Kaderavek \& Justice, 2002). Kirchner (1991) defines joint book reading as "the use of patterned children's literature to construct a structured, reciprocal discourse activity as a context for language intervention” (p. 313). Use of storybook reading as a clinical tool is strengthened by using books that encourage the child's participation such as repetitive storylines and manipulative features as with lift-the-flap books (Kaderavek \& Justice, 2002). The most predictable type of repetitive book format includes a phrase or sentence repeated throughout the book (Kirshner, 1991). A study of the effect of book type on language use during repeated storybook readings was conducted with four mothers and their children with language impairment. One book format included narrative text and illustrations while the other format consisted of narrative text, illustrations, and a manipulative feature such as dials that can be turned. The mothers' language use did not vary with the two formats; however, the children demonstrated increased sentence length 
and complexity, and asked more questions during the manipulative format. (Kaderavek \& Justice, 2005).

Crain-Thoreson and Dale (1999) point out that "shared book reading with parents and other adults seems to be an ideal context for children to practice and improve their language skills” (p. 28). They taught parents and early childhood special education staff shared book reading strategies to use with 32 children with language delays. The strategies included: giving the child time to respond, repeating what the child said, praising and encouraging the child, asking open ended questions, and expanding what the child said. Pre- and post-test measures included standardized vocabulary tests and analysis of taped shared book reading sessions. At the conclusion of the study, it was noted that the children participated more in the shared book reading sessions. In addition, they demonstrated increased utterance length, and produced more different words.

Crowe, Norris, and Hoffman (2003) also evaluated the effectiveness of an interactive reading procedure by teaching caregivers the components of an interactive storybook reading intervention and monitoring the results with six caregiver-child dyads. The participants were preschoolers who exhibited language impairment. Caregivers were instructed in techniques to establish joint attention to the book, ask relevant questions, use cloze procedures, and provide feedback by restating, extending, or clarifying the child's response. During baseline observations, the children answered questions or sat passively during storybook reading sessions. Following the five week home based intervention, analysis of caregiver-child interactions revealed significant increases in the frequency of children's communicative turns, the number of different words used, and the total number of words produced during the interactive reading procedure.

\section{Communicative Phonological Intervention}

Naturalistic procedures. The core procedures for phonological intervention typically do not include naturalistic procedures. Analysis and target selection techniques have shifted from traditional procedures; however, imitative drill as in traditional speech production methods remains the primary procedure used in most phonological intervention research (Camarata, 1995). Some researchers argue the importance of extending naturalistic procedures to speech intervention. Low, Newman, and Ravsten (1989) describe a pragmatic approach to treatment of phonological disorders. They assert 
that a communicative context creates the optimum conditions for phonological intervention. They promote practicing target speech sounds by focusing on phonemes in words that are part of socially useful communicative utterances. The child's response should be powerful in controlling the environment by causing something to happen as with a command or a request. Correct responses are reinforced by natural consequences.

Lowe and Weitz (1994) describe the process of designing pragmatically valid phonological intervention activities. Appropriate contexts for interaction include conversations, stories, or pretend play. Intervention activities should be familiar to the child to encourage active participation and incorporate the functional use of target words. Feedback procedures for errored productions include: acknowledging a misunderstanding, giving the child an opportunity for a revision of the message, or providing a communicative model by posing an either/or question ("you need the tea or the key?”).

Hoffman (1992) proposes that intervention for speech disorders should be provided in communicative settings. In this model for phonological treatment, intervention activities are structured with contextual opportunities for the child to use language meaningfully. Familiar behaviors and events are suggested as the intervention framework such as using picture books, dramatic play, or toys to provide contextually appropriate communicative opportunities. Contextually appropriate feedback is related to the child's utterance and is in the form of requests for clarification taking the form of a contrast pair (“Did you say ike or bike?”). An example of a communicative activity is using a doll and doll clothes with a child learning to say the "sh" sound at the beginning of words. During a natural play activity the child could request different "shirts" or "shoes" for the doll to wear. This would provide a reason for the child to practice saying "shirt" and "shoe" correctly in order to communicate specific information.

Naturalistic, communicative activities are a component of some phonological intervention programs. Williams (2003, 2005) presents an intervention approach for preschool children that includes imitation, contrast pairs, along with naturalistic, interactive activities. Tyler (2005a) uses both drill-play activities and naturalistic activities for production practice as components of a phonological intervention program. She incorporates one naturalistic activity within each intervention session especially for 
children who will not imitate words during drill-play activities. Conversational opportunities for verbal interaction are facilitated by designing thematic activities and creating a reason for the child to attempt target words.

Shared storybook reading. Repeated storybook reading is recommended as a communicative context for phonological intervention. Story contexts provide multiple opportunities for the child to hear words modeled and multiple opportunities for production practice. Recommended clinician strategies include repetitive modeling, cloze procedures, binary choice procedures, and communicative feedback (Hoffman, 1997; Norris \& Hoffman, 2005).

Research findings. Experimental studies examining the effects of communicative approaches to phonological intervention are limited. Camarata (1993) investigated the effect of naturalistic conversation training on speech production accuracy using a multiple baseline across subjects and behaviors design. Participants were two children from age 3 years, 10 months to 4 years, 3 months with speech impairments. Intervention was twice weekly for 45 minute sessions using books and toys containing the target phonemes to create opportunities for communicative feedback. Feedback consisted of conversational affirmation and correct modeling of target sounds in words. Percent of correct productions for individual targets was calculated for each session based on spontaneous utterances. At the conclusion of the study, all target speech sounds were acquired and produced in conversational contexts.

Bellon-Harn, Hoffman, and Harn (2004) used the combined application of interactive techniques (cloze procedures, cloze procedures with expansions, and contrast word procedures) to address language and phonology targets in three children between 5:5 and 6:0. The semantic and phonological complexity of the children's utterances was examined across a sequence of storybook reading intervention sessions. Storybooks were used because they provided redundant text, facilitated turn taking between the clinician and child, provided greater contextual support than conversation and created more opportunities for repetition. Repeated storybook readings also provide opportunities for the child to repair miscommunications. A contrast word procedure was used when the child made a phonological error ("Is it a do or a dog?"). Following intervention, the 
participants demonstrated semantic growth, an increase in percent of consonants correct, and a decrease in phonological process use.

\section{Summary}

Effective intervention strategies are an important component of intervention with young children who have moderate to severe phonological disorders. Communicative, naturalistic activities for phonological intervention have been proposed in the literature. Most of the information is descriptive with few scientific investigations examining the use of naturalistic and communicative approaches. The purpose of this study was to determine if communication-centered phonological intervention would be effective in improving speech production in preschool children with moderate to severe phonological disorders.

\section{Research Questions}

The following research questions are proposed:

1. Will preschool children demonstrate improvement in the use of target phonological patterns following 6 weeks of communication-centered phonological intervention?

2. Will preschool children demonstrate within class generalization of targeted phonological patterns after 6 weeks of communication-centered phonologica intervention?

3. Will preschool children demonstrate generalization of targeted phonological patterns to conversational speech after 6 weeks of communication-centered phonological intervention?

4. Will preschool children demonstrate maintenance and within class generalization of targeted phonological patterns one month after 6 weeks of communication-centered phonological intervention?

5. Will preschool children demonstrate maintenance and generalization of targeted phonological patterns to conversational speech one month after 6 weeks of communication-centered phonological intervention? 


\section{CHAPTER 2: METHOD \\ Overview}

This study was designed to determine the effectiveness of using a communication-centered phonological approach to improve speech production in preschool children with moderate to severe phonological disorders. Baseline and intervention conditions were completed for three children. Production accuracy of the target phonological pattern was recorded following each session. A standardized phonological test and a conversational language sample were analyzed for each subject prior to intervention, immediately following the intervention period, and one month following the last intervention session to document accuracy and generalization of the target phonological pattern.

Participants in this study were required to be between the ages of 3 years, 5 months and 4 years, 11 months. Additional requirements included passing a hearing screening, passing an oral mechanism examination, and scoring within normal limits on a broad-based language test. A severity rating of moderate or severe on the Hodson Assessment of Phonological Patterns, Third Edition (HAPP-3) (Hodson, 2004) was also required.

This study was approved by the Murray State University Institutional Review Board for implementation on the Murray State University campus. Review and oversight of the study were performed by the University of Kentucky Institutional Review Board which reviewed all elements of the study for the protection of human subjects. A copy of the consent form is found in Appendix A.

\section{Research Design}

A single subject multiple probe across subjects research design (Horner \& Baer, 1978) replicated across three subjects was used to assess the effectiveness of communication-centered phonological intervention. The communication-centered phonological intervention in this investigation consisted of the combined application of focused stimulation of key words during joint storybook reading and interactive practice of key words using communicative feedback. Experimental control was demonstrated when correct production of the target phonological pattern increased when the communication-centered phonological intervention procedure was implemented. 


\section{Single Subject Design}

Single-subject research is characterized as a "rigorous, scientific methodology used to define basic principles of behavior and establish evidence-based practices” (Horner, Carr, Halle, McGee, Odom, \& Wolery, 2005, p.165). Single subject designs involve intensive study of a small number of individuals with an emphasis on individual differences. An individual's performance is compared under different conditions using repeated measurement of the dependent variable (Hegde, 2003). Experimental conditions include a minimum of a baseline condition followed by an intervention condition with each condition described in detail. Visual inspection of the level, trend, or variability of graphed data is primarily used to analyze the effects of experimental manipulation (Wolery \& Dunlap, 2001). Use of single-subject designs also implies an emphasis on selecting dependent variables that demonstrate social validity, or the importance and practicality of the research procedures and results (Horner et al., 2005).

Single subject designs are used in many areas of research such as psychology, education, rehabilitation, and social work. These experimental designs can be used to rigorously evaluate the effects of interventions (Kazdin, 1982). With a single subject design, interventions are systematically controlled and "represent a powerful decision making tool for clinical research” (Zhan \& Ottenbacher, 2001, p. 1). Many single subject designs are frequently seen in the communication disorders research literature (Schiavetti \& Metz, 2002). The majority of experimental investigations of the effectiveness of phonological treatment have used single subject designs (Gierut, 1998).

\section{Multiple Probe Design}

The multiple probe research design (Tawney \& Gast, 1984) is a variation of the multiple baseline design. The multiple probe design shares the same features as the multiple baseline design except that fewer observations of the dependent variable are required. This design is appropriate when multiple observations of the dependent variable during extended baselines would cause an increase or decrease of the target behavior. Treatment can begin following a minimum of three data points demonstrating that measurement of the dependent variable is stable (Cowan, Hennessey, Vierstra, \& Rumrill, 2004). In the multiple probe across behaviors design, baseline measurements of

the target behavior are taken for each subject. Treatment begins for the first subject while 
the other subjects receive periodic probes. When the first subject reaches the established criterion, baselines are repeated on the remaining subjects. Intervention begins for the second subject with the remaining subjects receiving periodic probes. This sequence is replicated until all subjects receive the intervention. Experimental control is demonstrated when the target behaviors do not change until each subject begins the treatment phase (Hegde, 2003).

Independent variables. The independent variable for this study was the communication-centered phonological intervention, a package that included focused stimulation of key words during joint storybook reading and interactive practice of key words using communicative feedback.

Dependent variable. The dependent variable, correct production of the targeted pattern in key words, was measured during baseline and intervention sessions. A target phonological pattern was identified for each subject along with a list of phonemes that were considered correct productions of the target pattern. Since the target phonological pattern for each subject was correct production of fricatives, any fricative phoneme [f], [v], [s], [z], [J], [3], [ө], [ð], was considered a correct production. Pretest and posttest generalization measures included the Hodson Assessment of Phonological Patterns, Third Edition (Hodson, 2004) to measure across class generalization of the target phonological pattern and analysis of a 50 utterance spontaneous speech sample to measure generalization of the target phonological pattern to conversational speech. Posttest measures were taken at the conclusion of the intervention period and one month later.

Procedures

\section{Subjects}

Three children between 3 years, 7 months and 4 years, 11 months with moderate to severe phonological disorders participated in this study. Prior to intervention, each subject met the following criteria. Initial assessment results are summarized in Table 3.1. A detailed description of initial assessment results for each subject can be found in Chapter 3.

- $\quad$ Passed a pure-tone audiometric screening at 20dB for 1000, 2000, and $4000 \mathrm{~Hz}$ (American Speech-Language-Hearing Association Audiologic Assessment Panel, 1997) conducted by a licensed audiologist in a sound-treated booth; 
- $\quad$ Passed a screening of the speech mechanism using the Oral Speech Mechanism Screening Examination, Third Edition (OSMSE-3) (St. Louis \& Ruscello, 2000);

- $\quad$ Received a standard score of 85 to115 (within normal limits) on a broad-based standardized language assessment - the Preschool Language Scale, Fourth Edition (Zimmerman, Steiner, \& Pond, 2002); and

- $\quad$ Received a severity rating of moderate or severe on a standardized phonological assessment - Hodson Assessment of Phonological Patterns, Third Edition (HAPP3) (Hodson, 2004). All phonemes that were not produced spontaneously during the test were checked for stimulability. Sounds that could not be imitated with maximum modeling and cueing were not selected as targets.

\section{Selection of Treatment Targets}

Standardized testing. Following administration of the HAPP-3, each participant's phonological rule system was analyzed according to the test guidelines and through spontaneous sample results. According to the HAPP-3 guidelines, major phonological deviations were identified including syllable structure patterns and consonant category deficiencies yielding a “Total Occurrences of Major Phonological Deviations” (TOMPD) severity rating. The "Substitutions and Other Strategies" form was used to document each child's use of phonological processes. Definitions of common substitution processes described in the Hodson Assessment of Phonological Patterns, Third Edition (Hodson, 2004) are found in Table 2.1.

Phonological process selection. One substitution process was selected as a focus of treatment for each child. The process was optional, that is the process did not occur $100 \%$ of the time, and it had a $40 \%$ to $60 \%$ occurrence on the HAPP-3. For example, for the phonological process of fronting, if the child produced the [k] and [g] correctly in the final position of words, inconsistently in the medial position of words, and incorrectly in the initial position of words, this would result in the process of fronting occurring approximately $50 \%$ of the time making the pattern of fronting a potential target. Processes were selected that contained stimulable phonemes. For each phonological process specific phonemes were identified as targets. For example, if the phonological pattern of “stopping” were identified stimulable continuants would serve as possible 


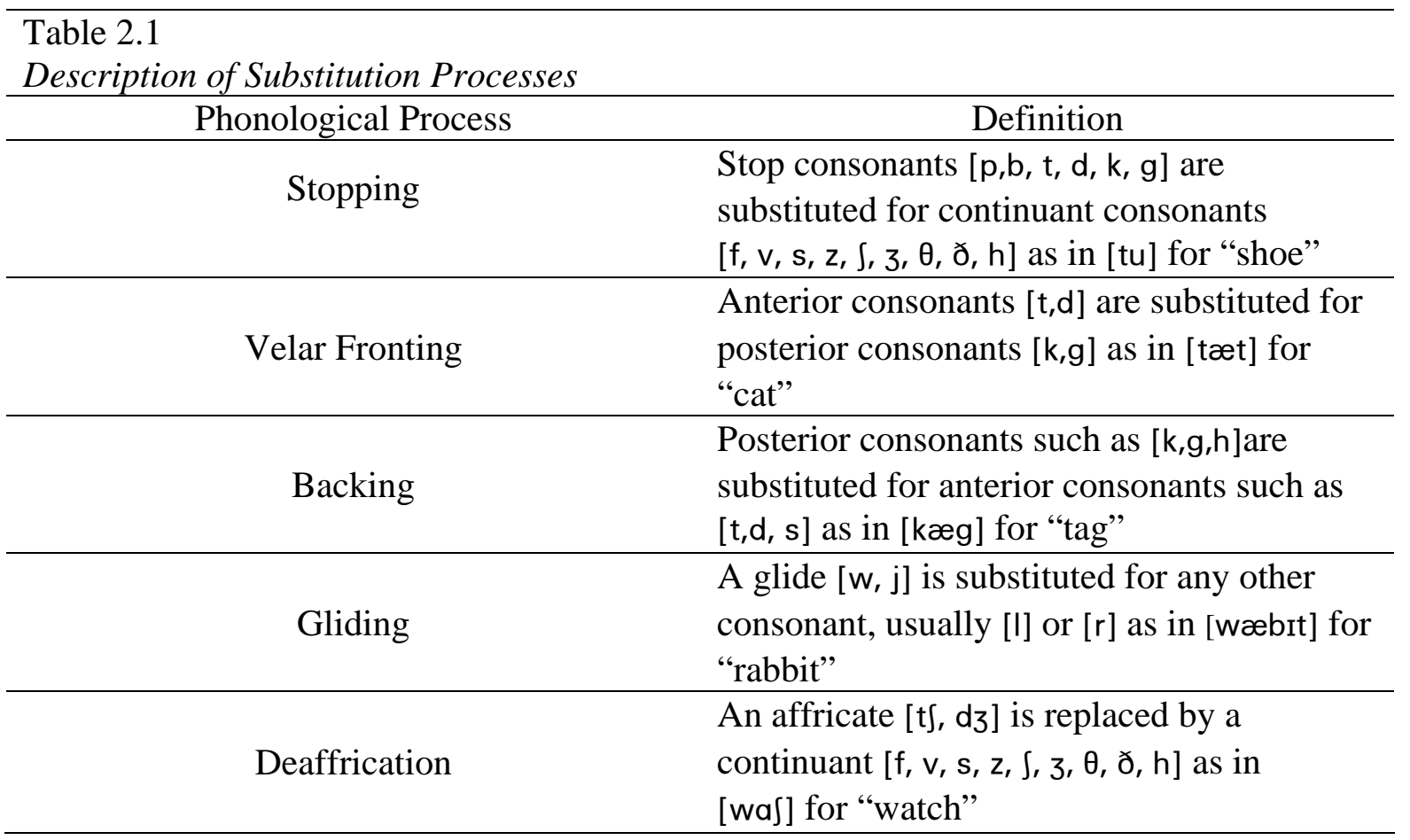

treatment targets such as [s] or [f]. Sound errors were stimulable if the child could modify and improve the production of the sound following examiner stimulation.

Baseline Sessions

Baseline data were obtained for each subject. Adam (Subject 1) participated in 3 sessions to establish a stable baseline prior to the initiation of intervention. Ben (Subject 2) participated in 3 baseline probe sessions and 3 additional baseline sessions. His baseline results were stable prior to beginning the intervention phase. Steven (Subject 3) participated in 6 baseline probe sessions and 3 additional baseline sessions prior to beginning intervention. His baseline results were also stable. Sessions followed the format of intervention sessions without application of the cueing and feedback procedures. A script for baseline sessions is found in Appendix A.

Weekly periodic baseline probe sessions were scheduled for subjects not yet receiving intervention. Once a treatment effect was observed for the first subject, intervention began with the second subject. A treatment effect was defined as a $40 \%$ increase in production of the targeted phonological pattern over the subject's baseline mean (Miccio et al., 1999; T. Powell, Elbert, Miccio, Strike-Roussos, \& Brasseur, 1998). 
Once a treatment effect was observed with the second subject, intervention began with the final participant.

\section{Treatment Sessions}

Setting. Individual treatment sessions were held twice weekly for 30 minutes each at Murray State University Speech and Hearing Clinic preschool sites for approximately 6 weeks of intervention. The researcher, a certified, licensed, speech-language pathologist, with over 20 years of clinical experience, conducted each treatment session. Activities took place face to face at a small table or on the floor.

Orientation session. Following the final baseline session, but prior to initiating the intervention procedures for each child, a 30 minute orientation session was held. During this session, the child decorated a set of characters for use during intervention. As the clinician and child decorated the characters, the clinician introduced the child's target pattern, descriptive term, and visual cue while talking about the character names. The clinician also described the format of the sessions and briefly explained the activity choices. A script for the orientation session is in Appendix B.

General procedures. Figure 2 illustrates the overall structure of the communication-centered intervention. The two components of the intervention were focused stimulation of key words through joint storybook reading and interactive practice of key words. Five intervention characters were individually selected for each child based on parent report of the child's interest (see Appendix C). The child's ability to pronounce the character based on phonological analysis results was taken into consideration in the selection of key words. The characters were real or imaginary items such as cats, dogs, or cars. The pattern for each character's name was an adjective beginning with the child's target plus the character name. For example, "Sad Bear”, "Silly Bear, "Sick Bear”, "Sun Bear”, and “Super Bear” were the key words for Subject 1 whose target was the initial $[\mathrm{s}]$.

A series of six clinician-made books with repetitive phrase structure and manipulative features was used for each child. Each book centered on events familiar to preschoolers and had a similar average sentence length (see Table 2.2). The text for each book is found in Appendix D. Following focused stimulation of key words using the 
Figure 2

Communication-centered intervention procedure

Phase 1: Focused stimulation of key words

- Key words are modeled during clinician-made repetitive books

- Cueing (descriptive term, visual cue) is provided for the target pattern

Phase 2: Interactive practice of key words

- The child selects 2 of 4 activities, using the story characters, for each session

- Communicative feedback is embedded within phase two activities and is provided for the child's production attempts of key words containing the target pattern as described below:

Correct production of the target pattern

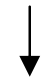

Communicative response

The clinician responds communicatively. For example, if the child says, "I need the sad cat", the correct cat would be given to the child while saying, "Here's the long sound sad cat.” (with visual cue)

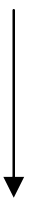

Follow-up comment The clinician provides an additional opportunity for the child tohear the target pattern modeled by making a comment about the character using the key word, descriptive. term, and cue. For example, "long sound sad cat (with visual cue) wants to be next."
Incorrect production of the target pattern

\section{Contrast question}

The clinician asks the child a choice question using the target word and a contrast word with the child's error. For example, if the child says, "I need the tad cat," the clinician will say," "Do you need tad or sad?” (with visual cue)

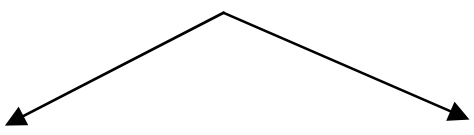

\section{Correct production}

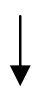

Communicative response

The clinician responds communicatively. For example, if the child says, "sad cat", the correct cat would be given to the child while saying, "Here's the long sound sad cat” (with visual cue) $\underline{\text { Incorrect production }}$

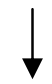

Use term and cue If the child responds incorrectly a second time, the clinician uses the descriptive term and visual cue you want the long sound sad cat" (with visual cue) For example, "Oh, 
Table 2.2

Description of Clinician Made Books

\begin{tabular}{|c|c|c|c|c|}
\hline $\begin{array}{l}\text { Book } \\
\text { titles }\end{array}$ & $\begin{array}{l}\text { Sentence } \\
\text { length }\end{array}$ & $\begin{array}{c}\begin{array}{c}\text { Familiar } \\
\text { events }\end{array} \\
\end{array}$ & $\begin{array}{c}\text { Predictable text } \\
\text { structure }\end{array}$ & $\begin{array}{c}\text { Manipulative } \\
\text { feature }\end{array}$ \\
\hline $\begin{array}{l}\text { "Dragon } \\
\text { Pizza” }\end{array}$ & $\begin{array}{c}4.8 \\
\text { words }\end{array}$ & $\begin{array}{l}\text { Pizza } \\
\text { delivery }\end{array}$ & $\begin{array}{l}\text { "Hi, furry dragon. } \\
\text { Where’s my pizza?" }\end{array}$ & Lift the flap \\
\hline $\begin{array}{l}\text { "Where’s My } \\
\text { Tail?”" }\end{array}$ & $\begin{array}{c}4.9 \\
\text { words }\end{array}$ & $\begin{array}{l}\text { Looking for } \\
\text { something }\end{array}$ & $\begin{array}{l}\text { “That's not my tail. } \\
\text { This tail is too fast. }\end{array}$ & Texture \\
\hline $\begin{array}{l}\text { "The } \\
\text { Cookie Jar" }\end{array}$ & $\begin{array}{c}4.7 \\
\text { words }\end{array}$ & $\begin{array}{l}\text { Looking for } \\
\text { cookies }\end{array}$ & $\begin{array}{l}\text { "Hey funny dragon, } \\
\text { Why don’t you } \\
\text { look in the kitchen?" }\end{array}$ & $\begin{array}{l}\text { Characters go } \\
\text { through slots }\end{array}$ \\
\hline $\begin{array}{l}\text { "Who Broke } \\
\text { This Toy?" }\end{array}$ & $\begin{array}{c}4.5 \\
\text { words }\end{array}$ & $\begin{array}{l}\text { No one } \\
\text { admits } \\
\text { breaking }\end{array}$ & $\begin{array}{l}\text { "Not me said } \\
\text { funny dragon. } \\
\text { I was in the sink." }\end{array}$ & $\begin{array}{l}\text { Moveable } \\
\text { characters }\end{array}$ \\
\hline $\begin{array}{l}\text { "I Went } \\
\text { Walking" }\end{array}$ & $\begin{array}{l}5.0 \\
\text { words }\end{array}$ & $\begin{array}{l}\text { Going for a } \\
\text { walk }\end{array}$ & $\begin{array}{l}\text { "I saw a fat dragon } \\
\text { following me." }\end{array}$ & $\begin{array}{l}\text { Pull tab to } \\
\text { reveal picture }\end{array}$ \\
\hline $\begin{array}{l}\text { The Dragon’s } \\
\text { Busy Morning” }\end{array}$ & $\begin{array}{c}5.2 \\
\text { words }\end{array}$ & $\begin{array}{c}\text { Daily } \\
\text { activities }\end{array}$ & $\begin{array}{l}\text { "What will funny } \\
\text { dragon eat?" }\end{array}$ & Lift the flap \\
\hline $\begin{array}{l}\text { "Bedtime for } \\
\text { Dragons" }\end{array}$ & $\begin{array}{l}5.0 \\
\text { words }\end{array}$ & $\begin{array}{l}\text { Avoiding } \\
\text { going to bed }\end{array}$ & $\begin{array}{l}\text { "I see fancy dragon, } \\
\text { He’s so cute.” }\end{array}$ & Lift the flap \\
\hline
\end{tabular}

book, the clinician engaged the child in interactive practice of the key words. The child selected two activities from a choice of four. Each activity was designed to provide communicative opportunities to elicit the target words.

Development of general procedures. Intervention procedures were implemented with two typically developing preschool children as part of developing materials and standard procedures. Each clinician-made book was read with the children. The books 
were also adjusted, as needed, to ensure that the children could easily "read” the text and operate the manipulative features of each book.

Materials were developed for each activity that the children could easily manage. The timing of the intervention sessions was established, with the book activity taking approximately five minutes, and each activity lasting approximately ten minutes. A 30minute session was planned with the extra 5 minutes for transition between activities. Activities facilitating consistent communicative opportunities for production of the characters by the preschool children were noted. Four activities were chosen and introductory scripts were refined. There was a general range of 10 to 15 opportunities for communicative use of the target words for each of the four activities. Based on the children's responses, 20 to 30 planned opportunities for production practice were incorporated into the interactive practice of key words during each 30 minute session. Response criteria are not usually given for naturalistic practice; however, the number of

planned response opportunities for this investigation is consistent with other phonological intervention research. Tyler (2005a) reported a goal of eliciting 24 to 32 productions during a 30 minute session using drill-play activities .

\section{Treatment Procedures}

Focused stimulation of key words. During the first part of each session, the clinician and child read the designated book for that week. The clinician read the book first using the descriptive term and visual cue appropriate for the subject's target pattern. Typical visual cues considered standard practice in phonological intervention, were used to highlight the features of the target phonological pattern and selected exemplar. Sample cues are described in Table 2.3. The descriptive term "long sound" with the associated visual cue was used with each subject since the phonological process of "stopping” was the common target pattern. After reading each page, the clinician provided the cues for the character. For example, for the book “I went walking”, cues for the first page were: "I went walking. What did you see? I saw a silly car looking at me.” After reading the page, the clinician said, "silly" (with cue - pointer finger moves forward through the air from the clinician's lips as the [s] is produced), "that starts with your long sound”...”silly" (with cue). 
Next, the child read the book to the clinician with the clinician providing assistance during reading. The cueing procedure was identical to the clinician's reading of the book. After the child read each page, the clinician said the key word using the visual cue, then followed with the descriptive term, and a repetition of the key word with the visual cue. During the joint book reading, the clinician had 10 opportunities to model the key word for the child. A script for focused stimulation of key words is included in the script for intervention sessions in Appendix E.

\section{Table 2.3}

Examples of Cues for Phonological Target Sounds

\begin{tabular}{|c|c|c|c|}
\hline $\begin{array}{l}\text { Phonological } \\
\text { rule }\end{array}$ & $\begin{array}{l}\text { Selected } \\
\text { exemplar }\end{array}$ & $\begin{array}{l}\text { Descriptive } \\
\text { term }\end{array}$ & Visual cue \\
\hline Stopping & $\begin{array}{l}{[\mathrm{s}]} \\
{[\mathrm{f}]} \\
{[\mathrm{S}]}\end{array}$ & $\begin{array}{l}\text { Long } \\
\text { Sound }\end{array}$ & $\begin{array}{l}\text { Pointer finger moves forward through air } \\
\text { from the clinician's lips as the } \\
\text { initial fricative in the word is produced }\end{array}$ \\
\hline $\begin{array}{l}\text { Velar } \\
\text { fronting }\end{array}$ & $\begin{array}{l}k] \\
{[g]}\end{array}$ & $\begin{array}{l}\text { Throat } \\
\text { Sound }\end{array}$ & $\begin{array}{l}\text { The clinician touches her throat with } \\
\text { her fingertips as the initial velar in the } \\
\text { word is produced }\end{array}$ \\
\hline Gliding [I] & [I] & $\begin{array}{l}\text { Tongue } \\
\text { Sound }\end{array}$ & $\begin{array}{l}\text { The clinician points to the corner of her } \\
\text { mouth with her index finger }\end{array}$ \\
\hline
\end{tabular}

Interactive practice of key words. Appendix E also contains the scripts for each interactive practice activity. The purpose of these activities was to create a communicative context for production practice of key words with communicative feedback. The child selected two of four activity choices and placed the activity cards on the schedule board at the beginning of each intervention session.

The four activites used for interactive practice were "Puzzle," "Game," "Make Something," and "Map.” For the puzzle activity, a set of puzzles was made for each child's characters by gluing the character on foam board and cutting each picture into four pieces. The clinician provided specific puzzle pieces to the child as they were requested.

For the game activity, bingo-type boards were made with the child's characters covering the board in rows. The clinician and child each had a stack of cards with a 
different character on each card. They took turns telling each other which character to cover with a token.

Simple items were made or decorated for each of the characters during the "Make Something” activity. The items were accessories for the characters such as hats, shirts, or toys. The clinician and child talked about which items would be for each character. For example, Subject 1 made necklaces, bathtubs, food, sunglasses, houses, and toolboxes for his bears.

The "Map" activity was based on the children's television program "Dora the Explorer.” The child used a map to find a special item (shiny rock, big shell, or pretty flower) with the help of the five characters. Three pictures were placed on the map indicating the barriers to be crossed. The child helped the characters cross each barrier by calling them by name.

Feedback procedures. Communicative feedback was provided for the child's production attempts of words containing target sounds during the two child-selected interactive practice activities as summarized in Figure 2. For correct production of the target pattern, the clinician responded communicatively using modeling and cueing. For example, if the child said, "I need the sad car", the clinician immediately gave the correct car to the child while saying, "Here's the long sound sad car." The designated visual cue was used as the clinician said the key word "sad." Then the clinician provided a followup repetition of the key word by saying, "sad...(using the visual cue) that's your long sound.”

If the child produced the target pattern incorrectly in the key word, the clinician asked the child a choice question. The question was structured as a minimal pair using the child's incorrect production and the correct production of the key word. For example, if the child said, "I need the tad car”, the response was "Do you need tad or sad?.” Placing the child's production first followed by the correct production of the word is the standard format for interactive use of minimal pairs in phonological intervention (Bellon-Harn et al., 2004; Hoffman, 1992). If the child answered the contrast question by saying "sad car" the clinician responded communicatively and gave the child the correct car while providing a model and cue for the key word. The clinician used the visual cue while saying, "Here's the long sound sad car." If the child responded incorrectly following the 
contrast question, the clinician responded with modeling and cueing of the correct production. For example, the clinician said, "Oh you want the long sound sad car" while simultaneously using the visual cue for [s].

Materials and Equipment. Each intervention session was video taped using a Panasonic PV-GS35 mini DV digital video camera on a tripod placed in the corner of the room. The clinician wore a Samson UM1 wireless microphone to facilitate audio recording of each session. Two data sheets were used to document progress during each session. The baseline data sheet is found in Appendix F and was used to document the accuracy of the children's production of the target phonological pattern. The baseline data sheet was also used to calculate procedural reliability and dependent variable reliability. The data sheet for intervention sessions is located in Appendix G. It was used to document progress during intervention sessions, dependent variable reliability, and procedural reliability.

Clinician-made books, one book for the baseline condition and six books for the intervention condition, were made for each subject. Materials for each of the interactive practice activity choices included: "Map" - laminated map with three pictures, blue towel, chair, trapezoid table, rock, shell, flower; "Make Something” - crayons, paper, pipe cleaners, glue, and other craft items; "Game" - two bingo-type boards with the child's characters covering the board in rows, smiley face tokens; "Puzzle" - one set of character puzzles for each subject made from foam board and a picture of each character.

\section{Data Collection}

Baseline data, intervention data, and generalization data were collected. Following pre-intervention assessments, a minimum of three baseline sessions were conducted for each subject. Baseline sessions followed the same format as intervention sessions with shared book reading followed by two interactive activities. However, the child's production of the target pattern in key words was measured without application of the intervention procedures. Data collection forms (Appendix F) were used during each baseline session.

During the treatment phase of the study, data were collected during interactive practice of key words for the two child-selected activities. A range of 10 to15 opportunities for production of the target phonological pattern were planned for each 
interactive activity for a total of 20 to 30 opportunities for each session. The first 30 responses were used to calculate a percent correct for the child's use of the target pattern in key words during each intervention session in order to compare an equivalent range of responses for the participants.

The clinician used the procedural reliability checklist for intervention sessions (Appendix H) to record the child's responses. Each attempt of the target pattern in a key word was recorded as $(+)$ for correct production of the target fricative pattern (production of any fricative sound was considered a correct response), or (-) for incorrect production of the target fricative pattern. Acceptable correct responses for each target pattern were generated at the completion of the target selection process. The accuracy of the child's responses following communicative feedback was recorded in the same manner.

At the end of the six week intervention period and during a one month follow-up sessions, two generalization measures were taken for each subject. The Hodson Assessment of Phonological Patterns, Third Edition (HAPP-3) was readministered and spontaneous language samples were collected with each child during free play with ageappropriate toys.

\section{Reliability}

Transcription reliability. Each administration of The Hodson Assessment of Phonological Patterns, Third Edition (HAPP-3) as well as language samples gathered before intervention, after intervention, and one month following intervention were video and audio recorded using a Panasonic PV-GS35 mini DV digital video camera and a Samson UM1 wireless lavaliere microphone. The tapes were copied to CD using Windows Media Player format for transcription analysis.

To determine the accuracy of the phonetic transcriptions, two listeners, the investigator and another speech-language pathologist experienced in phonetic transcription, independently transcribed each child's responses on the HAPP-3. Words containing each child's target phonological pattern from each language sample were also transcribed. Transcription reliability analysis was performed using the Logical International Phonetics Programs (Delgado \& Oller, 2001). Complete original transcriptions were entered for each listener and the computer analysis compared each word phoneme by phoneme for a reliability measure. Transcription reliability for The 
Hodson Assessment of Phonological Patterns, Third Edition (HAPP-3) was .95 and transcription reliability for the language samples was .97.

For those instances where the investigator and the second speech-language pathologist did not agree, a consensus transcription procedure was used following the guidelines presented by Shriberg, Kwiatkowski, and Hoffman (1984). Consensus was established by listening to the child's production a maximum of three additional times and applying one of the 17 consensus rules, if needed, to reach a decision.

Procedural reliability for independent variable. A trained observer, a certified, licensed, speech-language pathologist with over 15 years of clinical experience, used session video recordings and procedural reliability checklists to score $20 \%$ of the baseline sessions (Appendix F) and 20\% of the intervention sessions (Appendix H) for each subject to ensure accurate implementation of the intervention procedures and consistency across participants. The number of investigator behaviors observed was divided by the number of planned investigator behaviors and multiplied by 100 for the treatment integrity measure (Billingsley, White, \& Munson, 1980). Procedural reliability for baseline sessions was $100 \%$ across the 3 subjects. The average procedural reliability across subjects for the intervention sessions was $98 \%$ with a range of $96 \%$ to $100 \%$.

Dependent variable reliability. The same trained observer, an experienced speech-language pathologist, collected dependent variable reliability data while completing the procedural reliability checklists. Dependent variable reliability data were collected for $20 \%$ of the baseline sessions and $20 \%$ of the intervention sessions. Correct and incorrect attempts at key words containing the child's target pattern were recorded. The point by point method was used to determine the number of agreements of correct production of target pattern by the investigator and the observer, divided by the number of agreements plus disagreements, multiplied by 100 . The agreement for dependent variable reliability was expected to be at least $80 \%$ (Tawney \& Gast, 1984). Average reliability for baseline sessions across the 3 subjects was $93 \%$ with a range of $91 \%$ to $97 \%$. For treatment sessions, the average dependent variable reliability was $94 \%$ with a range of $89 \%$ to $100 \%$. 
Analysis of Results

Baseline and treatment data (percent correct on the target pattern) for each session were graphed for each subject. A narrative description of the nature of progress under each treatment condition for each subject in terms of level and trend changes seen in the data will be presented. Results are presented relating to each research question as follows. Baseline and intervention data were plotted for each subject to address Question 1. Data from the initial HAPP-3 administration, percent correct on the target pattern, and the percent correct on the target pattern from the HAPP-3 administration following intervention were examined to address Question 2. The initial language sample and language sample following intervention were analyzed for correct production of the target pattern for Question 3. Correct production of the target pattern for the initial HAPP-3 and the follow-up HAPP-3 were examined for Question 4. Data for Question 4 included correct production of the target pattern on the initial language sample as well as the follow-up language sample.

Copyright $\odot$ Sharon Blodgett Hart 2007 


\section{CHAPTER THREE: RESULTS}

\section{Overview}

A single subject multiple probe across subjects research design was used to evaluate the effectiveness of the communication-centered phonological intervention. Based on individual evaluation results, the phonological process of "stopping” was selected as a remediation pattern for each subject. Specific phoneme targets were initial [s] for Subjects One and Three, and initial [f] for Subject Two. Correct use of the fricative class of sounds $\left[f, v, s, z, \int, 3, \theta, \partial_{,}\right]$was measured before, immediately following, and one month following intervention sessions.

Results of the investigation relevant to each of the 5 research questions will be illustrated in narrative, graph, and table formats for each subject. Following the results for each subject, a summary of results of the 5 questions across the 3 subjects will be presented.

Results for Subject 1: Adam

\section{Background Information}

Subject 1, Adam, was 4 years, 11 months at the beginning of the study. Adam had an older brother and a twin sister. According to parent report, his twin sister had a mild speech impairment and was receiving intervention at her elementary school. Adam received speech services during the previous year at his preschool. His mother expressed concern about his limited intelligibility. He was difficult to understand unless the context was known. During the last 3 intervention sessions of this study, Adam began intervention services as part of his kindergarten program. According to the school speech-language pathologist, production of final consonants and the [k] and [g] sounds were initial targets.

\section{Initial Test Performance}

According to the Hodson Assessment of Phonological Patterns, Third Edition (HAPP-3), Adam's Total Occurrences of Major Phonological Deviations (TOMPD) score of 149 placed him in the "high severe"range. He received a standard score of 99 on the Auditory Comprehension and Expressive Communication subtests and a total language standard score of 99 on the Preschool Language Scale-4 (PLS-4) placing his language 
within normal limits. Oral examination and hearing screening results were within normal limits. His performance on the initial assessments is summarized on Table 3.1.

Table 3.1

Summary of Initial Assessments for All Subjects

\begin{tabular}{r|c|c|c}
\hline Initial Assessment & Subject 1 (Adam) & Subject 2 (Ben) & Subject 3 (Steven) \\
\hline HAPP-3: & 149 (Severe) & 95 (Moderate) & 109 (Severe) \\
\hline $\begin{array}{r}\text { Use of Stopping } \\
\text { Process }\end{array}$ & $41 \%$ & $50 \%$ & $59 \%$ \\
\hline $\begin{array}{r}\text { Correc Use of } \\
\text { Fricatives }\end{array}$ & $23 \%$ & $45 \%$ & $27 \%$ \\
\hline $\begin{array}{r}\text { Language Sample: } \\
\text { Process }\end{array}$ & $27 \%$ & $41 \%$ & $80 \%$ \\
\hline $\begin{array}{r}\text { Use of Stopping } \\
\text { Fricatives }\end{array}$ & $23 \%$ & $57 \%$ & $0 \%$ \\
\hline $\begin{array}{r}\text { Auditory } \\
\text { *PLS-4: } \quad 99 \text { (standard score) }\end{array}$ & 107 (standard score) & 107 (standard score) \\
\hline $\begin{array}{r}\text { Comprehension } \\
\text { Communication }\end{array}$ & 99 (standard score) & 107 (standard score) & 99 (standard score) \\
\hline $\begin{array}{r}\text { Total Language } \\
\text { Score }\end{array}$ & 99 (standard score) & 107 (standard score) & 104 (standard score) \\
\hline Hearing Screening & $*$ WNL & WNL & WNL \\
\hline Oral Examination & WNL & WNL & WNL \\
\hline
\end{tabular}

*TOMPD (Total Occurrences of Major Phonological Deviations)

"mild" 1-50 "moderate" 51-100 "severe" 101-150 "profound" >150

PLS-4 - Preschool Language Scale, Fourth Edition

WNL - "within normal limits"

On the HAPP-3, he demonstrated use of the following phonological processes: cluster reduction, final consonant deletion, gliding, stopping, fronting, reduplication, deaffrication, and stridency deletion. An analysis of consonant errors was also completed using the HAPP-3 responses. Adam demonstrated 27\% correct production of nasals $[m, n, n], 40 \%$ correct production of stops [p,b, t, d, k, g], 15\% correct production fricatives 
$\left[f, v, s, z, \int, 3, \theta, \partial, h\right], 0 \%$ correct production of affricates [t], dz], 18\% correct production of liquids $[l, r]$, and $80 \%$ correct production of glides $[w, j]$. The only substitution process that met the criteria of being "optional" by occurring between $40 \%$ and $60 \%$ was the process of "stopping". Therefore, the phonological process of "stopping" was chosen for intervention with Adam. He demonstrated $41 \%$ use of the stopping pattern on the HAPP3. Examples from his initial assessment included: [pis]for fish, [lip]for glove, [kudadə]for screwdriver, and [tedebibis] for television.

\section{Target Selection}

Based on analysis of his error patterns and stimulability testing, the initial [s] was chosen as the treatment target for Adam. Using feedback from the parent questionnaire, "bears” were chosen for Adam's intervention characters. The 5 key words used during the intervention were sad bear, sick bear, silly bear, super bear, and sun bear.

\section{Intervention Effectiveness}

Baseline. Adam's baseline remained at $0 \%$ accuracy for production of the target pattern during his 3 baseline sessions. His baseline remained stable as seen in Figure 3.

Intervention sessions. Adam demonstrated steady improvement during the 12 intervention sessions. As displayed in Figure 3, he demonstrated 21\% accuracy of the target pattern during the first intervention session. In general, his accuracy trended upward throughout the remaining 11 sessions. During his final intervention session, Adam produced the target pattern with 73\% accuracy. Adam's accuracy of the phonological pattern for session three was not included because the investigator was unable to collect data during that session. When the contrast question procedure was used, he responded with "I'm not going to tell you" or "I want you to do that." Adam did not attempt to say any of the key words. This pattern was not seen during subsequent sessions, and his mother reported that he had displayed a negative disposition for most of the day.

Within class generalization following intervention. Following the intervention period, Adam displayed within class generalization. The initial [s] was targeted during intervention as an example of the fricative class of sounds. Adam demonstrated generalization of the initial [s] to other fricatives from his initial HAPP-3 to the HAPP-3 administered immediately following the treatment sessions as shown in Table 3.2. On the 
Figure 3

Baseline and intervention sessions for Adam, Ben, and Steven

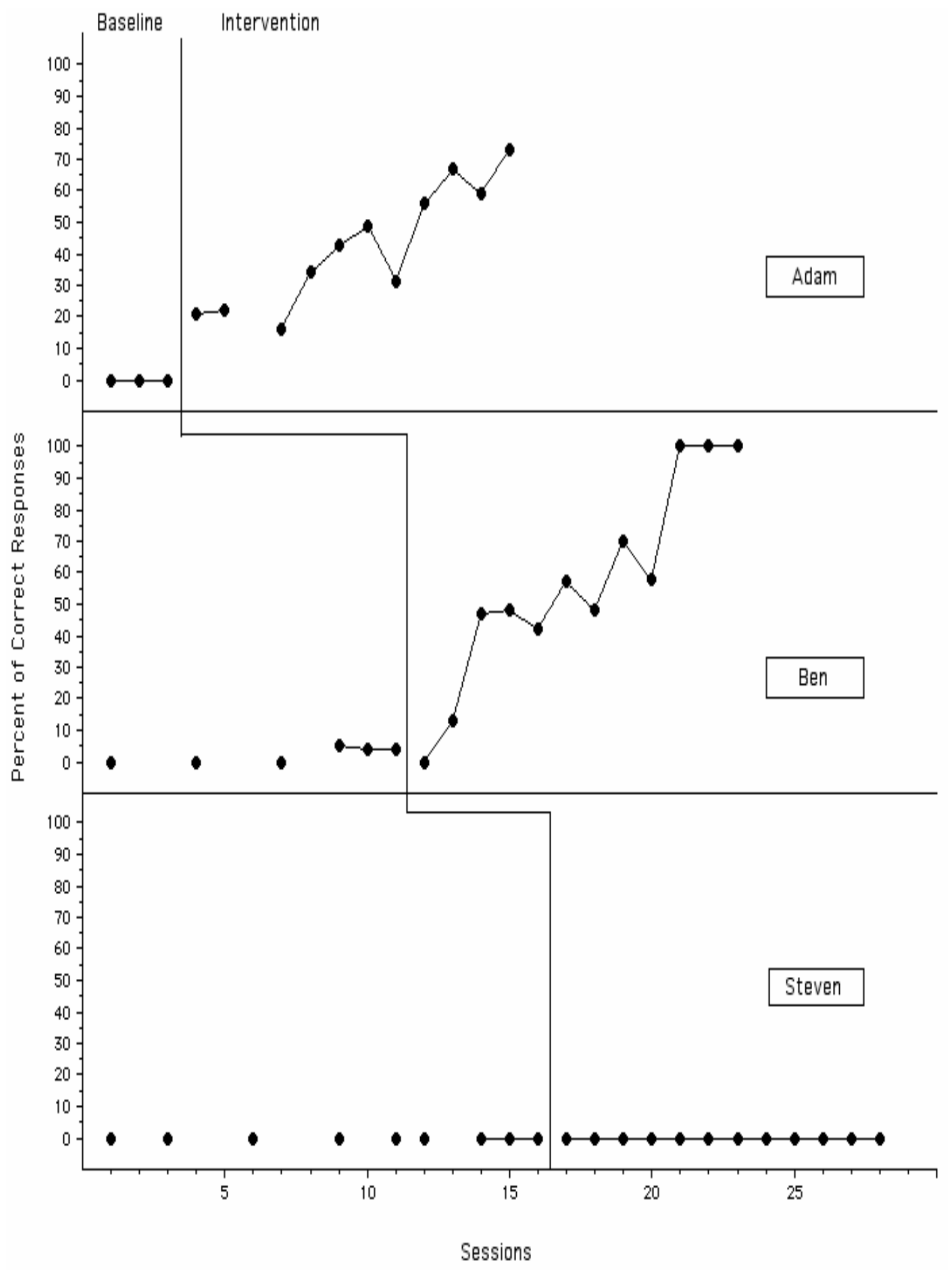


Table 3.2

Summary of Assessments for All Subjects

\begin{tabular}{|c|c|c|c|c|c|c|c|c|c|}
\hline & \multicolumn{3}{|c|}{ Subject 1: Adam } & \multicolumn{3}{|c|}{ Subject 2: Ben } & \multicolumn{3}{|c|}{ Subject 3: Steven } \\
\hline Assessment & Initial & Post & Follow-up & Initial & Post & Follow-up & Initial & Post & Follow-up \\
\hline HAPP-3: & & & & & & & & & \\
\hline *TOMPD & $\begin{array}{c}149 \\
\text { high } \\
\text { severe }\end{array}$ & $\begin{array}{c}151 \\
\text { low } \\
\text { profound }\end{array}$ & $\begin{array}{c}172 \\
\text { profound }\end{array}$ & $\begin{array}{c}95 \\
\text { moderate }\end{array}$ & $\begin{array}{c}76 \\
\text { moderate }\end{array}$ & $\begin{array}{c}52 \\
\text { moderate }\end{array}$ & $\begin{array}{c}109 \\
\text { severe }\end{array}$ & $\begin{array}{c}100 \\
\text { moderate }\end{array}$ & $\begin{array}{c}107 \\
\text { severe }\end{array}$ \\
\hline $\begin{array}{r}\text { Use of } \\
\text { Stopping } \\
\text { Process } \\
\end{array}$ & $41 \%$ & $32 \%$ & $36 \%$ & $50 \%$ & $36 \%$ & $23 \%$ & $59 \%$ & $68 \%$ & $64 \%$ \\
\hline $\begin{array}{r}\text { Correct } \\
\text { Use of } \\
\text { Fricatives } \\
\end{array}$ & $23 \%$ & $36 \%$ & $23 \%$ & $45 \%$ & $59 \%$ & $77 \%$ & $27 \%$ & $32 \%$ & $32 \%$ \\
\hline $\begin{array}{l}\text { Language } \\
\text { Sample: }\end{array}$ & & & & & & & & & \\
\hline $\begin{array}{r}\text { Use of } \\
\text { Stopping } \\
\text { Process } \\
\end{array}$ & $34 \%$ & $41 \%$ & $36 \%$ & $41 \%$ & $13 \%$ & $6 \%$ & $80 \%$ & $54 \%$ & $61 \%$ \\
\hline $\begin{array}{r}\text { Correct } \\
\text { Use of } \\
\text { Fricatives } \\
\end{array}$ & $42 \%$ & $45 \%$ & $23 \%$ & $57 \%$ & $87 \%$ & $92 \%$ & $0 \%$ & $44 \%$ & $23 \%$ \\
\hline
\end{tabular}

*Total Occurrences of Major Phonological Deviations (TOMPD)
Mild
$1-50$
Moderate
$51-100$
Severe
$101-150$
Profound
$>150$ 
initial administration of the HAPP-3 he used fricatives with 23\% accuracy; on the second administration, he produced the fricative class of sounds with $36 \%$ accuracy. Along with improved production of the initial [s], the target phoneme, he demonstrated improvement on the final [v] and the initial [S].

Within class generalization to conversational speech following intervention. Adam demonstrated little generalization of the target phonological pattern to conversational speech immediately following intervention. On the initial language sample, he used fricatives with $42 \%$ accuracy. On the second language sample, he used fricatives with $45 \%$ accuracy. It may be that with his final accuracy level of $73 \%$, Adam had not acquired the target phonological pattern during the intervention period. He may have required sustained intervention in order to demonstrate within class generalization to conversational speech.

Maintenance and within class generalization at one month follow up. Adam did not evidence within class generalization of the target phonological pattern one month following intervention. He demonstrated $23 \%$ correct use of fricatives on the initial HAPP-3 assessment, 36\% accuracy on the second administration, and 23\% accuracy of fricatives on the follow up. However, Adam did maintain correct production of the target pattern for the specific target phoneme [s] by pronouncing "soap" as "zoap" on the follow-up assessment. It appears that complete acquisition of the target phonological pattern may not have occurred since he did not maintain the gains made during intervention.

Maintenance and generalization of target pattern to conversational speech at one month follow up. Adam did not demonstrate within class generalization to conversational speech one month following the intervention period. On his initial language sample, Adam used fricatives with $42 \%$ accuracy. On the second language sample he used fricatives with $45 \%$ accuracy; however, on the follow up language sample, he used fricatives with only $23 \%$ accuracy. However, he demonstrated maintenance of the specific target phoneme [s] on the final language sample. There were no opportunities for the initial [s] on the first language sample. On the second sample, Adam had one opportunity for the initial [s] and substituted a [t]. On the follow-up language sample, there were four opportunities for the initial [s] and he produced the words "sound" and 
"said" using the initial [z], which resulted in 50\% correct use of the fricative pattern for that phoneme.

\author{
Results for Subject 2: Ben
}

\title{
Background Information
}

Subject 2, Ben, was 3 years, 7 months at the beginning of the study and did not have any siblings. Ben was enrolled in a preschool program and had received speech services in his preschool setting for two semesters prior to this study. Ben was unintelligible at times if the context was unknown to the listener. During the course of the current investigation, Ben did not receive additional speech intervention.

\section{Initial Test Performance}

According to the Hodson Assessment of Phonological Patterns, Third Edition (HAPP-3), his Total Occurrences of Major Phonological Deviations (TOMPD) score of 95 placed him in the "moderate" severity level. On the Preschool Language Scale-4 (PLS-4), he received a standard score of 107 on the Auditory Comprehension and Expressive Communication subtests giving him a total language standard score of 107, placing his language within normal limits. Oral examination and hearing screening results were within normal limits. His performance on the initial assessments is summarized in Table 2.3.

On the HAPP-3, he demonstrated use of the following phonological processes: stopping, cluster reduction, fronting, gliding, vowelization, and deaffrication. An analysis of consonant errors was also completed using the HAPP-3 responses. Ben demonstrated $100 \%$ correct production of nasals $[m, n, n], 70 \%$ correct production of stops $[p, b, t, d, k, g], 39 \%$ correct production fricatives [f, v, s, z, $, 3, \theta$, z, h], $0 \%$ correct production of affricates [t], d3], $0 \%$ correct production of liquids [l, r], and $40 \%$ correct production of glides $[w, j]$.The substitution process of "stopping" was the only phonological process that occurred between $40 \%$ and $60 \%$ and was chosen for Ben's intervention process. He demonstrated 50\% use of the stopping pattern on the HAPP-3. Examples from his initial assessment included: [pIs]for fish, [g^b] for glove, [du] for shoe, and [bert] for vase. 


\section{Target Selection}

Based on analysis of his error patterns and stimulability testing, the initial [f] was chosen as the treatment target for Ben. Using feedback from the parent questionaire, “cars” were chosen for Ben's intervention characters. The 5 key words used during the intervention were fat car, fin car, funny car, foot car, and furry car.

\section{Intervention Effectiveness}

Baseline. Ben's average baseline over 3 baseline probes and 3 baseline sessions was $2.2 \%$ accuracy of the target pattern as displayed in Figure 3. There were no significant changes during the baseline period.

Intervention sessions. Ben's production of the target phonological pattern improved markedly during the intervention period. As shown in Figure 3, he demonstrated $0 \%$ accuracy of the target pattern during the first intervention session. During the remaining 11 intervention sessions, his accuracy improved to 100\% accuracy of the target pattern noted during the final 3 sessions.

Within class generalization following intervention. Ben evidenced within class generalization of the target phonological pattern immediately following intervention. The initial [f] was targeted as an example of the fricative class of sounds. Ben demonstrated generalization to other fricatives from his initial HAPP-3 to the HAPP-3 administered immediately following the treatment sessions as shown in Table 3.2. On the initial administration, he used fricatives with 45\% accuracy; on the second administration he produced the fricative class of sounds with 59\% accuracy. In addition to improvement producing the initial [f], the target phoneme, Ben improved his production of the initial [S], the initial [z], initial [s], and the final [s].

Within class generalization to conversational speech following intervention. Ben achieved within class generalization to conversation speech. As seen in Table 3.2, on the initial language sample, Ben used fricatives with 57\% accuracy. On the second language sample, he used fricatives with $87 \%$ accuracy. Along with correct production of the initial [f], the target phoneme, he improved his production of the initial [s] following intervention. 
Maintenance and within class generalization at one month follow up. One month following the intervention period, Ben exhibited maintenance and within class generalization of the fricative class of sounds on the standardized assessment. He demonstrated 45\% correct use of fricatives on the initial HAPP-3 assessment, 59\% correct use of fricatives on the second $H A P P-3$, and $77 \%$ correct use of fricatives on the one month follow up administration of the HAPP-3 (see Table 3.2). On the follow up assessment, he demonstrated continued correct production of the initial [f] target phoneme. He also maintained his improved production of the initial [S], the initial [z], initial [s], and the final [s] from the second HAPP-3 administration. Ben evidenced widespread within class generalization of the target fricative pattern to "s-clusters." A consonant cluster is comprised of a sequence of adjacent consonants, in this case, beginning with "s." On the final assessment he added the "s" to clusters beginning with "sm," "sp," and "str" which had previously been omitted for the words "smoke," "spoon," and "string." He improved his accuracy of the "sl" and "skw" clusters. For the word slide, the "sl" cluster was prounounced "w" on the first HAPP-3 administration, "fw" on the second administration, and "sw" on the follow-up. He also added the fricative component to the "sw" cluster by improving his production of "swimming" from "wimming” to "fwimming." In addition, he improved his production of the initial $[\theta]$ in the word "thumb" from [t^m] on the second HAPP-3 to [s^m] on the final administration indicating continued within class generalization.

Maintenance and generalization of target pattern to conversational speech at one month follow up. Maintenance and generalization of the target pattern to conversational speech was observed at the one month follow up assessment. On his initial language sample, Ben used fricatives with 57\% accuracy. On the second language sample, he used fricatives with $87 \%$ accuracy, and on the follow up language sample, he used fricatives with 92\% accuracy (see Table 3.2). On the final language sample, he continued to correctly produce the initial [f]. He also continued to improve his production of the initial [J]. For example, his production of the word "shoe" was [su] on the second language sample and [su] on the final sample. 


\section{Background Information}

\section{Results for Subject 3: Steven}

Subject 3, Steven, was 3 years, 10 months at the beginning of the study and did not have any siblings. Steven was enrolled in a preschool program and had received speech services in his preschool setting for two semesters prior to this study. He was unintelligible at times if the context was not known to the listener. During the course of the current investigation, he did not receive additional speech intervention.

\section{Initial Test Performance}

According to the Hodson Assessment of Phonological Patterns, Third Edition (HAPP-3), his Total Occurrences of Major Phonological Deviations (TOMPD) score of 109 placed him in the "severe" range. On the Preschool Language Scale-4 (PLS-4), he received a standard score of 107 on the Auditory Comprehension subtest and a standard score of 99 on the Expressive Communication Subtest. His total language standard score of 104 placed his language within normal limits. Oral examination and hearing screening results were within normal limits. His performance on the initial assessments is summarized in Table 3.1.

On the HAPP-3, he demonstrated use of the following phonological processes: stopping, glottal stop replacement, cluster reduction, fronting, gliding, and deaffrication. An analysis of consonant errors was also completed using the HAPP-3 responses. Steven demonstrated $93 \%$ correct production of nasals [m,n, $]$ ], $40 \%$ correct production of stops $[p, b, t, d, k, g], 35 \%$ correct production fricatives $\left[f, v, s, z, \int, 3, \theta, \partial, h\right], 0 \%$ correct production of affricates $[t], d 3], 57 \%$ correct production of liquids $[1, r]$, and $100 \%$ correct

production of glides $[w, j]$. The only substitution process that met the criteria of occuring between $40 \%$ and $60 \%$ was the process of "stopping." This process was chosen for intervention with Steven who demonstrated 59\% use of the stopping pattern on the HAPP-3. Examples from his initial assessment included: [b^də] for feather, [pis]for fish, [doup] for soap, and [dip] for zip.

\section{Target Selection}

Based on analysis of his error patterns and stimulability testing, the initial [s] was chosen as the treatment target for Steven. Using feedback from the parent questionaire, 
“cars” were chosen for Steven's intervention characters. The 5 key words used during the intervention were sad car, sick car, silly car, super car, and sun car.

Intervention Effectiveness

Baseline. Steven's baseline remained at 0\% accuracy for production of the target pattern during the 6 probe sessions and 3 baseline sessions reflecting a stable pattern.

Intervention sessions. Steven's production of the target phonological pattern did not improve during the 12 intervention sessions. As displayed in Figure 3, Steven demonstrated $0 \%$ accuracy of the target pattern during intervention Session 1 through intervention Session 12. However, he did evidence within class generalization following intervention, and generalization to conversational speech following intervention and one month later, indicating that positive changes occurred in his phonological system.

Within class generalization following intervention. Steven evidenced moderate within class generalization following the 12 intervention sessions. For Steven, Subject 3, the initial [s] was targeted as an example of the fricative class of sounds. He demonstrated generalization to other fricatives from his initial HAPP-3 and the HAPP-3 administered immediately following the treatment sessions as shown in Table 3.2. On the initial administration, he used fricatives with 27\% accuracy; on the second administration, he produced the fricative class of sounds with $32 \%$ accuracy. On the second administration, he included the final [f], which had initially been omitted from the words “leaf” and "mouth,” indicating within class generalization. He also improved his production of the final [S] from [pIs] on the initial HAPP-3 to [pIS] on the second administration indicating an improvement in production accuracy.

Within class generalization to conversational speech following intervention.

Within class generalization occurred to conversational speech following intervention. On the initial language sample, Steven used fricatives with $0 \%$ accuracy. On the second language sample, he used fricatives with 44\% accuracy. Examples include Steven's improved use of the final [s] as a plural form on the second language sample. To illustrate, the word "arms” was pronounced "arm” on the first language sample and [armf] on the sample following intervention. Steven also improved his production of the final 
"th” in conversational speech. On the first language sample he said [bæp] for "bath” and on the second sample he said [mauf] for "mouth."

Maintenance and within class generalization at one month follow up. Steven was successful with within class generalization one month following intervention. He demonstrated $27 \%$ correct use of fricatives on the initial HAPP-3 assessment, 32\% correct use of fricatives on the second HAPP-3, and maintained 32\% accuracy on the one month follow up. He maintained his correct production of the final [f] and [s] on the words "leaf" and "fish." He also continued to use a fricative for the final sound in the word "mouth" which he pronounced as [mauf]. He also improved his production of the final [v] in the word "glove.” His said [bw^bz]on the first and second assessments, and [gw^vz]on the final assessment, which demonstrated continued within class generalization.

Maintenance and generalization of target pattern to conversational speech at one month follow up. Steven showed improvement in his use of the target phonological pattern at the 1 month follow up. On his initial language sample, he used fricatives with $0 \%$ accuracy. Following intervention, he used fricatives with $44 \%$ accuracy, and on the follow up language sample, he used fricatives with 23\% accuracy. On the follow up sample, he sustained improvement in his use of the final [s]and [z]as a plural form. He also correctly produced the medial [z] in the word "crazy” during the language sample. On previous assessments, a [b] or [p] was substituted for the the medial [z].

System-wide changes. System-wide changes were seen for Subject Three, Steven. Because he did not change his production of the target fricative during the intervention period, it was important to note this phonological improvement. Immediately following intervention improvement was seen in his use of the [k] and the [g], the velar class of sounds. His production of the word "gum" was [d^m] on the first assessment and [g^m] following intervention. His production of the medial "sk" cluster was [bætı?] for "basket" originally and [bækıt] on the second assessment. His production of "L-clusters” also improved. The word “cloud” was originally pronounced [paus]. On the second assessment the word was pronounced [pwauds]. The word "plane” changed from [pein] to [pwein]. An improvement in the overall structure of two-element clusters was seen. He 
progressed from using a single stop consonant with the [l] omitted, to using the stop consonant plus the [w]. Steven also changed his production of the initial [z] on the word "zip.” On the first assessment he said [dip] and on the second administration, he said [gip]. Although this did not represent an improvement in his use of the fricative class of sounds, it does point to a possible attempt to change his production of the initial [z].

Steven continued to display further overall changes in his phonological system on the follow up standardized assessment. He maintained improvement on the initial [g], and the medial [sk] cluster. He also demonstrated additional growth in the pronunciation of [l] clusters. For the word "flower," he said [pwauwə ] on the first two assessments and [fauwə ${ }^{x}$ on the follow-up HAPP-3. It was noted that Steven modified some fricative productions by substituting a "g." For example, on the first assessment he said [tju] for "shoe." On the second assessment he said [du], and on the third assessment he said [gju]. For the word “zip,” he said [dip], [gip], and [gip] respectively. Steven also modified his production of the word "soap." On the first and second assessment, he said [doup] and on the follow up assessment, he said [goup]. Although these examples did not represent an improvement in his fricative production, they may have been attempts to modify his production of the fricatives.

\section{Summary of Results for All 3 Subjects}

\section{Multiple Probe Single Subject Design}

The multiple probe results for all subjects are illustrated in Figure 3. After demonstrating a stable baseline of $0 \%$ accuracy for the target phonological pattern, Adam began treatment sessions. During this time, Ben and Steven received periodic probes of their production accuracy of the target pattern until Adam achieved $40 \%$ accuracy above baseline. When Adam, the first subject, reached 43\% accuracy, Ben, the second subject, began the treatment phase while Steven, the third subject, continued receiving periodic probes. Ben reached $47 \%$ accuracy during his third treatment session allowing Steven to begin the treatment phase.

\section{Intervention Effectiveness}

Intervention Sessions. Two out of the three subjects demonstrated improvement in the use of the target phonological patterns during the intervention sessions. Adam began 
with $0 \%$ accuracy and reached $73 \%$ accuracy in production of the target pattern, and Ben went from $2.2 \%$ accuracy to $100 \%$ accuracy. Steven remained at $0 \%$ accuracy during the intervention period.

Within class generalization following intervention. Within class generalization of the target phonological pattern was seen for all three subjects on the second administration of the HAPP-3 following the intervention period. Adam (Subject One) demonstrated 23\% correct production of fricatives on the initial assessment and 36\% correct production following intervention. Ben (Subject Two) demonstrated a similar pattern with $45 \%$ correct production of fricatives on the initial assessment and 59\% correct production following intervention. Steven's (Subject Three) initial accuracy level was $27 \%$ correct and was 32\% following intervention.

Within class generalization to conversational speech following intervention. All three subjects demonstrated generalization of the target phonological pattern to conversational speech following the intervention period. Ben went from 57\% correct use of fricatives on the first language sample to $87 \%$ correct use of fricatives on the language sample following the intervention period. Steven's correct use of fricatives increased from $0 \%$ on the first language sample to $44 \%$ correct use of fricatives on the second language sample. Adam demonstrated $42 \%$ correct use of fricatives on the initial language sample and 45\% correct use of fricatives on the second language sample.

Maintenance and generalization at one month follow up. Two of the three subjects demonstrated generalization of the target phonological patterns one month following the intervention period. Subject Two, Ben, demonstrated within class generalization of the target pattern on the HAPP-3. He used fricatives with $45 \%$ accuracy on the initial assessment, 59\% accuracy on the second administration, and 77\% accuracy on the one month follow up assessment. He also clearly showed generalization of the target phonological pattern to conversational speech with 57\% accuracy initially, 87\% accuracy on the second language sample, and 92\% accuracy on the follow up language sample. Although Subject 3, Steven, did not improve his production of the target pattern during intervention sessions, he demonstrated generalization of the target phonological pattern one month later on the HAPP-3. On the initial assessment, he used fricatives with 27\% accuracy and with 32\% accuracy one month later. On the initial language sample, he 
used fricatives with $0 \%$ accuracy and he used fricatives with $23 \%$ accuracy on the one month sample. He also evidenced some system-wide improvement in his phonological structure. Subject 1, Adam, did not exhibit generalization of the target phonological pattern one month following the intervention period. However, he displayed maintenance of the target phonological pattern on the final language sample.

Copyright $\odot$ Sharon Blodgett Hart 2007 


\section{CHAPTER 4: DISCUSSION}

\section{Overview}

This study was designed to evaluate the effectiveness of communication-centered phonological intervention with children who have moderate to severe phonological disorders. The research questions explored acquisition of the target phonological pattern during intervention, within class generalization of the target phonological pattern following intervention, and within class generalization of the target pattern one month later. Questions also addressed within class generalization of the target phonological pattern to conversational speech following intervention and one month later. The research questions are presented with the findings summarized and analyzed for the three subjects. Contributions of this study to the literature, limitations of the study, and implications for future research will be discussed.

The Research Questions

Research Question 1: Will preschool children demonstrate improvement in the use of target phonological patterns following 6 weeks of communication-centered phonological intervention?

Two of the three subjects in the study demonstrated improvement in the use of fricatives, the target phonological pattern, following the intervention period. The communication-centered intervention package included focused stimulation of key words through joint storybook reading and interactive practice of key words. One of the primary components of the intervention was the use of a minimal pair contrast question following an incorrect production during interactive practice of the key words. For example, if the child said, "I want tad car,” the investigator said, “Do you want tad or sad?” The three subjects consistently made adjustments to their productions following contrast questions indicating a recognition of the need to do something different when producing the word. Modifications included: phonetic adjustments (using a different sound), prosodic adjustments (stress and intonation changes), or gestural efforts. Gestural efforts included leaning toward the investigator, or clapping hands in conjunction with saying a word. The children's use of these modifications following communicative feedback supports Gallagher's (1977) finding that children make adjustments in response to communicative failure. The children's responses to the use of contrast questions were consistent with 
descriptions of naturalistic procedures for speech intervention described by Low, Newman, and Ravsten (1989), Hoffman (1992), and Lowe and Weitz, (1994). They suggested that posing contrast questions to request clarification during a naturalistic context would provide the child with an opportunity for revision of the message.

It was interesting to note the strategies each child used in response to contrast questions. Table 4.1 illustrates the progression of Ben's pronunciation of the key words during each intervention session. For example, during Session 3, he altered his production of the word "fat" in two ways. The arrows on the chart indicate a change in the way the word was said following the contrast question, in this case, "Do you want pat or fat? After the contrast question, Ben said the word "pat" again with a louder voice. He also modified his production from [pæt] "pat" to "fat" during the session. During the first few sessions, when Ben was confronted with a contrast question, he modified his production of the key words using loudness, vowel lengthening, and leaning forward in the investigators direction. An example of vowel lengthening was "foot" being pronounced as [pu:t] "puuuuut" during Session 1. By the third intervention session, Ben improved his production of the key words following contrast questions. Not only was he using the correct phonological pattern, he was consistently using the correct specific phonological target, the initial [f]. Communication-centered intervention appeared to facilitate use of the target phonological pattern in Ben.

Subject One, Adam, primarily demonstrated phonetic adjustments during intervention sessions as seen in Table 4.2. During Session 1, he began using a [z] for the initial [s] in the key words "sun", "sad", and "sick". This represented an improvement in his production of the initial [s]. During Sessions 7 and 8, he improved his use of the fricative pattern on the words "super" and "silly". By the final intervention session, he continued to use the initial [s] for the words "sun", "sad", and "sick. For the words "super" and "silly," he used the initial [s] following the contrast question procedure. It appeared to take Adam longer to improve his production of the two-syllable key words. One syllable words may have been more successful in facilitating phonological 


\begin{tabular}{|c|c|c|c|c|c|}
\hline \multicolumn{6}{|c|}{$\begin{array}{l}\text { Table } 4.1 \\
\text { Changes During Intervention for Subject 2(Ben) }\end{array}$} \\
\hline Session & Fat & Funny & Furry & Foot & Fin \\
\hline Baseline & [pæt] & [p^ni] & [p^wi] & [put] & [pin] \\
\hline $\mathrm{T}-1$ & $\begin{array}{l}{[p æ t] \rightarrow L} \\
{[p æ t]} \\
{[p æ t] \rightarrow L}\end{array}$ & [p^ni] & $\begin{array}{c}\text { [p^wi] } \\
{[p \wedge w i] \rightarrow[m \wedge w i] L} \\
{[p \wedge w i] \rightarrow L}\end{array}$ & $\begin{array}{c}\text { [put }] \\
{[\text { put }] \rightarrow \mathrm{L} \mathrm{V}} \\
{[\text { put }] \rightarrow \mathrm{L}}\end{array}$ & $\begin{array}{c}\text { [pIn] [pint] } \\
\text { [pIn] } \rightarrow \mathrm{L} \\
{[\text { pint }]}\end{array}$ \\
\hline $\mathrm{T}-2$ & $\begin{array}{c}\text { [pæt] } \\
{[p æ t] \rightarrow V}\end{array}$ & {$[p \wedge n i] \rightarrow[m \wedge n i]$} & $\begin{array}{c}*[p \wedge w i] \rightarrow[f \wedge w i] \\
{[p \wedge w i]} \\
*[p \wedge w i] \rightarrow[f \wedge w i] \\
{[p \wedge w i] \rightarrow L}\end{array}$ & {$[p v t] \rightarrow L$} & $\begin{array}{c}\text { [pin] } \\
{[\text { pin] } \rightarrow \text { L V }}\end{array}$ \\
\hline $\mathrm{T}-3$ & $\begin{array}{c}{[p æ t] \rightarrow L} \\
*[p æ t] \rightarrow[f æ t]\end{array}$ & $*[p \wedge n i] \rightarrow[f \wedge n i]$ & $\begin{array}{c}*[p \wedge w i] \rightarrow[f \wedge w i] \\
{[f \wedge w i]} \\
*[p \wedge w i] \rightarrow[f \wedge w i] \\
{[f \wedge w i]}\end{array}$ & $\begin{array}{c}{[\text { put }] *[\text { put }] \rightarrow[\text { fut }]} \\
{[\text { put }] \rightarrow F} \\
{ }^{\circ}[\text { put }] \rightarrow[\text { fwut }] \\
*[\text { put }] \rightarrow[\text { fut }][\text { put }]\end{array}$ & $\begin{array}{c}{[\mathrm{fIn}]} \\
{[\mathrm{pIn}] \rightarrow \mathrm{L}}\end{array}$ \\
\hline $\mathrm{T}-4$ & $*[\mathrm{f} æ t]$ & $\begin{array}{c}*[\mathrm{f} \wedge \mathrm{ni}][\mathrm{p} \wedge \mathrm{ni}] \\
*[\mathrm{f} \wedge \mathrm{ni}] \\
*[\mathrm{p} \wedge \mathrm{ni}] \rightarrow[\mathrm{f} \wedge \mathrm{ni}]\end{array}$ & $\begin{array}{c}*[\mathrm{f} \wedge \mathrm{wi}] \quad[\mathrm{p} \wedge \mathrm{wi}] \\
*[\mathrm{f} \wedge \mathrm{wi}] \\
*[\mathrm{p} \wedge \mathrm{wi}] \rightarrow[\mathrm{f} \wedge \mathrm{wi}] \\
*[\mathrm{f} \wedge \mathrm{wi}]\end{array}$ & {$[p u t]$} & {$[$ pIn] $\rightarrow$ L } \\
\hline $\mathrm{T}-5$ & $*[f æ t] \quad[p æ t]$ & $\begin{array}{c}*[\mathrm{f} \wedge n \mathrm{i}] \quad[p \wedge n i] \\
*[\mathrm{f} \wedge \mathrm{ni}]\end{array}$ & $\begin{array}{l}{[p \wedge w i] \rightarrow[f \wedge w i]} \\
{[p \wedge w i] \rightarrow[f \wedge w i]}\end{array}$ & $*[$ put $] \rightarrow[$ fut $]$ & $\begin{array}{l}\text { [pIn] } \\
{[\mathrm{fIn}]}\end{array}$ \\
\hline T-6 & $\begin{array}{l}\text { [pæt }] \\
*[\text { fæt }]\end{array}$ & $\begin{array}{c}{[p \wedge n i] \rightarrow[f \wedge n i]} \\
*[f \wedge n i]\end{array}$ & $\begin{array}{c}*[\mathrm{f} \wedge \mathrm{wi}] \\
*[\mathrm{p} \wedge \mathrm{wi}] \rightarrow[\mathrm{f} \wedge \mathrm{wi}] \\
*[\mathrm{f} \wedge \mathrm{wi}]\end{array}$ & $\begin{array}{c}*[\text { put }] \rightarrow[\text { fut }][\text { put }] \\
{[\text { fut }] *[\text { put }] \rightarrow[\text { fut }]} \\
{[\text { put }] \rightarrow[\text { puti }]} \\
\quad *[\text { put }] \rightarrow[\text { fut }]\end{array}$ & $\begin{array}{c}{[\text { pIn }] \rightarrow[\text { fin }]} \\
{[\text { pIn }] \quad[\text { fIn }]}\end{array}$ \\
\hline $\mathrm{T}-7$ & $*[f æ t]$ & $\begin{array}{c}{[p \wedge n i] \rightarrow[f \wedge n i]} \\
*[f \wedge n i]\end{array}$ & $\begin{array}{c}*[\mathrm{f} \wedge \mathrm{wi}] \\
*[\mathrm{p} \wedge \mathrm{wi}] \rightarrow[\mathrm{f} \wedge \mathrm{wi}] \\
*[\mathrm{f} \wedge \mathrm{wi}] \\
*[\mathrm{p} \wedge \mathrm{wi}] \rightarrow[\mathrm{f} \wedge \mathrm{wi}] \\
*[\mathrm{f} \wedge \mathrm{wi}]\end{array}$ & $*[$ put $]$ & $\begin{array}{l}\text { [pIn] } \rightarrow \text { [pInd] } \\
{[\text { fIn] }[\text { pIn] } \rightarrow \text { L }}\end{array}$ \\
\hline T-8 & $\begin{array}{c}*[f æ t] \\
*[p æ t] \rightarrow[f æ t] \\
*[f æ t]\end{array}$ & $*[f \wedge n i]$ & $\begin{array}{c}*[f \wedge w i][p \wedge w i] \\
{[f \wedge w i]}\end{array}$ & $\begin{array}{c}{[\text { fut }]} \\
*[p u t] \rightarrow[\text { fut }]\end{array}$ & $\begin{array}{c}{[\mathrm{fIn}]} \\
{[\mathrm{pIn}] \rightarrow[\mathrm{fIn}]}\end{array}$ \\
\hline T-9 & $\begin{array}{c}*[p æ t] \rightarrow[f æ t] \\
*[f æ t] \\
*[p æ t] \rightarrow[f æ t]\end{array}$ & $\begin{array}{l}\text { [p^ni] } \\
*[f \wedge n i]\end{array}$ & $*[\mathrm{f} \wedge \mathrm{wi}]$ & $\begin{array}{c}{[\text { fut }]} \\
*[\text { put }] \rightarrow[\text { fut }]\end{array}$ & {$[$ pin] $\rightarrow$ V V V } \\
\hline $\mathrm{T}-10$ & $*$ [fæt] & $*[f \wedge n i]$ & $*[\mathrm{f} \wedge \mathrm{wi}]$ & [fut] & $*[\mathrm{fin}]$ \\
\hline $\mathrm{T}-11$ & $*$ [fæt] & $*[f \wedge n i]$ & $*[\mathrm{f} \wedge \mathrm{wi}]$ & [fut] & $*[\mathrm{fin}]$ \\
\hline $\mathrm{T}-12$ & $*[\mathrm{f} æ t]$ & $*[\mathrm{f} \wedge \mathrm{ni}]$ & $*[\mathrm{f} \wedge \mathrm{wi}]$ & [fut] & $*[\mathrm{fIn}]$ \\
\hline
\end{tabular}

$\mathrm{T}=$ Treatment session

* = Correct use of the target phonological pattern

$\rightarrow=$ "becomes" $\quad \mathrm{L}=$ louder $\quad \mathrm{V}=$ lengthened vowel $\quad \mathrm{F}=$ leaned forward 


\begin{tabular}{|c|c|c|c|c|c|}
\hline \multicolumn{6}{|l|}{$\begin{array}{l}\text { Table } 4.2 \\
\text { Changes } L\end{array}$} \\
\hline Session & Super & Sun & Silly & Sad & Sick \\
\hline Baseline & [juju] & {$[\mathrm{d} \varepsilon][\mathrm{d} \varepsilon s]$} & [IIli] & [ja] & [di] [dis] \\
\hline $\mathrm{T}-1$ & $\begin{array}{l}\text { [juju] } \\
\text { [juju]L } \\
\text { [juju] } \\
\end{array}$ & $\begin{array}{c}{[\mathrm{d} \varepsilon]} \\
*[\mathrm{z} \varepsilon] \\
{[\mathrm{j} \varepsilon]} \\
\end{array}$ & $\begin{array}{l}{[\text { IIli] }} \\
{[\text { IIli]L }} \\
{[\text { IIli] }} \\
\end{array}$ & $\begin{array}{c}*[\mathrm{zæ}][\mathrm{d} 3 æ] \\
{[\mathrm{d} æ] \rightarrow[\mathrm{zæ}] \mathrm{L}} \\
*[\mathrm{zæ}]\end{array}$ & $\begin{array}{l}\text { [dIs] } \\
*[\mathrm{zI}] \mathrm{L} \\
*[\mathrm{zIS}] \\
\end{array}$ \\
\hline $\mathrm{T}-2$ & $\begin{array}{l}\text { [juju] } \rightarrow \text { L } \\
\text { [juju] }\end{array}$ & $\begin{array}{c}*[\mathrm{~d} \varepsilon] \rightarrow[\mathrm{z} \varepsilon] \\
{[\mathrm{d} z \varepsilon] \quad *[\mathrm{z} \varepsilon]} \\
*[\mathrm{~d} \varepsilon] \rightarrow[\mathrm{z} \varepsilon]\end{array}$ & [IIli] & $\begin{array}{r}d z æ] \\
*[\mathrm{zæ}] \\
{[\mathrm{ja}]}\end{array}$ & $\begin{array}{c}*[\mathrm{di}] \rightarrow[\mathrm{zI}] \\
{[\mathrm{zi}]}\end{array}$ \\
\hline $\mathrm{T}-4$ & $\begin{array}{c}\text { [juju] } \\
\text { [juju] } \rightarrow \mathrm{L} \\
\text { [juju] }\end{array}$ & $\begin{array}{c}{[j \varepsilon] \rightarrow[d \varepsilon]} \\
{\left[d_{3} \varepsilon\right]}\end{array}$ & $\begin{array}{c}{[\text { IIli }]} \\
{[\mid \mathrm{Ili}] \rightarrow \mathrm{L}} \\
{[\text { IIli }]} \\
\end{array}$ & $\begin{array}{c}{[\mathrm{jæ}]} \\
*[\mathrm{da}] \rightarrow[\mathrm{za}] \\
*[\mathrm{zæ}][\mathrm{ja}] \\
\end{array}$ & $\begin{array}{c}*[\mathrm{zI}] \\
{[\mathrm{d} \mathrm{I}]} \\
*[\mathrm{zI}]\end{array}$ \\
\hline $\mathrm{T}-5$ & $\begin{array}{c}\text { [juju] } \\
\text { [juju] } \rightarrow \mathrm{L} \\
\text { [juju] }\end{array}$ & $\begin{array}{c}{[\mathrm{d} \varepsilon]} \\
{[\mathrm{d} \varepsilon] \rightarrow \mathrm{L}}\end{array}$ & $\begin{array}{c}{[\mid \mathrm{IIli}]} \\
{[\mathrm{IIli}] \rightarrow \mathrm{L}}\end{array}$ & $\begin{array}{l}*[\mathrm{zæ}] *[\mathrm{za}] \\
*[\mathrm{zæ}] *[\mathrm{za}]\end{array}$ & $\begin{array}{l}*[\mathrm{zi}] *[\mathrm{zI}] \\
{[\mathrm{dI}] *[\mathrm{zi}]}\end{array}$ \\
\hline T-6 & [juju] & $\begin{array}{c}*[\mathrm{z} \varepsilon] \\
*[\mathrm{~d} \varepsilon] \rightarrow[\mathrm{z} \varepsilon] \\
*[\mathrm{z} \varepsilon]\end{array}$ & 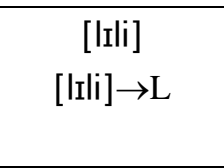 & $*[\mathrm{zæ}]$ & $\begin{array}{l}*[\mathrm{zI}] \\
\quad *[\mathrm{zi}]\end{array}$ \\
\hline $\mathrm{T}-7$ & $\begin{array}{c}\text { [juju }] \\
{[\text { juju }] \rightarrow L} \\
*[\text { juju }] \rightarrow[\text { suju }]\end{array}$ & $\begin{array}{r}*[\mathrm{z} \varepsilon] \\
{[\mathrm{d} \varepsilon]} \\
*[\mathrm{z} \varepsilon]\end{array}$ & [IIli] & $*[\mathrm{z})]$ & $\begin{array}{c}\text { [di }] \\
*[\mathrm{di}] \rightarrow[\mathrm{sI}] \\
*[\mathrm{zi}] *[\mathrm{zI}]\end{array}$ \\
\hline $\mathrm{T}-8$ & $\begin{array}{ll}\text { [juju] } & \text { [julu] } \\
\text { [juju] } & \text { [julu] }\end{array}$ & $\begin{array}{c}*[\mathrm{z} \varepsilon] \\
{[\mathrm{d} \varepsilon] \rightarrow *[\mathrm{z} \varepsilon]}\end{array}$ & $\begin{array}{c}\text { [IIli] } \\
*[z|I| i]\end{array}$ & $\begin{array}{c}*[\mathrm{z} æ] \\
{[\mathrm{j} æ]}\end{array}$ & $\begin{array}{ll}*[\mathrm{zi}] & {[\mathrm{diz}]} \\
*[\mathrm{zi}] & *[\mathrm{zis}]\end{array}$ \\
\hline T-9 & $\begin{array}{cc}\text { [juju] } & \text { [julu] } \\
* \text { [zuju] } & \text { [juju] }\end{array}$ & $*[\mathrm{z} \varepsilon]$ & [IIli] & $\begin{array}{l}*[\mathrm{za}] \\
*[\mathrm{zæ}]\end{array}$ & $\begin{array}{l}*[\mathrm{zI}] \\
*[\mathrm{zi}]\end{array}$ \\
\hline $\mathrm{T}-10$ & $\begin{array}{c}\text { [julu }] \\
*[\text { julu }] \rightarrow[\text { sulu }] \\
*[\text { sulu }]\end{array}$ & $\begin{array}{l}*[\mathrm{z} \varepsilon] \\
*[\mathrm{~s} \varepsilon]\end{array}$ & $\begin{array}{c}{[\text { IIli }]} \\
*[\text { slIli }] \\
{[\text { IIIli }]}\end{array}$ & $\begin{array}{l}*[\mathrm{z} æ] \\
*[\mathrm{~s} æ]\end{array}$ & $\begin{array}{l}*[\mathrm{zis}] \\
*[\mathrm{sI}]\end{array}$ \\
\hline $\mathrm{T}-11$ & $\begin{array}{c}*[\text { juju }] \rightarrow[\text { suju }] \\
{[\text { suju }]}\end{array}$ & $\begin{array}{c}*[\mathrm{~d} \varepsilon] \rightarrow[\mathrm{s} \varepsilon] \\
*[\mathrm{~s} \varepsilon]\end{array}$ & $\begin{array}{c}*[\text { IIli }] \rightarrow[\text { slıli }] \\
*[\text { slıli }][\text { IIli }] \\
*[\text { IIli }] \rightarrow[\text { slili }]\end{array}$ & $*$ [sæ] & $\begin{array}{l}*[\mathrm{di}] \rightarrow[\mathrm{sI}] \\
\quad *[\mathrm{si}] \\
\quad *[\mathrm{sI}] \\
\end{array}$ \\
\hline $\mathrm{T}-12$ & $\begin{array}{c}\text { *[julu }] \rightarrow[\text { suju }] \\
*[\text { suju }][\text { juju }] \\
*[\text { juju }] \rightarrow[\text { suju }] \\
*[\text { suju }] \\
*[\text { juju }] \rightarrow[\text { suju }] \\
*[\text { suju }][\text { juju }] \\
*[\text { juju }] \rightarrow[\text { suju }] \\
*[\text { suju }]\end{array}$ & $*[s \varepsilon]$ & $\begin{array}{c}*[\text { slIli }] \\
*[\text { IIli }] \rightarrow[\text { slili }]\end{array}$ & $*$ [sæ] & $*[\mathrm{sI}]$ \\
\hline
\end{tabular}

* Correct use of the target phonological pattern
$\rightarrow=$ "becomes"
$\mathrm{L}=$ louder 
improvement for Adam. Nevertheless, the communicative-centered intervention appeared to facilitate use of the target phonological pattern in Adam.

Steven, Subject 3, used a variety of strategies throughout the treatment sessions in response to contrast questions which indicated recognition of needed changes. However, he did not correctly produce the target phonological pattern during the intervention period. Following contrast questions, he used prosodic adjustments, phonetic adjustments, and gestural efforts as depicted in Table 4.3. His use of prosodic adjustments began during the first session when he produced the key word louder after being questioned. During the second session, he used vowel lengthening and a softer production after the contrast question. During the third session, he combined vowel lengthening and a softer production. During Session Four, he used loudness, vowel lengthening, and a softer production. For the remaining sessions, he continued to use loudness, softer production, and vowel lengthening as strategies. For Sessions 8 through 12, he used vowel lengthening following contrast questions. He also exhibited phonetic adjustments by regularly substituting the initial [k] or [g] at the beginning of the key words “sad," "super," and "sick.” This represented a change from his typical substitution pattern of using a [t] instead of the target [s]; however, it was not an improvement in the production of the fricative class of sounds.

Communicative-centered intervention did not appear to facilitate use of the target phonological pattern for Steven. The investigator postulated that his adjustments following contrast questions indicated that Steven would modify his productions further toward the fricative class of sounds during the intervention period. In a typical clinical situation, therapeutic adjustments would have been made such as providing additional modeling and cueing techniques, more intensive treatment, modifications to the treatment method, or an extended treatment period. As noted in the literature, treatment for children who have severe phonological disorders is typically a long-term process and immediate improvement may not always be seen (Hodson, 2007; Williams, 2003). Steven may have exhibited improvement during the intervention period if the target selection criteria had been different. Instead of targeting one fricative, several fricatives could have been targeted in succession as in the Cycles Phonological Remediation Approach (Hodson \& Paden, 1991). He may also have benefited from an initial period using a drill-play format 


\begin{tabular}{|c|c|c|c|c|c|}
\hline \multicolumn{6}{|c|}{$\begin{array}{l}\text { Table } 4.3 \\
\text { Changes During Intervention for Subject } 3 \text { (Steven) }\end{array}$} \\
\hline Session & Sun & Silly & Sick & Sad & Super \\
\hline Baseline & {$[\mathrm{t} \wedge \mathrm{n}]$} & [tIwi] & [tI?] & [tæd] & [tupər] \\
\hline *T-1 & $\begin{array}{c}{[\mathrm{t} \wedge \mathrm{ni}]} \\
{[\mathrm{t} \wedge \mathrm{n}] \rightarrow \mathrm{L}} \\
{[\mathrm{t} \wedge \mathrm{n}]}\end{array}$ & $\begin{array}{c}\text { [trwi] } \rightarrow \text { [trwi] } \\
{[\text { tıwi] }[\text { tıwi] } \rightarrow \mathrm{L}} \\
{[\text { tıwi] }}\end{array}$ & $\begin{array}{c}{[\mathrm{tI} P][\mathrm{tI} P] \rightarrow \mathrm{L}} \\
{[\mathrm{tI} P]} \\
{[\mathrm{tI} P] \rightarrow \mathrm{L}}\end{array}$ & $\begin{array}{c}\text { [tæd][tæd] } \rightarrow \mathrm{L} \\
\quad[\mathrm{tæd}] \\
{[\mathrm{tæd}] \rightarrow[\mathrm{gæd}] \mathrm{L}}\end{array}$ & [tupə`] \\
\hline $\mathrm{T}-2$ & $\begin{array}{l}{[\mathrm{t} \wedge \mathrm{n}][\mathrm{t} \wedge \mathrm{n}] \rightarrow \mathrm{V}} \\
{[\mathrm{t} \wedge \mathrm{n}] \rightarrow \mathrm{S}[\mathrm{t} \wedge \mathrm{n}]}\end{array}$ & $\begin{array}{c}\text { [trwi] [tıwi] } \rightarrow \mathrm{L} \\
\text { [tıwi] }\end{array}$ & $\begin{array}{c}{[\operatorname{tt} P]} \\
{[\operatorname{tt} P] \rightarrow[g I P]}\end{array}$ & $\begin{array}{c}{[\mathrm{tæd}] \rightarrow \mathrm{L}[\mathrm{tæd}]} \\
{[\mathrm{tæd}] \rightarrow \mathrm{V}}\end{array}$ & [tupər] \\
\hline $\mathrm{T}-3$ & & $\begin{array}{c}\text { [giwi] [tIwi] } \\
{[\text { tIwi] } \rightarrow \mathrm{S} \text { [tIwi] } \rightarrow \mathrm{L}}\end{array}$ & & $\begin{array}{c}{[\mathrm{tæd}] \rightarrow[\mathrm{gæc}]} \\
{[\mathrm{tæd}] \rightarrow \mathrm{V}}\end{array}$ & $\begin{array}{c}{[\text { tupər] } \rightarrow \mathrm{L}} \\
{[\text { tupər] }}\end{array}$ \\
\hline $\mathrm{T}-4$ & $\begin{array}{c}{[t \wedge n][t \wedge n] \rightarrow L} \\
{[t \wedge n] \rightarrow V[t \wedge n] \rightarrow S}\end{array}$ & $\begin{array}{c}{[\text { trwi] }} \\
{[\text { tIwi] } \rightarrow \text { S }}\end{array}$ & $\begin{array}{l}{[\mathrm{tI} P][\mathrm{tI} P] \rightarrow \mathrm{V}} \\
{[\mathrm{tI} P] \rightarrow \mathrm{S}}\end{array}$ & $\begin{array}{c}{[\mathrm{tæd}][\mathrm{t} æ d] \rightarrow \mathrm{V}} \\
{[\mathrm{tæd}] \rightarrow \mathrm{C}}\end{array}$ & $\begin{array}{c}{\left[\text { tup } \curvearrowright^{`}\right]} \\
{[\text { tupər] } \rightarrow C}\end{array}$ \\
\hline $\mathrm{T}-5$ & {$[\mathrm{t} \wedge \mathrm{n}]$} & $\begin{array}{l}\text { [tıwi] [tıwi] } \rightarrow \mathrm{L} \\
\quad[\text { tıwi] } \rightarrow \mathrm{S}\end{array}$ & $\begin{array}{l}{[\mathrm{tt} P] \rightarrow[\mathrm{gI} P]} \\
{[\mathrm{gI} P][\mathrm{tt} P]}\end{array}$ & $\begin{array}{c}{[\mathrm{tæd}] \rightarrow \mathrm{V}} \\
{[\mathrm{tæd}] \rightarrow[\mathrm{gæ}]} \\
{[\mathrm{tæd}]}\end{array}$ & 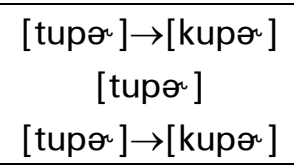 \\
\hline T-6 & {$[\mathrm{t} \wedge \mathrm{n}] \rightarrow \mathrm{S}$} & $\begin{array}{c}{[\text { trwi] } \rightarrow \text { S [trwi] }} \\
{[\text { tıwi }] \rightarrow S}\end{array}$ & [tI?] & $\begin{array}{l}{[t æ d][t æ d] \rightarrow C} \\
{[t æ d] \rightarrow S[t æ d]}\end{array}$ & 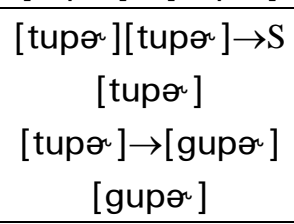 \\
\hline $\mathrm{T}-7$ & $\begin{array}{c}{[t \wedge n]} \\
{[t \wedge n] \rightarrow V}\end{array}$ & $\begin{array}{c}\text { [trwi] }{ }^{*}[\text { trwi }] \rightarrow S \\
{[\text { tIwi }] \rightarrow \mathrm{V}} \\
{[\text { tıwi }] \rightarrow \mathrm{L}}\end{array}$ & $\begin{array}{c}{[\mathrm{gI} P] \rightarrow[\mathrm{dI} P]} \\
{[\mathrm{tI} P]} \\
{[\mathrm{gI} P] \rightarrow[\mathrm{dI} P] \mathrm{S}} \\
{[\mathrm{tI} P][\mathrm{tI} P] \rightarrow S}\end{array}$ & $\begin{array}{c}{[\mathrm{tæd}] \mathrm{V}} \\
{[\mathrm{tæd}]} \\
{[\mathrm{tæd}] \rightarrow S}\end{array}$ & 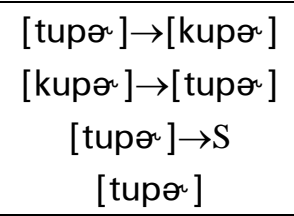 \\
\hline $\mathrm{T}-8$ & $\begin{array}{c}{[\mathrm{t} \wedge \mathrm{n}] \rightarrow \mathrm{S} \mathrm{V}} \\
{[\mathrm{t} \wedge \mathrm{n}] \rightarrow \mathrm{L}} \\
{[\mathrm{t} \wedge \mathrm{n}] \rightarrow \mathrm{V}}\end{array}$ & $\begin{array}{l}{[\text { trwi }] \rightarrow \mathrm{L}} \\
{[\text { trwi }]}\end{array}$ & & $\begin{array}{c}{[\mathrm{tæd}] \rightarrow \mathrm{V}} \\
{[\mathrm{tæd}] \mathrm{V} \rightarrow \mathrm{L}} \\
{[\mathrm{tæd}] \mathrm{V} \rightarrow \mathrm{S}} \\
{[\mathrm{tæd}] \rightarrow \mathrm{V}}\end{array}$ & 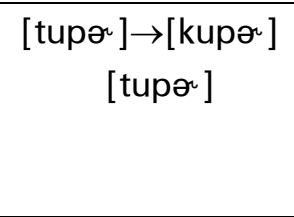 \\
\hline T-9 & $\begin{array}{c}{[t \wedge n]} \\
{[t \wedge n] \rightarrow V}\end{array}$ & $\begin{array}{c}{[\text { tIwi }] \rightarrow \mathrm{V}} \\
{[\text { tIwi] } \rightarrow \text { kIwi }]} \\
{[\text { tIwi }]}\end{array}$ & $\begin{array}{l}{[\mathrm{tI} P] \rightarrow \mathrm{V}} \\
\quad[\mathrm{tI} P]\end{array}$ & $\begin{array}{c}\text { [tæd] } \rightarrow \mathrm{V} \\
{[\mathrm{tæd}] \mathrm{L} \mathrm{V} \rightarrow \mathrm{V}} \\
{[\mathrm{tæd}]}\end{array}$ & 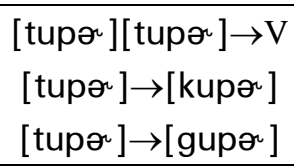 \\
\hline $\mathrm{T}-10$ & $\begin{array}{c}{[t \wedge n] \rightarrow V} \\
{[t \wedge n]}\end{array}$ & $\begin{array}{c}\text { [tıwi] }[\text { tIwi] } \rightarrow \mathrm{F} \\
\text { tIwi] } \rightarrow \mathrm{L}\end{array}$ & $\begin{array}{c}{[\mathrm{tI} P]} \\
{[\mathrm{tI} P] \rightarrow \mathrm{V}}\end{array}$ & $\begin{array}{c}\text { [tæd }] \\
{[\mathrm{tæd}] \rightarrow \mathrm{V}[\mathrm{tæd}]}\end{array}$ & $\begin{array}{c}{\left[\text { tup } \vartheta^{`}\right] \rightarrow F \text { L }} \\
{\left[\text { tup }^{`}\right] \rightarrow\left[\text { kup } \vartheta^{`}\right]}\end{array}$ \\
\hline $\mathrm{T}-11$ & $\begin{array}{c}{[\mathrm{t} \wedge \mathrm{n}] \rightarrow \mathrm{V}} \\
{[\mathrm{t} \wedge \mathrm{n}] \mathrm{V} \rightarrow[\mathrm{t} \wedge \mathrm{n}]}\end{array}$ & $\begin{array}{l}\text { [tıwi] } \rightarrow \mathrm{V} \text { [tıwi] } \\
{[\text { tıwi] } \rightarrow \mathrm{S} \text { [tıwi] }}\end{array}$ & {$[\mathrm{tI} P]$} & $\begin{array}{l}\text { [tæ] } \quad[\mathrm{tæd}] \\
{[\mathrm{tæ}][\mathrm{tæ}] \rightarrow \mathrm{V}} \\
\end{array}$ & 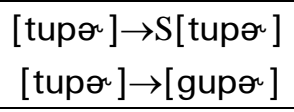 \\
\hline T-12 & $\begin{array}{c}{[\mathrm{t} \wedge \mathrm{n}] \rightarrow \mathrm{V}} \\
{[\mathrm{t} \wedge \mathrm{n}] \mathrm{V} \rightarrow[\mathrm{t} \wedge \mathrm{n}] \mathrm{V}} \\
{[\mathrm{t} \wedge \mathrm{n}][\mathrm{t} \wedge \mathrm{n}] \rightarrow \mathrm{V}}\end{array}$ & $\begin{array}{c}{[\text { trwi }] \rightarrow \mathrm{V}} \\
{[\text { trwi }] \mathrm{V} \rightarrow[\text { trwi }]} \\
{[\text { trwi }]}\end{array}$ & {$[\mathrm{tr} P]$} & 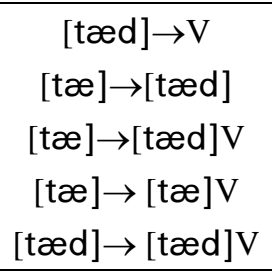 & 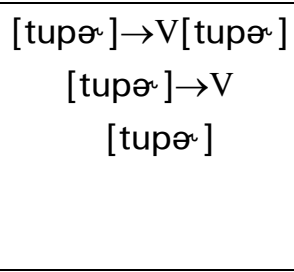 \\
\hline
\end{tabular}

* $\mathrm{T}=$ treatment session

Productive changes: $\mathrm{L}=$ louder $\mathrm{S}=$ softer $\mathrm{V}=$ lengthened vowel $\mathrm{F}=$ leaned forward $\mathrm{C}=$ clap 
followed by naturalistic production practice as seen in some current phonological intervention programs (Tyler, 2005a; Williams, 2005). Although Steven did not demonstrate progress on the target phonological pattern, he demonstrated improvement in the fricative class of sounds following the intervention period on the standardized assessment and on a sample of conversational speech. He also exhibited generalization of the target pattern to conversational speech one month following intervention. These findings will be addressed further under Research Questions 2, 3, 4, and 5.

Research Question 2: Will preschool children demonstrate within class generalization of targeted phonological patterns after 6 weeks of communication-centered phonological intervention?

Generalization, or system-wide improvement is the aim of phonological intervention (Gierut, 2001). The phonological process selected for intervention for each subject was "stopping", which occurs when stop consonants $[p, b, t, d, k, g]$ are substituted for the fricative class of sounds $\left[f, v, s, z, \int, 3, \theta, \partial_{,}\right]$as in [tu] for "shoe". The target phonological pattern for each subject was correct production of the fricative sound class $\left[f, v, s, z, \int, 3, \theta, \succ_{,}\right]$. Each child received intervention using five key words containing one fricative sound in the initial position of each word. During intervention sessions, productions were counted as correct if they demonstrated use of a fricative. Any fricative phoneme was counted as correct even if it was not the child's specific target. Based on results from the initial HAPP-3 administration before intervention and immediately following intervention, within class generalization of the targeted pattern was seen for all participants. In the context of this investigation, within class generalization occurred when improvement was seen in the production of fricatives not specifically targeted during intervention.

The initial [s] was the target sound for Subject 1 (Adam). Improvement following intervention was seen for the initial "sh" in the word "shoe" which was pronounced [u] on the initial assessment and [su] following intervention. Before intervention the initial fricative was omitted from the word, and following intervention, an initial fricative was included. This is considered within class generalization because the "sh" was not focused on during intervention sessions. Use of the "s" for the "sh" indicated improvement in the overall production of fricatives following intervention. Improvement was also seen in the 
production of the final "v" in the word "glove." Before intervention, a "p" was used as the final sound in the word. Following intervention, the fricative "s" was substituted for the "v." Adam also demonstrated an overgeneralization pattern on the second HAPP-3. Beginning on Item 21 of 50, he added an initial [s] to 26 of the remaining 30 words such as "watch" being pronounced as "swa." His use of overgeneralization may represent a general awareness of the target phonological pattern.

The target sound for Ben was the initial [f]. Examples of within class generalization on the HAPP-3 following intervention include improvement on initial "sh," final "s," and initial "z". Before intervention, a "d" was used in the initial position of the word "shoe," and following intervention, the word was pronounced correctly using the initial "sh." Improvement was seen on the final "s" in the word "vase." Before intervention, a " $\mathrm{t}$ " was substituted for the final " $\mathrm{s}$ " which was pronounced correctly following intervention. The word "zip" was pronounced "dip" before intervention and "sip" after the intervention period. Although the " $\mathrm{z}$ " was not correctly produced, use of the "s" signified correct use of the fricative class of sounds.

Although Steven's production of the target sound, initial "s", remained at $0 \%$ accuracy during intervention sessions, some improvement in the fricative class of sounds was seen on the second administration of the HAPP-3. He included the final "f" on the words "leaf" and "mouth" which had been omitted during the first administration of the HAPP-3.

Research Question 3: Will preschool children demonstrate generalization of targeted phonological patterns to conversational speech after 6 weeks of communication-centered phonological intervention?

Ben (Subject 2) and Steven (Subject 3) demonstrated generalization of the target fricative pattern to conversational speech immediately following intervention. Ben pronounced his target phoneme [f] correctly during the language sample following the intervention period on the words "feet," "face," and "falling," He also improved his production of the initial "sh" by saying [suz] for "shoes." Before intervention, he pronounced "shoes" as "dues" on the HAPP-3. His use of the initial "s" rather than the initial "d" indicated improvement in the fricative class of sounds during spontaneous speech. Although Steven did not demonstrate improvement on the target fricative pattern 
during intervention sessions, his use of the final [s] as a plural form improved on the second language sample. For example the word "arms" was pronounced "arm" on the first language sample and [armf] on the sample following intervention. Steven also improved his production of the final "th" in conversational speech. On the first language sample he said [bæp] for "bath" and on the second sample he said [mauf] for "mouth." Although his production of the final "th" was not correct, his use of the final " $\mathrm{f}$ " was an improvement in the use of the fricative class of sounds in spontaneous speech.

Adam (Subject 1) demonstrated improvement in his production of the target fricative pattern during intervention sessions, but showed little generalization of the target pattern to conversational speech. His production of the word "this" improved by his increased use of [drs] instead of [dr] from the first to the second language sample. Adam's severity level, as well as the length and intensity of treatment, may have been a factor in his failure to generalize production of the target phonological pattern to conversational speech. Of the three participants in this study, Adam presented with the most severe phonological disorder. He may have required sustained treatment for a longer period of time in order to acquire the new phonological pattern. Hodson (1991) pointed out that it takes time for a child to integrate a new pattern into their phonological systems. For example, using the Cycles Phonological Remediation Approach, it typically takes 30-40 hours of intervention for children with severe phonological disorders to become intelligible (Hodson, 1997). With continued intervention, Adam may have acquired the new phonological pattern and generalized it to conversational speech.

Research Question 4: Will preschool children demonstrate maintenance and within class generalization of targeted phonological patterns one month after 6 weeks of communication-centered phonological intervention?

Each subject displayed a unique pattern of maintenance and within class generalization of the target fricative pattern on the HAPP-3 administered one month following the intervention period. Subject Two, Ben, maintained improvement on nontarget fricatives that was noted following intervention. He also displayed extensive generalization to "S-Clusters" on the one month follow-up. Subject One, Adam, did not demonstrate maintenance and within class generalization of the fricative pattern on the one month follow-up. Subject Three, Steven, presented with an unusual profile. Although 
he did not achieve improved production of the target fricative pattern during the intervention period, he demonstrated improved production of the fricative class of sounds on the one month follow-up. He also displayed overall changes in the structure of his phonological system.

Grunwell (1997), an influential writer in clinical phonology, states that children are not just learning correct pronunciation of individual words, but are organizing their phonological systems. She proposes that the goal of intervention is to "facilitate cognitive reorganization of the child's phonology"(p.76). Grunwell describes four mechanisms of phonological change that result from phonological intervention: innovation, destabilization, stabilization, and generalization. Innovation refers to introduction of a new phonological pattern, while destabilization is a disruption of the original error pattern. During stabilization, new contrasts are established into a stable pattern of production. Generalization occurs when the new sound contrast is integrated into the child's phonological system as a new rule (Grunwell, 1997; Williams, 2003).

Following introduction of the fricative pattern, Subject One and Subject Three, appeared to exhibit "destabilization." Subject Two appeared to move through each level of phonological change including "stabilization" and "generalization." For Subject One, improvement in the use of the target pattern was seen during intervention sessions indicating a disruption of his error pattern; however, stabilization of the pattern on the follow-up assessments was not seen. It appears that Subject Three also exhibited destabilization of his error pattern which was evidenced by changes seen in his phonological system on the follow up standardized assessment. Although the overall phonological changes noted in Subject Three may have been due to maturation, it appears likely that the communication-centered intervention resulted in the system wide phonological changes representing cognitive reorganization described by Grunwell. Research Question 5: Will preschool children demonstrate maintenance and generalization of targeted phonological patterns to conversational speech one month after 6 weeks of communication-centered phonological intervention?

Maintenance and generalization patterns differed among the three subjects on the follow-up language sample. Subjects One (Adam) and Two (Ben) demonstrated maintenance of the specific target phoneme in conversational speech one month 
following intervention. Subject Three (Steven), who did not demonstrate improved use of the target fricative pattern during intervention, sustained improvement of the $[\mathrm{s}]$ and $[z]$ as plural forms from the second language sample to the follow-up language sample one month later. The only subject to clearly demonstrate generalization of the target fricative pattern to conversational speech one month later was Ben, Subject Two, who improved his production of the initial "sh" after targeting "f" during intervention.

The communication-centered phonological intervention appears to warrant further investigation. In this study, Subject Two demonstrated marked improvement in the production of the specific target phoneme as well as other phonemes in the fricative class. This improvement was noted not only during intervention sessions, but one month later on a standardized assessment and during conversational speech. Subject One demonstrated improvement of the fricative pattern only during intervention sessions. For some children, especially children with severe phonological impairments, a more intensive, sustained period of intervention may be needed in order to stabilize and generalize a new phonological rule. Although it appears that phonological reorganization

was occurring for Subject Three, additional intervention strategies may have been needed in order to effect acquisition and generalization of the fricative pattern to conversational speech.

\section{Implications}

Pragmatic approaches to phonological intervention have been the subject of discussion for decades; however, limited research has been conducted examining communication-centered approaches to phonological intervention. This study provides some preliminary support that communication-centered approaches are effective in facilitating change in children's phonological systems.

\section{Structured Play Format}

Although additional research is needed, this study has implications for current clinical practice. The structured play format used in this study could be implemented in most school or clinical settings. The children actively participated throughout the intervention period. Each child picked 2 of the 4 tasks to complete during intervention sessions. Overall, the children made very different selections indicating that giving children a choice of activity may impact their engagement. The children did not require 
encouragement to practice target sounds since they were embedded in meaningful activities.

\section{Minimal Pairs}

The use of contrast questions to facilitate communicative change has been proposed in the literature (Bellon-Harn et al., 2004; Hoffman, 1992; Lowe \& Weitz, 1994). This study lends support to using contrast questions in context during phonological intervention. Most clinicians are familiar with using minimal pairs during phonological intervention using a drill or drill-play format. This study provides evidence for using minimal pairs in the form of contrast questions during meaningful activities. Following the baseline period, initial use of contrast questions to request clarification seemed to create a period of tension in each subject. However, soon the children began using a variety of strategies to change their original production of a word. The contrast procedure appeared to prompt the children to determine how to be understood. This process may be key to using a communication-centered approach. The child may think, “Oh, I need to change something about how I'm talking.” For some children, this procedure is enough to facilitate production of a new pattern. For other children, this communicative component may be important; however, other clinical strategies may also be necessary to facilitate phonological change.

\section{Books as Therapeutic Tools}

Some researchers have proposed using books during phonological intervention (Bellon-Harn et al., 2004; Hoffman, 1997). This study lends support to using books as a tool during phonological intervention. In this study, books were used to provide opportunities to focus on the auditory and visual cues associated with the target fricative pattern. The children were actively involved during joint book reading and appeared to enjoy the predictable books and their manipulative features. Clinicians could create books such as these to supplement their current therapeutic strategies for children with phonological disorders. The books in the study were composed using basic computer techniques and commonly available materials. Clinicians could individualize predictable phrases to highlight their clients’ phonological targets. By incorporating shared book reading into phonological intervention, clinicians could provide multiple opportunities for children to hear key words modeled or provide multiple opportunities for meaningful 
production practice. If joint book reading activities are included in intervention sessions, clinicians may see a positive impact on children's progress.

\section{Collaborative Opportunity}

The communicative model for phonological intervention used in this investigation could be adapted for a collaborative effort between a school-based speech-language pathologist and a preschool teacher. Speech intervention could be provided in the preschool setting using the clinician-made books and the contrast question procedure. Specific auditory and visual cues identified for the child would be shared and modeled with the preschool teacher, who could incorporate the cues during other daily routines such as large group book reading. By using the speech sound production cues during other classroom activities, the teacher would be supporting the generalization process. Ongoing Progress

In the literature, percent of consonants correct (PCC) is often suggested as a measure to report phonological progress. In this study, it was obvious from the beginning that children were recognizing a need to do something different. Small adjustments in their pronunciation of words were seen throughout the intervention period. Based on analysis of data from each child's intervention sessions, gradual patterns of phonological change were seen. It could be important for clinicians to note changes from session to session during intervention in order to make ongoing adjustments to the intervention process.

\section{Limitations of the Study}

\section{Subject Selection}

Limitations relating to subject selection were seen with the participants in this investigation. This study included 3 Caucasian male preschoolers. Although a higher incidence of phonological impairment is seen in males, with the prevalence ratio of males to females with phonological impairment among rural White children being 2.4:1 (Shriberg, Tomblin, \& McSweeny, 1999), it would be important to address established gender ratios in future replications. There was also no ethnic diversity among the participants who were drawn from a rural county in Western Kentucky. According to demographic characteristics (U.S. Census Bureau, 2000), the percentage of individuals in the county who are white is $93.5 \%$. Future replications should include individuals from 
diverse ethnic backgrounds. The number of subjects in this study was small due to difficulty in identifying additional subjects that met the narrow selection criteria established for this investigation. However, the number of subjects was sufficient for the single subject design that was used (Tawney \& Gast, 1984).

\section{Method and Procedures}

There were several limitations of this study related to the method and procedures. The communication-centered intervention consisted of focused stimulation of key words during joint storybook reading in conjunction with interactive practice of key words using communicative feedback. Because storybook reading and the communicative feedback procedure were components of each intervention session, it was not possible to determine the relative importance of either component from the results of this study. It was necessary to analyze the intervention procedures as a total package.

The communication-centered procedures were carefully followed to ensure procedural reliability. This was necessary in order to provide the same therapeutic experience for each subject. However, when one child did not respond during the intervention, the investigator could not modify the procedures as would typically be done during phonological intervention with young children.

The procedures in this study also required focusing on one phonological target throughout the entire intervention period. Some linguistic approaches, such as the Cycles Approach (Hodson \& Paden, 1991), incorporate several, or rotating targets over time to facilitate the gradual nature of phonological improvement. In addition, target selection was pre-determined in order to use the same target selection process with each child. Typically, target selection is based on each child's unique phonological system. For example, Subject One, the child with the most severe phonological disorder, evidenced several omission patterns that, during standard treatment, would have been initial intervention targets.

\section{Internal Validity}

Threats to internal validity were systematically addressed during the planning and implementation of this study. Good attendance was seen for all 3 subjects who completed every baseline and treatment session. Maturation was addressed by using a multiple probe design rather than a continuous baseline. The relatively short intervention period 
and short session length also reduced the maturation threat. Experimental effects were minimized by including the small digital camera in the room for all baseline and treatment sessions.

Subject Two and Subject Three did not receive additional speech intervention during the study period; however, a potential history threat occurred with Subject One. During his final three intervention sessions, he began receiving speech intervention as part of his kindergarten program. This could potentially have influenced his results; however, his school speech-language pathologist reported that she has not focused on fricative production as part of his school intervention. Final consonants and the [k] and [g] sounds were initial targets. It appears that multiple treatment interference may not have been a factor impacting Subject One's performance in this study. If Subject One had demonstrated significant improvement at the one month follow-up, this might have pointed to the impact of the school intervention.

\section{Research Design}

Although the multiple probe design was appropriate to evaluate the effectiveness of communication-centered intervention, this single subject design did not permit direct comparison of the communication-centered intervention with an alternative intervention strategy. Systematic replication of this study is needed in order to establish external validity. It is important to continue to investigate intervention strategies for children who have phonological disorders. Children with moderate to severe phonological disorders are at risk not only for communication difficulties, but related academic problems such as delayed literacy development. It will be important to replicate the intervention procedures in this study with other clinicians in other clinical and educational contexts to establish social validity.

\section{Future Research}

The communication-centered phonological intervention employed in this investigation appeared to facilitate phonological improvement in children with moderate to severe phonological disorders and merits further research. Replication of this study across additional subjects, settings, or investigators is necessary to validate the effectiveness of this intervention. 


\section{Intervention Package}

The communication-centered phonological intervention consisted of focused stimulation of key words during joint storybook reading and interactive practice of key words using communicative feedback. Because both procedures were part of the intervention package, it would be useful to examine each component of the intervention to determine each element's relative contribution to phonological improvement. Phonological change could be monitored following a period of stimulation using only focused stimulation of key words during joint storybook reading to determine the effectiveness of using the bookreading procedure alone.

In this study, contrast questions using minimal pairs were used as therapeutic feedback during interactive practice of key words. Research comparing types of corrective feedback should also be completed. The effectiveness of using the communicative feedback procedure could be compared with the primary methods of corrective feedback used during phonological intervention, token reinforcement and verbal praise.

\section{Intervention Format}

This investigation used a structured play intervention format. Although drill and drill play formats are primarily employed by speech-language clinicians, naturalistic intervention formats have also been suggested for phonological intervention (Hoffman, 1992; Lowe \& Weitz, 1994). While naturalistic formats may create an appropriate communicative context, they can be problematic when designing a controlled intervention that will be consistent across participants. Structured play has the advantage of having characteristics of a naturalistic environment, but can be designed to provide a similar therapeutic experience for children. Additional replications of this study using the structured play format should be conducted to further examine the effectiveness of this intervention format.

In addition, replication of this study employing a longer intervention period may be necessary to document the intervention's effectiveness, especially for children who have severe phonological disorders. Longitudinal studies using the communicationcentered phonological intervention are recommended to provide further information about the course of phonological change during intervention 


\section{Treatment Approach Component}

Communication-centered intervention may also be effective when included as a component of an overall phonological treatment approach. Communicative activities are included in some phonological intervention programs (Tyler, 2005a; Williams, 2005). Future research should be conducted to investigate the use of communication-centered intervention in combination with other intervention formats. For example, the combination of a period of drill-play followed by communication-centered strategies may prove to be an effective treatment protocol for some children.

\section{Evidence-Based Practice}

Rehabilitation professionals are expected to use intervention strategies based on the best available current research. Clinicians integrate high-quality research evidence with practitioner expertise and client preference when making clinical decisions (American Speech-Language-Hearing Association, 2005). Evidence-based practice is critical for high quality professional practice. Experienced speech-language pathologists seek research that answers clinical questions related to phonological treatment. This study contributes to the research base in phonological intervention. Further research is needed relating to practical clinical issues such as phonological intervention that professionals can use to structure effective treatment for young children using current evidence and clinical experience. 
Appendix A

Consent to Participate in a Research Study

\section{THE EFFECTIVENESS OF USING COMMUNICATION-CENTERED INTERVENTION TO FACILITATE PHONOLOGICAL LEARNING IN YOUNG CHILDREN \\ WHY ARE YOU BEING INVITED TO TAKE PART IN THIS RESEARCH?}

Your child is being invited to take part in a research study to investigate an intervention method for children with speech disorders. Your child is being invited to take part in this research study because he or she is between the ages of three years, five months and four years, eleven months and is currently enrolled in speech therapy at preschool. If you volunteer for your child to take part in this study, your child will be one of four children to do so.

WHO IS DOING THE STUDY?

The individual responsible for this study is Sharon Hart. She is Coordinator of the Speech and Hearing Clinic at Murray State University and is a student in the Rehabilitation Sciences Doctoral Program at the University of Kentucky. Dr. Lori Gonzalez is her advisor. There may be other people on the research team assisting at different times during the study.

WHAT IS THE PURPOSE OF THIS STUDY?

The purpose of this study is to determine if communication-centered intervention will improve speech production in preschool children with moderate to severe phonological disorders. The communication-centered intervention will consist of repetition of key words by the investigator during joint storybook reading and interactive practice of key words.

WHERE IS THE STUDY GOING TO TAKE PLACE AND HOW LONG WILL IT LAST?

The research procedures will be conducted at the Murray State University Speech and Hearing Clinic. You will need to bring your child twice weekly for 30 minutes sessions for a period of six weeks between June 1, 2006 and August 31, 2006. A follow-up session will be scheduled approximately one month after the end of the 6 week intervention. WHAT WILL YOU BE ASKED TO DO?

During the first part of each session, the investigator and child will read the designated book for that week. The investigator will read the book first using the descriptive term and visual cue appropriate for the child. Next the child will be asked to read the book to the investigator. The investigator will provide assistance as the child reads the book. Following repetition of key words using the book, the investigator will engage the child in interactive practice of the key words. The child will select two activities from a choice of four. Each activity is designed to provide a chance for the child to use the target words. The four activites that will be used for interactive practice are called "Puzzle," "Game," "Make Something," and "Map.” For the puzzle activity, the investigator will hand out specific puzzle pieces to the child as they are requested. For the game activity, the investigator and child will play a bingo type game. Simple items will be made or decorated during the "Make Something" activity. During the "Map" activity the child and investigator uses a map to find a special item such as a shiny rock. 


\section{ARE THERE REASONS WHY YOUR CHILD SHOULD NOT TAKE PART IN THIS STUDY?}

If you will be unable to attend all sessions for the six week period of intervention you should not participate.

WHAT ARE THE POSSIBLE RISKS AND DISCOMFORTS?

The risks of participating in the study are minimal. The subjects will be participating in activities designed to improve communication skills.

WILL YOU BENEFIT FROM TAKING PART IN THIS STUDY?

Your child may benefit from participating in this study. Your child will be receiving six weeks of speech intervention designed to improve communication skills.

DO YOU HAVE TO TAKE PART IN THE STUDY?

If you decide for your child to take part in the study, it should be because you really want them to participate. If you decide not for your child to take part in this study, your decision will have no effect on the quality of regular speech therapy your child receives.

IF YOU DON'T WANT TO TAKE PART IN THE STUDY, ARE THERE OTHER CHOICES?

If you do not want to be in the study, there are no other choices except not to take part in the study.

WHAT WILL IT COST YOU TO PARTICIPATE?

There will be no cost to you if your child participates in the study.

WHO WILL SEE THE INFORMATION THAT YOU GIVE?

We will keep private all research records that identify your child to the extent allowed by law. However, there are some circumstances in which we may have to show your information to other people. For example, the law may require us to show your information to a court. Also, we may be required to show information which identifies you to people who need to be sure we have done the research correctly; these would be people from such organizations as the University of Kentucky.

Your child's information will be combined with information from other children taking part in the study. When we write about the study to share it with other researchers, we will write about the combined information we have gathered. Your child will not be identified in these written materials. We may publish the results of this study; however, we will keep your child's name and other identifying information private.

We will make every effort to prevent anyone who is not on the research team from knowing that you gave us information, or what that information is. All study information will be stored under lock and key.

\section{CAN YOUR TAKING PART IN THE STUDY END EARLY?}

If you decide for your child to take part in the study you still have the right to decide at any time that you no longer want to continue. Your child will not be treated differently if you decide to stop taking part in the study.

WHAT HAPPENS IF YOU GET HURT OR SICK DURING THE STUDY? It is not anticipated that your child will get hurt or become ill due to this study. The materials and activities used in the project are typical for speech intervention. The tasks that your child will be asked to do are designed for preschool children.

WILL YOU RECEIVE ANY REWARDS FOR TAKING PART IN THIS STUDY? 
Your willingness to allow your child to take part in this study may help speech-language pathologists improve intervention procedures for children with speech disorders. Your child will receive intervention services during this summer project free of charge.

WHAT IF YOU HAVE QUESTIONS, SUGGESTIONS, CONCERNS, OR COMPLAINTS?

Before deciding to participate in this study, please feel free to ask any questions that come to mind right now. Later, if you have any questions suggestions, concerns, or complaints about the study, you can contact Sharon Hart at 270-809-6841 or Dr. Lori Gonzalez at (859) 323-1100, ext 80480. If you have questions about your rights as a volunteer in this research project, contact the staff at the Office of Research Integrity at the University of Kentucky at 859-257-9428 or toll free at 1-866-400-9428. You will receive a copy of this consent form to take with you.

WHAT ELSE DO YOU NEED TO KNOW?

You are welcome to observe each intervention session through our two-way mirrors at the Murray State University Speech and Hearing Clinic.

Signature of person agreeing to take part in the study

Date

Printed name of person agreeing to take part in the study

Name of [authorized] person obtaining informed consent Date

Signature of Investigator 


\section{Appendix B}

\section{Script for Baseline Sessions}

The format of the baseline sessions was the same as the intervention sessions with shared book reading followed by two interactive activities. However, the child's production of the target pattern in key words was measured without application of the intervention procedures.

Introductory Activities

The clinician greeted the child. "We're going to play with our (character name) today. Let's make our plan.” The clinician presented the schedule board and placed the book picture on the board. The other four activity choices were presented and the child selected two and placed them on the schedule board.
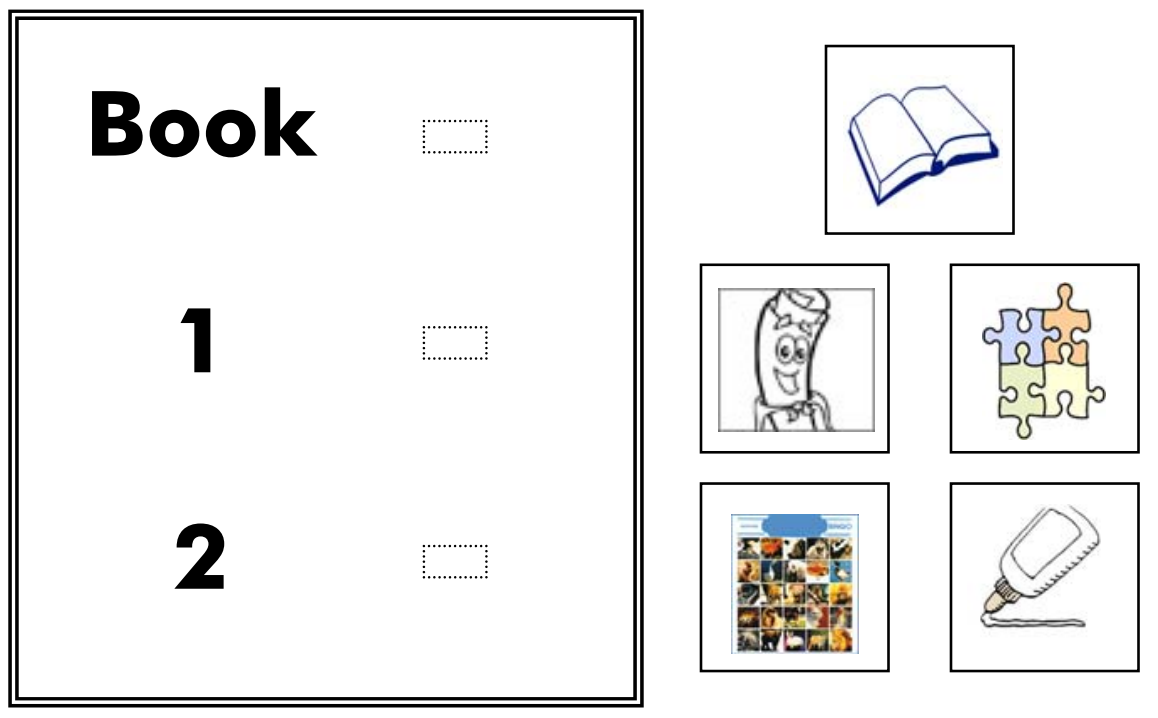

\section{Phase 1: Focused Stimulation of Key Words}

The clinician read the session book; however, the descriptive term and visual cue appropriate for the subject's target phonological pattern were not used. Next, the child read the book with help from the clinician without the cueing procedure.

Phase 2: Interactive Practice of Key Words

"Let's check the schedule. First, we're going to (name first child selected activity) and then we'll (name second child selected activity)”. Scripts for each interactive practice activity follow. The scripts are identical to the intervention sessions and were followed during baseline sessions. The communicative feedback procedure was not used if the child mispronounced a target word.

\section{Puzzle script.}

A set of puzzles was made for each child's characters by gluing the character on foam board and cutting each picture into four pieces. The clinician set out the subject's set of five puzzles, one for each character. "Let's make our (character name) puzzles. You be the puzzle maker, and I'll hand you the pieces. Tell me who you want first.” The clinician continued to hand puzzle pieces to the child as they were requested for each character's puzzle. 


\section{Game script.}

Bingo-type boards were made with the child's characters covering the board in rows. The object was cover each of the characters on the board with a smiley fact token. "Let's play our (character) game. You take these cards and I'll take these cards. We'll take turns telling each other which cat to put a smiley face on.” The clinician and child played the bingo-like game telling each other to "put a smiley face on silly cat" or "put one on sunny cat." The exact request varied slightly.

Make something script.

An item was made or decorated for each of the characters such as hats, new tails (or other body parts), accessories for the characters (such as fire for the dragons). The clinician and child talked about which items would be for each character. "We're going to make (item for the characters) for all of the (characters). Tell me who you're making each (item) for." Sample dialogue will be, "This is for funny dragon", "I made this for fat dragon", or This belongs to fancy dragon." The exact dialogue varied according to the context.

Map script.

This activity was modeled after the children's television program "Dora the Explorer”. The child used a map to find an item (shiny rock, big shell, or pretty flower) with the help of the five characters. Three pictures were placed on the map and indicated barriers to be crossed. The child helped the characters cross each barrier by calling them by name. The pictures were alternated during the intervention period with the props and overall format remaining the same as listed below.

\begin{tabular}{|l|l|l|l|l|l|}
\hline Direction & Picture One & Picture Two & Picture Three \\
\hline$\underline{\text { Picture }}$ & $\begin{array}{l}\text { Through the... } \\
\text { Tunnel Woods, or }\end{array}$ & $\begin{array}{l}\text { River, Lake, or } \\
\text { Pond }\end{array}$ & $\begin{array}{l}\text { Mountain, Hill, or } \\
\text { Tree }\end{array}$ \\
\hline$\underline{\text { Prop }}$ & Trapezoid Table & Blue Towel & Chair and Table \\
\hline
\end{tabular}

The clinician said, "I need your help. We need to find (the shiny rock). Here's the map.” The clinician gave child the map with three pictures on it and described the task. "We need to go through the woods, over the lake, and up the hill. You're the leader. You take the map and I'll get the (dragons). The (dragons) are scared so you have to tell them what to do. Just tell them, Come on (fast dragon)...you can do it." The child called the characters one by one to cross the barriers to find the lost item.

Data collection procedure.

Data was collected during Phase 2, interactive practice of key words, for the two activities selected for each session. A range of 10-15 opportunities for production of the target phonological pattern were planned for each interactive activity for a total of 20-30 opportunities for each session. A maximum of 30 responses were used to calculate a percent correct for the child's use of the target pattern in key words during the baseline session.

The clinician used the procedural reliability checklist for baseline sessions form (Appendix F) to record the child's responses. Each attempt of the target pattern in a key 
word was recorded. The time index from the video recording was entered next to each key word production. The accuracy of the child's responses was determined. Correct productions of the target pattern in a key word were coded as $(+)$ and incorrect productions of the target pattern in a key word were coded with a (-). 
Appendix C

Script for the Orientation Session

Clinician: "When you come to see me we're going to be playing with our dragons (character name). Let's decorate each of our dragons with glitter. All of your dragons start with long (descriptive term) sound / f / (phoneme exemplar)”. The clinician says a word containing the child's target pattern while simultaneously using the appropriate visual cue (Table 2.3). The clinician explains the visual cue. “That’s why I move my finger away from my lips.”

As the clinician and child decorate the characters, the clinician uses the visual cue while saying the dragon names. For example, the clinician might say, "Let's see we have fat dragon, fancy dragon, furry dragon, funny dragon, and fast dragon.”

“When you come we'll read a book about the dragons. Next, you'll pick two activities for us to do. Here are your choices.” The clinician shows the picture card representing each activity to the child and describes each choice.

"Map Hunt”: "You will lead the dragons on a hunt for something special." "Make Something”: "You will make something for each dragon like a new tail or a hat." "Game”: "You and I will play a bingo game and tell each other which dragons to cover up with these smiley faces.”

"Puzzle": "You will be a puzzle maker and I will hand you the pieces while you put together a puzzle of each of your dragons."

"I think we're going to have lots of fun." 


\section{Appendix D \\ Parent Questionnaire}

Date:

Child's Name:

Parent/Guardian's Name:

I will be using a set of five characters during each session with your child. I need your help picking characters your child will enjoy playing with. Please circle two choices that you think would work best for your child.

$\begin{array}{lll}\text { Cats } & \text { Dogs } & \text { Frogs }\end{array}$

$\begin{array}{lll}\text { Turtles } & \text { Bears } & \text { Birds }\end{array}$

$\begin{array}{lll}\text { Lions } & \text { Rabbits } & \text { Dinosaurs }\end{array}$

$\begin{array}{lll}\text { Monsters } & \text { Dragons } & \text { Fairies }\end{array}$

List other real or pretend characters your child might like better: 
Appendix E

Text of Clinician-Made Books

Baseline Book: “Bear Pizza” based on Hi Pizza Man by Virginia Walter

Mom...I'm hungry. Can we order a pizza?

Sure! The pizza man will be here soon.

What will you say when he comes to the door?

Hi, pizza man!

What if it's not a pizza man?

What if it's a sad bear?

Then what will you say?

Hi, sad bear.

Where's my pizza?

What if it's not a pizza man?

What if it's a silly bear?

Then what will you say?

Hi, silly bear.

Where's my pizza?

What if it's not a pizza man?

What if it's a sick bear?

Then what will you say?

Hi, sick bear.

Where’s my pizza?

What if it's not a pizza man?

What if it's a sun bear?

Then what will you say?

Hi, sun bear.

Where's my pizza?

What if it's not a pizza man?

What if it's a super bear?

Then what will you say?

$\mathrm{Hi}$, super bear.

Where’s my pizza?

Ring! Ring! Here it is. 
Book 1: “Where's My Tail” based on That's not my dinosaur by Rachel Wells

Super bear can't find his tail

That's not my tail...

This tail is too sad.

This is your tail sad bear.

That's not my tail...

This tail is too silly.

This is your tail silly bear.

That's not my tail...

This tail is too sick.

This is your tail sick bear.

That's not my tail...

This tail is too sunny.

This is your tail sun bear.

That's my tail...

My tail is so super!

Book 2: "Who broke this toy" based on Who's making that mess by Phillip Hawthorn and Jenny Tyler

Who broke this toy?

Not me said sad bear...I was in the sink.

Who broke this toy?

Not me said sick bear...I was in the mailbox.

Who broke this toy?

Not me said silly bear...I was in the refrigerator.

Who broke this toy?

Not me said super bear...I was in the garbage can.

Who broke this toy?

Not me said sun bear...I was in the birdbath.

Wait a minute...

It's not broken after all.

Never mind. 
Book 3: "I Went Walking” based on I Went Walking By Sue Williams

I went walking.

What did you see?

I saw a silly bear following at me.

I went walking.

What did you see?

I saw a sad bear following at me.

I went walking.

What did you see?

I saw a sick bear following at me.

I went walking.

What did you see?

I saw a sun bear following at me.

I went walking.

What did you see?

I saw a super bear following at me.

I went walking.

What did you see?

I saw lots of bears following at me.

Book 4: “The Bear’s Busy Morning” based on Bear's Busy Morning By Harriet Ziefert

The bears are busy all morning long.

What do they do?

See if you can guess.

Eight o'clock is breakfast time.

What will Silly Bear eat?

See if you can guess.

Silly Bear is eating some eggs.

It's nine o'clock. Time to paint and draw.

What will Sad Bear need?

See if you can guess.

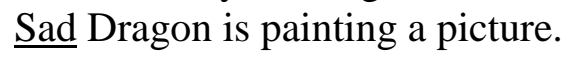


Ten o'clock is snack time.

What will Sun Bear drink?

See if you can guess.

Sun Bear is drinking lemonade.

It's eleven o'clock.

Time to play outside.

Where will Sick Bear climb?

See if you can guess.

Sick Dragon is climbing a tree.

At twelve o'clock it's time to go inside.

Who will give Super Bear a hug?

See if you can guess.

Super Bear's mother is giving him a hug.

Book 5: "Bedtime for Bears" based on Bedtime little monsters By Emma Harris

"Bedtime for bears!"

But the bears want some fun.

Scamper, scamper! Crash and bang!

Quickly! Off they run.

Who's that hiding under the bed?

I see sad bear's head.

Who's that hiding in the fruit?

I see silly bear, he's so cute!

Who's that playing in the sink?

I see sick bear taking a drink!

Who's that making all the noise?

I see super bear playing with toys.

Who's that playing in the tub?

I see sun bear, rub a dub dub!

All the bears have all been found.

They're tucked into bed.

Shh! Don't make a sound. 
Book 6: "Who Can Find the Cookie Jar?" by Sharon Hart

The bears are hungry.

Let's help them find the cookie jar.

Hey, sun bear.

Why don't you look in the bedroom?

No cookies in here.

Hey, silly bear.

Why don't you look in the bathroom?

No cookies in here.

Hey, sick bear.

Why don't you look in the living room?

No cookies in here.

Hey, sad dragon.

Why don't you look in the basement?

No cookies in here.

Hey, super dragon.

Why don't you look in the kitchen?

Come on everyone.

Here they are! 
Appendix F

Script for Intervention Sessions

\section{Introductory Activities}

The clinician greeted the child. "We're going to play with our (character name) today. Let's make our plan.” The clinician presented the schedule board and placed the book picture on the board. The other four activity choices were presented and the child selected two and placed them on the schedule board.
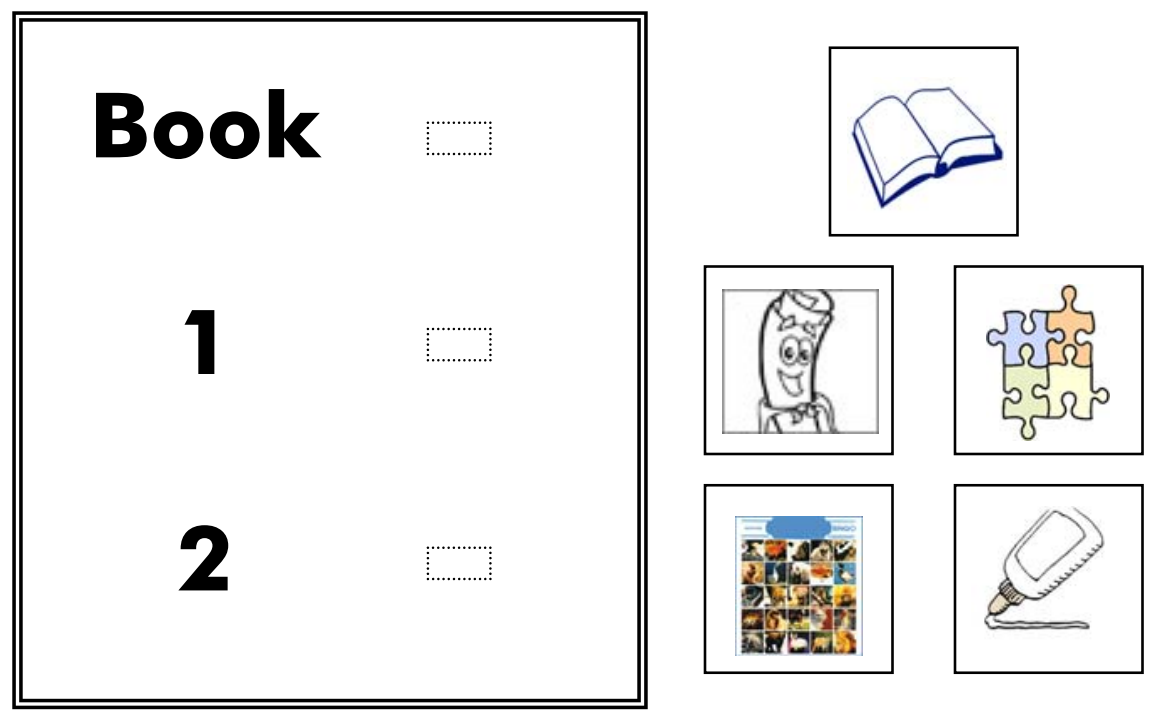

Phase 1: Focused Stimulation of Key Words

The clinician read the session book using the descriptive term and visual cue appropriate for the subject's target phonological pattern after reading each page. Sample cues are described in Table 3.2. An example of the procedure follows using the first four pages of "The Cookie Jar."

Page 1: "The bears are hungry. Let's help them find the cookie jar."

Page 2: "Hey, sad bear. Why don't you look in the bedroom?"

"sad" (with cue - pointer finger moves forward through the air from the clinician's lips as the [f] is produced), "that starts with your long sound"..."fat" (with cue) Page 3: "No cookies in here."

Page 4: Hey, silly bear. Why don't you look in the bathroom?"

"silly" (with cue), that starts with your long sound"..."silly" (with cue)

Next, the child read the book with help from the clinician. The cueing procedure was identical to the clinician's reading of the book. After each page, the clinician said the key word using the visual cue, then followed with the descriptive term, and a repetition of the key word with the visual cue.

Phase 2: Interactive Practice of Key Words

"Let's check the schedule. First, we're going to (name first child selected activity) and then we'll (name second child selected activity). Scripts for each interactive practice activity follow. 
Puzzle script.

A set of puzzles were made for each child's characters by gluing the character on foam board and cutting each picture into four pieces. The clinician set out the subject's set of five puzzles, one for each character. "Let's make our (character name) puzzles. You be the puzzle maker, and I'll hand you the pieces. Tell me who you want first." The clinician continued to hand puzzle pieces to the child as they were requested for each character's puzzle.

\section{Game script.}

Bingo-type boards were made with the child's characters covering the board in rows. The object was to cover each of the characters on the board with a smiley face token. "Let's play our (character) game. You take these cards and I'll take these cards. We'll take turns telling each other which cat to put a smiley face on." The clinician and child played the bingo-like game telling each other to "put a smiley face on silly cat" or "put one on sunny cat." The exact request varied slightly.

Make something script.

An item was made or decorated for each of the characters such as hats, new tails (or other body parts), accessories for the characters (such as fire for the dragons). The clinician and child talked about which items will be for each character. "We're going to make (item for the characters) for all of the (characters). Tell me who you're making each (item) for." Sample dialogue will be, "This is for funny dragon", "I made this for fat dragon”, or This belongs to fancy dragon.” The exact dialogue varied with the context.

\section{Map script.}

This activity was modeled after the children's television program "Dora the Explorer". The child used a map to find an item (shiny rock, big shell, or pretty flower) with the help of the five characters. Three pictures were placed on the map and indicated barriers to be crossed. The child helped the characters cross each barrier by calling them by name. The pictures were alternated during the intervention period with the props and overall format remaining the same as listed below.

\begin{tabular}{|l|l|l|l|l|}
\hline & Picture One & Picture Two & Picture Three \\
\hline$\underline{\text { Direction }}$ & Through the... & Over the... & Up the... \\
\hline$\underline{\text { Picture }}$ & $\begin{array}{l}\text { Cave, Woods, or } \\
\text { Tunnel }\end{array}$ & $\begin{array}{l}\text { River, Lake, or } \\
\text { Pond }\end{array}$ & $\begin{array}{l}\text { Mountain, Hill, or } \\
\text { Tree }\end{array}$ \\
\hline$\underline{\text { Prop }}$ & Trapezoid Table & Blue Towel & Chair and Table \\
\hline
\end{tabular}

The clinician said, "I need your help. We need to find (the shiny rock). Here's the map.” The clinician gave the child the map with three pictures on it and described the task. "We need to go through the woods, over the lake, and up the hill. You're the leader. You take the map and I'll get the (dragons). The (dragons) are scared so you have to tell them what to do. Just tell them, Come on (fast dragon)...you can do it.” The child called the characters one by one to cross the barriers to find the lost item.

Communicative feedback procedure. The same communicative feedback procedure was used during each of the interactive practice activities. For correct production of the target pattern, the clinician responded communicatively using modeling 
and cueing. For example, if the child said, "I need a piece for soft cat", the clinician handed the child a puzzle piece for the soft cat puzzle while saying, "Here's the long sound soft cat." The designated visual cue was used as the clinician said the key word "soft." Then the clinician provided a follow-up repetition of the key word by saying, "soft...(using the visual cue) that's your long sound."

If the child produced the target pattern incorrectly in the key word, the clinician asked the child a choice question. The question was structured as a minimal pair using the child's incorrect production and the correct production of the key word. For example, if the child said, "I need the toft cat", the response was "Do you need the toft cat or the soft cat?" If the child answered the contrast question by saying "soft cat" the clinician responded communicatively and gave the child the correct cat while providing a model and cue for the key word. The clinician used the visual cue while saying, "Here's the long sound soft cat." If the child responded incorrectly following the contrast question, the clinician responded with modeling and cueing of the correct production. For example, the clinician said, "Oh you want the long sound soft cat" while simultaneously using the visual cue for [s].

Data collection procedure.

Data was collected during Phase 2, interactive practice of key words, for the two activities selected for each session. A range of 10-15 opportunities for production of the target pattern were planned for each interactive activity for a total of 20-30 opportunities for each session. A maximum of 30 responses were used to calculate a percent correct for the child's use of the target pattern in key words during each intervention session.

The clinician used the procedural reliability checklist for intervention sessions form (Appendix H) to record the child's responses. Each attempt of the target pattern in a key word was recorded. The time index from the video recording was entered next to each key word production. The accuracy of the child's responses was determined. Correct productions of the target pattern in a key word were coded as $(+)$ and incorrect productions of the target pattern in a key word were coded with a (-). If the child responded with an incorrect production of the target pattern, the clinician asked the child a contrast question using the child's incorrect production and the correct production ("Do you need the toft cat or the soft cat?"). The child's response to the question was recorded on the data sheet under "target word" along with the time index. The child's attempts were coded as (+) for correct productions of the target pattern in the key word or (-) for an incorrect production of the target pattern. 
Appendix G

Reliability Data Sheet for Baseline Sessions

Subject Number:

Session Number:

Date:

\begin{tabular}{|l|l|l}
4 activity & Read book to &
\end{tabular}

\begin{tabular}{|c|c|c|c|c|}
$\begin{array}{c}4 \text { activity } \\
\text { choices } \\
\text { presented }\end{array}$ & $\begin{array}{c}\text { Child } \\
\text { picks } 2 \\
\text { activities }\end{array}$ & $\begin{array}{c}\text { Read book to } \\
\text { child (no } \\
\text { descriptive term } \\
\text { or visual cue) }\end{array}$ & $\begin{array}{c}\text { Child } \\
\text { "reads” } \\
\text { book }\end{array}$ & A
\end{tabular}

Procedure is observed $(+)$

Procedure is not observed (-)
Activities:

(A) Map

(B) Puzzle

(C) Game

(D) Make Something 


\section{Reliability Data Sheet for Baseline Sessions p.2}

$\begin{array}{ll} & \text { Activities: } \\ \text { Procedure is observed }(+) & \text { (A) Map } \\ & \text { (B) Puzzle } \\ \text { Procedure is not observed (-) } & \text { (C) Game } \\ & \text { (D) Make Something }\end{array}$

\begin{tabular}{|c|c|c|c|c|c|c|c|c|c|}
\hline $\begin{array}{l}4 \text { activity } \\
\text { choices } \\
\text { presented }\end{array}$ & $\begin{array}{c}\text { Child } \\
\text { picks } 2 \\
\text { activities }\end{array}$ & $\begin{array}{l}\text { Read book to } \\
\text { child (no } \\
\text { descriptive term } \\
\text { or visual cue) }\end{array}$ & $\begin{array}{l}\text { Child } \\
\text { "reads" } \\
\text { book }\end{array}$ & Activity & $\begin{array}{l}\text { Set out } \\
\text { materials } \\
\text { for } \\
\text { activity } \\
\end{array}$ & $\begin{array}{l}\text { Introduce } \\
\text { activity }\end{array}$ & Target word & $\begin{array}{l}\text { Time } \\
\text { index }\end{array}$ & $\begin{array}{c}\text { Accuracy of } \\
\text { child's } \\
\text { response } \\
(+/-)\end{array}$ \\
\hline & & & & & & & & & \\
\hline & & & & & & & & & \\
\hline & & & & & & & & & \\
\hline & & & & & & & & & \\
\hline & & & & & & & & & \\
\hline & & & & & & & & & \\
\hline & & & & & & & & & \\
\hline & & & & & & & & & \\
\hline & & & & & & & & & \\
\hline & & & & & & & & & \\
\hline & & & & & & & & & \\
\hline & & & & & & & & & \\
\hline & & & & & & & & & \\
\hline & & & & & & & & & \\
\hline & & & & & & & & & \\
\hline & & & & & & & & & \\
\hline & & & & & & & & & \\
\hline & & & & & & & & & \\
\hline & & & & & & & & & \\
\hline
\end{tabular}


Appendix $\mathrm{H}$

Reliability Data Sheet for Intervention Sessions (Phase I - Joint Book Reading)

Observer:

Subject Number:

Session Number:
Target phoneme: $1 / 1$

Procedure is observed $(+)$

Procedure is not observed (-)
Target pattern $(+)$ fricative used $\quad(-)$ non-fricative used

Descriptive term: "Long Sound"

Visual cue: Finger moves out from mouth

\begin{tabular}{|c|c|c|c|c|c|c|c|c|c|}
\hline \multirow{2}{*}{$\begin{array}{l}4 \text { activity } \\
\text { choices } \\
\text { presented }\end{array}$} & \multirow{2}{*}{$\begin{array}{l}\text { Child picks } \\
2 \text { activities }\end{array}$} & \multicolumn{4}{|c|}{ Read book to child } & \multicolumn{4}{|c|}{ Child “reads” book } \\
\hline & & Key word & $\begin{array}{l}\text { Time } \\
\text { index }\end{array}$ & $\begin{array}{c}\text { Use } \\
\text { descriptive } \\
\text { term with key } \\
\text { word }\end{array}$ & $\begin{array}{c}\text { Use } \\
\text { visual } \\
\text { cue with } \\
\text { key } \\
\text { word }\end{array}$ & Key word & $\begin{array}{l}\text { Time } \\
\text { index }\end{array}$ & $\begin{array}{c}\text { Use } \\
\text { descriptive } \\
\text { term with key } \\
\text { word }\end{array}$ & $\begin{array}{c}\text { Use } \\
\text { visual } \\
\text { cue with } \\
\text { key } \\
\text { word }\end{array}$ \\
\hline & & & & & & & & & \\
\hline & & & & & & & & & \\
\hline & & & & & & & & & \\
\hline & & & & & & & & & \\
\hline & & & & & & & & & \\
\hline & & & & & & & & & \\
\hline & & & & & & & & & \\
\hline & & & & & & & & & \\
\hline & & & & & & & & & \\
\hline & & & & & & & & & \\
\hline & & & & & & & & & \\
\hline & & & & & & & & & \\
\hline & & & & & & & & & \\
\hline & & & & & & & & & \\
\hline & & & & & & & & & \\
\hline & & & & & & & & & \\
\hline
\end{tabular}




\section{Appendix I}

Reliability Data Sheet for Intervention Sessions (Phase II - Interactive Practice)

Observer:

Subject Number:

Session Number:

\begin{tabular}{|c|c|c|c|c|c|c|c|c|c|c|c|c|}
\hline \multirow{4}{*}{$\begin{array}{c}\text { Set out } \\
\text { materials }\end{array}$} & \multirow{4}{*}{$\begin{array}{c}\text { Intro } \\
\text { activity }\end{array}$} & \multirow{4}{*}{ Target word } & \multirow{4}{*}{$\begin{array}{l}\text { Time } \\
\text { index }\end{array}$} & \multirow{4}{*}{$\begin{array}{l}\text { Accuracy } \\
\text { of child's } \\
\text { response } \\
(+/-)\end{array}$} & \multicolumn{8}{|c|}{ The clinician provides feedback depending on the subject's response } \\
\hline & & & & & \multicolumn{2}{|c|}{ Correct response } & \multicolumn{6}{|c|}{ Incorrect response } \\
\hline & & & & & \multirow{2}{*}{$\begin{array}{c}\text { Clinician } \\
\text { provides } \\
\text { communicative } \\
\text { response }\end{array}$} & \multirow{2}{*}{$\begin{array}{l}\text { Clinician } \\
\text { provides } \\
\text { follow-up } \\
\text { repetition }\end{array}$} & \multirow{2}{*}{$\begin{array}{l}\text { Clinician } \\
\text { asks } \\
\text { contrast } \\
\text { question }\end{array}$} & \multicolumn{3}{|c|}{ Child's response to contrast question } & \multicolumn{2}{|c|}{ Clinician’s response } \\
\hline & & & & & & & & Target word & $\begin{array}{l}\text { Time } \\
\text { index }\end{array}$ & $\begin{array}{c}\text { Accuracy } \\
\text { of child's } \\
\text { response } \\
(+/-)\end{array}$ & $\begin{array}{c}\text { If correct, } \\
\text { provide } \\
\text { communicative } \\
\text { response }\end{array}$ & $\begin{array}{c}\text { If } \\
\text { incorrect, } \\
\text { provide } \\
\text { term and } \\
\text { cue } \\
\end{array}$ \\
\hline & & & & & & & & & & & & \\
\hline & & & & & & & & & & & & \\
\hline & & & & & & & & & & & & \\
\hline & & & & & & & & & & & & \\
\hline & & & & & & & & & & & & \\
\hline & & & & & & & & & & & & \\
\hline & & & & & & & & & & & & \\
\hline & & & & & & & & & & & & \\
\hline & & & & & & & & & & & & \\
\hline & & & & & & & & & & & & \\
\hline & & & & & & & & & & & & \\
\hline & & & & & & & & & & & & \\
\hline & & & & & & & & & & & & \\
\hline & & & & & & & & & & & & \\
\hline & & & & & & & & & & & & \\
\hline
\end{tabular}

Target pattern (+/-) fricative used

Descriptive term: "Long Sound"

Procedure is observed $(+)$

Procedure is not observed (-) isual cue: Finger moves out from mouth
Activity:

$\begin{array}{ll}\text { Map } & \text { Game } \\ \text { Puzzle } & \text { Make Something }\end{array}$




\section{References}

Almost, D., \& Rosenbaum, P. (1998). Effectiveness of speech intervention for phonological disorders: A randomized controlled trial. Developmental Medicine \& Child Neurology, 40(5), 319-325.

American Psychiatric Association. (1994). Diagnostic and statistical manual of mental disorders (fourth ed.). Washington DC: American Psychiatric Association.

American Speech-Language-Hearing Association. (2001). Roles and responsibilities of speech-language pathologists with respect to reading and writing in children and adolescents (position statement, executive summary of guidelines, technical report). In Asha supplement 21 (pp. 17-28). Rockville, MD: American SpeechLanguage Hearing Association.

American Speech-Language-Hearing Association. (2004). 2004 schools survey: Caseload characteristics. Retrieved 3/1/05, from http://www.asha.org/NR/rdonlyres/35793FB5-99F6-46D9-B2F55D5973B05A95/0/SpecialCaseloads04.pdf

American Speech-Language-Hearing Association. (2005). Evidence-based practice in communication disorders [position statement]. Retrieved 3/4/07, from http://www.asha.org/members/deskref-journals/deskref/default

American Speech-Language-Hearing Association Audiologic Assessment Panel. (1997). Guidelines for audiologic screening. Rockville, MD: American Speech-Language Hearing Association.

Baker, E., \& Bernhardt, B. (2004). From hindsight to foresight: Working around barriers to success in phonological intervention. Child Language Teaching and Therapy, 20, 287-318.

Barlow, J., \& Gierut, J. (2002). Minimal pair approaches to phonological remediation. Seminars in Speech and Language, 23, 57-68.

Bauman-Waengler, J. (2004). Articulatory and phonological impairments - a clinical focus (Second ed.). Boston: Pearson Education, Inc.

Bellon-Harn, M., Hoffman, P., \& Harn, W. (2004). Use of cloze and contrast word procedures in repeated storybook reading: Targeting multiple domains. Journal of Communication Disorders, 37, 53-75.

Bernthal, J., \& Bankson, N. (1998). Articulation and phonological disorders (Fourth ed.). Boston: Allyn and Bacon.

Billingsley, F., White, O., \& Munson, R. (1980). Procedural reliability: A rationale and an example.

Bird, J., Bishop, D., \& Freeman, M. (1995). Phonological awareness and literacy development in children with expressive phonological impairments. Journal of Speech and Hearing Research, 38, 446-462.

Blache, S., Parsons, C., \& Humphreys, J. (1981). A minimal-word-pair model for teaching the linguistic significance of distinctive feature properties. Journal of Speech and Hearing Disorders, 46, 291-296.

Blodgett, E., \& Miller, V. (1989). Easy does it for phonology - a complete program to remediate phonological disorders in young children. East Moline, IL: LinguiSystems, Inc. 
Bohannon, J., \& Warren-Leubaker, A. (1985). Theoretical approaches to language acquisition. In J. Berko Gleason (Ed.), The development of language. Columbus, $\mathrm{OH}$ : Charles E. Merrill Publishing Company.

Bradshaw, M., Hoffman, P., \& Norris, J. (1998). Efficacy of expansions and cloze procedures in the development of interpretations by preschool children exhibiting delayed language development. Language, Speech, and Hearing Services in Schools, 29, 85-95.

Camarata, S. (1993). The application of naturalistic conversation training to speech production in children with speech disabilities. Journal of Applied Behavior Analysis, 26, 173-182.

Camarata, S. (1995). A rationale for naturalistic speech intelligibility intervention. In M. Fey, J. Windsor \& S. Warren (Eds.), Language intervention: Preschool through the elementary years. Baltimore, MD: Paul H. Brookes Publishing Co.

Camarata, S., \& Nelson, K. (1994). Comparison of conversational-recasting and imitative procedures for training grammatical structures in children with specific language impairment. Journal of Speech and Hearing Research, 37, 1414-1424.

Carroll, J., \& Snowling, M. (2004). Language and phonological skills in children at high risk of reading difficulties. Journal of Child Psychology and Psychiatry, 45, 631640.

Chomsky, N., \& Halle, M. (1968). The sound pattern of english. New York: Harper \& Row.

Cowan, R., Hennessey, M., Vierstra, C., \& Rumrill, P. (2004). Small-n designs in rehabilitation research. Journal of Vocational Rehabilitation, 20, 201-211.

Craig, H. (1983). Applications of pragmatic language models for intervention. In T. Gallagher \& C. Prutting (Eds.), Pragmatic assessment and intervention issues in language. San Diego, CA: College-Hill Press, Inc.

Crain-Thoreson, C., \& Dale, P. (1999). Enhancing linguistic performance: Parents and teachers as book reading partners for children with language delays. Topics in Early Childhood Special Education, 19, 28-40.

Crowe, L., Norris, J., \& Hoffman, P. (2003). Training caregivers to facilitate communicative participation of preschool children with language impairment during storybook reading. Journal of Communication Disorders, 37, 177-196.

Dean, E., Howell, J., Walters, D., \& Reid, J. (1995). Metaphon: A metalinguistic approach to the treatment of phonological disorder in children. Clinical Linguistics and Phonetics, 9, 19.

Delgado, R., \& Oller, K. (2001). Lipp, version 2.10. Miami, FL: Intelligent Hearing Systems.

Donegan, P., \& Stampe, D. (1979). The study of natural phonology. In D. Dinnsen (Ed.), Current approaches to phonological theory. Bloomington, IN: Indiana University Press.

Dyson, A., \& Robinson, T. (1987). The effect of phonological analysis procedures on the selection of potential remediation targets. Language, Speech, and Hearing Services in Schools, 18, 364-377.

Edwards, M. (1997). Historical overview of clinical phonology. In B. Hodson \& M. Edwards (Eds.), Perspectives in applied phonology. Gaithersburg, MD: Aspen Publishers, Inc. 
Edwards, M., \& Shriberg, L. (1983). Phonology: Applications in communicative disorders. San Diego, CA: College-Hill Press, Inc.

Elbert, M. (1989). Generalization in the treatment of phonological disorders. In L. McReynolds \& J. Spradlin (Eds.), Generalization strategies in the treatment of communication disorders. Toronto: B.C. Decker, Inc.

Elbert, M., Dinnsen, D., Swartzlander, P., \& Chin, S. (1990). Generalization to conversational speech. Journal of Speech and Hearing Disorders, 55, 694-699.

Elbert, M., \& Gierut, J. (1986). Handbook of clinical phonology. San Diego: College-Hill Press.

Elbert, M., \& McReynolds, L. (1975). Transfer of /r/ across contexts. Journal of Speech and Hearing Disorders, 40, 380-387.

Elbert, M., \& McReynolds, L. (1978). An experimental analysis of misarticulating children's generalization. Journal of Speech and Hearing Research, 21, 136-150.

Elbert, M., \& McReynolds, L. (1985). The generalization hypothesis: Final consonant deletion. Language and Speech, 28, 281-294.

Elbert, M., Powell, T., \& Swartzlander, P. (1991). Toward a technology of generalization: How many exemplars are sufficient? Journal of Speech and Hearing Research, 34, 81-87.

Fey, M. (1986). Language intervention with young children. Boston, MA: Allyn and Bacon.

Fey, M. (1992a). Articulation and phonology: Inextricable constructs in speech pathology. Language Speech and Hearing Services in Schools, 23, 225-232.

Fey, M. (1992b). Clinical forum: Phonological assessment and treatment. Articulation and phonology: An addendum. Language Speech and Hearing Services in Schools, 23, 277-282.

Forrest, K., \& Elbert, M. (2001). Treatment for phonologically disordered children with variable substitution patterns. Clinical Linguistics and Phonetics, 15, 41-45.

Forrest, K., Elbert, M., \& Dinnsen, D. (2000). The effect of substitution patterns on phonological treatment outcomes. Clinical Linguistics and Phonetics, 14, 519531.

Gallagher, T. (1977). Revision behaviors in the speech of normal children developing language. Journal of Speech and Hearing Research, 20, 303-318.

Gierut, J. (1990). Differential learning of phonological oppositions. Journal of Speech and Hearing Research, 30, 462-479.

Gierut, J. (1992). The conditions and course of clinically induced phonological change. Journal of Speech and Hearing Research, 35(1049-1063).

Gierut, J. (1998). Treatment efficacy: Functional phonological disorders in children. Journal of Speech, Language, and Hearing Research, 41, S85-S100.

Gierut, J. (1999). Syllable onsets: Clusters and adjuncts in acquisition. Journal of Speech, Language, and Hearing Research, 42, 708-726.

Gierut, J. (2001). Complexity in phonological treatment: Clinical factors. Language, Speech, and Hearing Services in Schools, 32, 229-241.

Gierut, J. (2005). Phonological intervention: The how or the what? In A. Kamhi \& K. Pollock (Eds.), Phonological disorders in children - clinical decision making in assessment and intervention. Baltimore, MD: Paul H. Brookes Publishing Co. 
Gierut, J., \& Champion, A. (1999). Interacting error patterns and their resistance to treatment. Clinical Linguistics and Phonetics, 13, 421-431.

Gierut, J., \& Champion, A. (2001). Syllable onsets ll: Three element clusters in phonological treatment. Journal of Speech, Language, and Hearing Research, 44, 886-904.

Gierut, J., Elbert, M., \& Dinnsen, D. (1987). A functional analysis of phonological knowledge and generalization learning in misarticulating children. Journal of Speech and Hearing Research, 33, 28-37.

Gierut, J., Morrisette, M., \& Champion, A. (1999). Lexical constraints in phonological acquisition. Journal of Child Language, 26, 261-294.

Grunwell, P. (1997). Developmental phonological disability: Order in disorder. In B. Hodson \& M. Edwards (Eds.), Perspectives in applied phonology (pp. 62-84). Gaithersburg, MD: Aspen Publishers, Inc.

Hegde, M. (2003). Clinical research in communicative disorders: Principles and strategies. Austin, TX: Pro-ed.

Hesketh, A. (2004). Early literacy achievement of children with a history of speech problems. International Journal of Language \& Communication Disorders, 39, 453-568.

Hesketh, A., Adams, C., Nightingale, C., \& Hall, R. (2000). Phonological awareness therapy and articulation training approaches for children with phonological disorders: A comparative outcome study. International Journal of Language and Communication Disorders, 35, 337-354.

Hodson, B. (1984). Facilitating phonological development in children with severe speech disorders. In H. Winitz (Ed.), Treating articulation disorders for clinicians by clinicians. Baltimore, MD: University Park Press.

Hodson, B. (1997). Disordered phonologies: What have we learned about assessment and treatment? In B. Hodson \& M. Edwards (Eds.), Perspectives in applied phonology. Gaithersburg, MD: Aspen Publishers, Inc.

Hodson, B. (2004). Hodson assessment of phonological patterns (Third ed.). Austin, TX: Pro-Ed.

Hodson, B. (2007). Evaluating and enhancing children's phonological systems-research and theory to practice. Greenville, SC: Thinking Publications.

Hodson, B., \& Paden, E. (1991). Targeting intelligible speech (2nd ed.). Austin, Texas: ProEd.

Hoffman, P. (1992). Synergistic development of phonetic skill. Language, Speech, and Hearing Services in Schools, 23, 254-260.

Hoffman, P. (1997). Phonological intervention within storybook reading. Topics in Language Disorders, 17, 69-88.

Hoffman, P., \& Daniloff, R. (1990). Evolving views of children's disordered speech sound production from motoric to phonological. Journal of Speech Language Pathology and Audiology, 14, 13-22.

Horner, R., \& Baer, D. (1978). Multiple-probe technique: A variation of the multiple baseline. Journal of Applied Behavior Analysis, 11, 189-196.

Horner, R., Carr, E., Halle, J., McGee, G., Odom, S., \& Wolery, M. (2005). The use of single-subject research to identify evidence-based practice in special education. Exceptional Children, 71, 165-179. 
Ingram, D. (1976). Phonological disability in children. New York: Elsevier.

Ingram, D. (1989). Phonological disability in children, second edition. San Diego: Singular Publishing Group, Inc.

Kaderavek, J., \& Justice, L. (2002). Shared storybook reading as an intervention context: Practices and potential pitfalls. American Journal of Speech Language Pathology, 11, 395-406.

Kaderavek, J., \& Justice, L. (2005). The effect of book genre in the repeated readings of mothers and their children with language impairment: A pilot investigation. Child Language Teaching and Therapy, 21, 75-92.

Kamhi, A. (2000). Practice makes perfect: The incompatibility of practicing speech and meaningful communication. Language, Speech, and Hearing Services in Schools, 31, 182-185.

Kazdin, A. (1982). Single-case research designs: Methods for clinical and applied settings. New York: Oxford University Press.

Kirshner, D. (1991). Reciprocal book reading: A discourse-based intervention strategy for the child with atypical language development. In T. Gallagher (Ed.), Pragmatics of language: Clinical practice issues. San Diego, CA: Singular Publishing Group, Inc.

Lewis, B., Freebairn, L., \& Taylor, H. (2000). Follow-up of children with early expressive phonology disorders. Journal of Learning Disabilities, 33, 433-445.

Loeb, D. (1997). Language theory and practice. In L. McCormick, D. Loeb \& R. Schiefelbusch (Eds.), Supporting children with communication difficulties in inclusive settings: School-based language intervention. Boston, MA: Allyn and Bacon.

Low, G., Newman, P., \& Ravsten, M. (1989). Pragmatic considerations in treatment: Communication centered instruction. In N. Creaghead, P. Newman \& W. Secord (Eds.), Assessment and remediation of articulatory and phonological disorders. Columbus, OH: Merrill Publishing Company.

Lowe, R., \& Weitz, J. (1994). Intervention. In R. Lowe (Ed.), Phonology: Assessment and intervention applications in speech pathology. Baltimore, MD: Williams \& Wilkins.

McCauley, R. (1993). A comprehensive phonological approach to the assessment and treatment of sound system disorders. Seminars in Speech and Language, 14, 153165.

McReynolds, L. (1972). Articulation generalization during articulation training. Language and Speech, 15, 149-115.

McReynolds, L., \& Elbert, M. (1981). Generalization of correct articulation in clusters. Applied Psycholinguistics, 2, 119-132.

Miccio, A., Elbert, M., \& Forrest, K. (1999). The relationship between stimulability and phonological acquisition in children with normally developing and disordered phonologies. American Journal of Speech Language Pathology, 8, 347-363.

Morrisette, M., \& Gierut, J. (2002). Lexical organization and phonological change in treatment. Journal of Speech, Language, and Hearing Research, 45, 143-159.

Nathan, L., Stackhouse, J., Goulandris, N., \& Snowling, M. (2004). The development of early literacy skills among children with speech difficulties: A test of the "critical 
age hypothesis". Journal of Speech, Language, and Hearing Research, 47, 377391.

National Institute on Deafness and Other Communication Disorders. (2005). Statistics on voice, speech, and language. Retrieved 3/5/05, from http://www.nidcd.nih.gov/health/statistics/vsl.asp

Norris, J., \& Hoffman, P. (1990). Language intervention within naturalistic environments. Language, Speech, and Hearing Services in Schools, 21, 72-84.

Norris, J., \& Hoffman, P. (2005). Goals and targets: Facilitating the self-organizing nature of a neuro-network. In A. Kamhi \& K. Pollock (Eds.), Phonological disorders in children: Clinical decision making in assessment and intervention. Baltimore, MD: Paul H. Brookes Publishing Co.

Pena-Brooks, A., \& Hegde, M. (2000). Assessment and treatment of articulation and phonological disorders in children. Austin, TX: Pro-Ed, Inc.

Powell, T. (1991). Planning for phonological generalization: An approach to treatment target selection. American Journal of Speech Language Pathology, 1, 21-27.

Powell, T., \& Elbert, M. (1984). Generalization following the remediation of early-and later-developing consonant clusters. Journal of Speech and Hearing Disorders, 49, 211-218.

Powell, T., Elbert, M., \& Dinnsen, D. (1991). Stimulability as a factor in the phonological generalization of misarticulating preschool children. Journal of Speech and Hearing Research, 34, 1318-1328.

Powell, T., Elbert, M., Miccio, A., Strike-Roussos, C., \& Brasseur, J. (1998). Facilitating /s/ production in young children: An experimental evaluation of motoric and conceptual treatment approaches. Clinical Linguistics and Phonetics, 12, 127-146.

Powell, T., Miccio, A., Elbert, M., Brasseur, J., \& Strike-Roussos, C. (1999). Patterns of sound change in children with phonological disorders. Clinical Linguistics and Phonetics, 13, 163-182.

Rockman, B., \& Elbert, M. (1984). Generalization in articulation training. In H. Winitz (Ed.), Treating articulation disorders for clinicians by clinicians. Baltimore, MD: University Park Press.

Rvachew, S., \& Nowak, M. (2001). The effect of target-selection strategy on phonological learning. Journal of Speech, Language, and Hearing Research, 44, 610-623.

Saben, C., Costello, \& Ingham, J. (1991). The effect of minimal pairs treatment on the speech sound production of two children with phonologic disorders. Journal of Speech and Hearing Research, 34, 1023-1040.

Schiavetti, N., \& Metz, D. (2002). Evaluating research in communicative disorders. Boston, MA: Allyn and Bacon.

Secord, W. (1989). The traditional approach to treatment. In N. Creaghead, P. Newman \& W. Secord (Eds.), Assessment and remediation of articulatory and phonological disorders, second edition. Columbus, OH: Merrill Publishing Company.

Shriberg, L., \& Kwiatkowski, J. (1980). Natural process analysis: A procedure for phonological analysis of continuous speech samples. New York: John Wiley \& Sons. 
Shriberg, L., \& Kwiatkowski, J. (1982). Phonological disorders ll: A conceptual framework for management. Journal of Speech and Hearing Disorders, 47, 242256.

Shriberg, L., Kwiatkowski, J., \& Hoffman, K. (1984). A procedure for phonetic transcription by consensus. Journal of Speech and Hearing Research, 27, 456465.

Shriberg, L., Tomblin, B., \& McSweeny, J. (1999). Prevalence of speech delay in 6-yearold children and comorbidity with language impairment. Journal of Speech, Language, and Hearing Research, 42, 1461-1481.

St. Louis, K., \& Ruscello, D. (2000). Oral speech mechanism screening examination (Third ed.). Austin, TX: Pro-Ed.

Stampe, D. (1969). The acquisition of phonetic representation. In R. Binnick, A. Davison, G. Green \& J. Morgan (Eds.), Papers from the fifth regional meeting of the chicago linguistic society. Chicago: University of Chicago Department of Linguistics.

Stampe, D. (1979). A dissertation on natural phonology. New York: Garland Publishing, Inc.

Stoel-Gammon, C., \& Dunn, C. (1985). Normal and disordered phonology in children. Austin, TX: PRO-ED, Inc.

Stoel-Gammon, C., Stone-Goldman, J., \& Glaspey, A. (2002). Pattern-based approaches to phonological therapy. Seminars in Speech and Language, 23, 3-13.

Stone, J., \& Stoel-Gammon, C. (1990). One class at a time: A case study of phonological learning. Child Language Teaching and Therapy, 6, 173-192.

Tawney, J., \& Gast, D. (1984). Single subject research in special education. Columbus, OH: Charles E. Merrill Publishing Co.

Tyler, A. (2005a). Planning and monitoring intervention programs. In A. Kamhi \& K. Pollock (Eds.), Phonological disorders in children: Clinical decision making in assessment and intervention. Baltimore, MD: Paul H. Brookes Publishing Co.

Tyler, A. (2005b). Promoting generalization. In A. Kamhi \& K. Pollock (Eds.), Phonological disorders in children: Clinical decision making in assessment and intervention. Baltimore, MD: Paul H. Brookes Publishing Co.

Tyler, A., \& Figurski, G. (1994). Phonetic inventory changes after treating distinctions along an implicational hierarchy. Clinical Linguistics and Phonetics, 8, 91-107.

U.S. Census Bureau. (2000). Profile of general demographic characteristics: 2000. Retrieved 5-5-07, from http://censtats.census.gov/data/KY/05021035.pdf

Van Riper, C. (1978). Speech correction principles and methods (Sixth ed.). Englewood Cliffs, NJ: Prentice-Hall, Inc.

Vilaseca, R., \& Del Rio, M. (2004). Language acquisition by children with down syndrome: A naturalistic approach to assisting language acquisition. Child Language Teaching and Therapy, 20, 163-180.

Webster, P., Plante, A., \& Couvillion, M. (1997). Phonologic impairment and prereading: Update on a longitudinal study. Journal of Learning Disabilities, 30, 365-375.

Weiner, F. (1981). Treatment of phonological disability using the method of meaningful minimal contrasts: Two case studies. Journal of Speech and Hearing Disorders, 46, 320-328. 
Weiner, F., \& Ostrowski, A. (1979). Effects of listener uncertainty on articulatory inconsistency. Journal of Speech and Hearing Disorders, 44, 487-493.

Williams, A. (1991). Generalization patterns associated with training least phonological knowledge. Journal of Speech and Hearing Research, 34, 722-733.

Williams, A. (1993). Phonological reorganization: A qualitative measure of phonological improvement. American Journal of Speech Language Pathology, 2, 44-51.

Williams, A. (2003). Speech disorders: Resource guide for preschool children. Clifton Park, NY: Thomson Delmar Learning.

Williams, A. (2005). A model and structure for phonological intervention. In A. Kamhi \& K. Pollock (Eds.), Phonological disorders in children: Clinical decision making in assessment and intervention. Baltimore, MD: Paul H. Brookes Publishing Co.

Winitz, H. (1975). From syllable to conversation. Baltimore, MD: University Park Press.

Wolery, M., \& Dunlap, G. (2001). Reporting on studies using single-subject experimental methods. Journal of Early Intervention, 24, 85-89.

Zhan, S., \& Ottenbacher, K. (2001). Single subject research designs for rehabilitation. Disability and rehabilitation, 23, 1-8.

Zimmerman, I., Steiner, V., \& Pond, R. (2002). Preschool language scale (Fourth ed.). San Antonio, TX: The Psychological Corporation. 


\section{VITA}

\section{SHARON B. HART \\ Department of Wellness \& Therapeutic Sciences \\ Murray State University}

Date of Birth: January 7, 1961

Place of Birth: Fort Lee, Virginia

\section{EDUCATION}

M.A. 1984 The University of Tennessee, Knoxville, TN

Speech Pathology

B.S. 1983 Murray State University, Murray, KY

Communication Disorders

\section{PROFESSIONAL EXPERIENCE}

Murray State University, August 1997 to present, Clinic Coordinator/Instructor,

Department of Wellness \& Therapeutic Sciences, Division of Communication Disorders

Calloway County School System, Murray, KY, August 1989 to August 1997

Henry County School System, Paris, TN, August 1988 to June 1989

Obion County School System, Union City, TN, August 1986 to June 1988

Private Practice of Marcia Jennison, CCC-SLP, Chattanooga, TN, June 1985 to August 1985

Bradley County School System, Cleveland, TN, January 1985 to June 1986

\section{STATE REFEREED PRESENTATIONS}

Hart, S. (1993, March) Speech Language Pathologist and the Primary Program presented to Kentucky Conference on Communication Disorders, Lexington, Kentucky

Blodgett, E. \& Hart S. (1996, February) Let’s Try for a Cognitive Click: School Aged Children with Speech Sound Disorders. Presented to Kentucky Conference on Communication Disorders, Lexington, KY

Hart, S. (2000, March) Language Intervention with School Age Children: Strategies for SLPA's and Those New to Providing School Services presented to Kentucky Conference on Communication Disorders, Louisville, Kentucky

Hart, S. (2004, February) Target Selection for Phonological Intervention - Clinical Choices presented to Kentucky Conference on Communication Disorders, Louisville, Kentucky 


\section{SELECTED INVITED PRESENTATIONS}

Hart, S. \& Haney, A. (1991, November). Making Connections For Learning - The Brain Compatible Classroom Presented to meeting of People Understanding Children with Handicaps (PUNCH) Paducah, Kentucky

Hart, S. (1992, June). Speech-Language Therapy Integrated Into The Pre-School Classroom Presented to Early Childhood Preschool Summer Topical Conference, Louisville, Kentucky

Hart, S. (1995, October) Language Intervention in the Schools. Presented to KSHA Fall Workshop, Bowling Green, Kentucky

Hart, S. (1998, November) A Primer for Special Education Personnel: The role of the speech language Pathologist as a Team Member from Evaluation through Service Delivery. Presented to Exceptional Children's Conference, Louisville, KY

\section{SELECTED INSERVICE PRESENTATIONS}

Hart, S. \& Haney, A. (1991, November) Making Connections For Learning - The Brain Compatible Classroom Presented to the Murray State University chapter of Phi Delta Kappa, Murray, Kentucky

Hart, S., Haney, A., Cherry, P., Combs, E. (1992, June) Developing A Primary Classroom Focusing On The Whole Child. Presented to Primary Institute III, (Lexington and Murray Kentucky)

Hart, S. \& Haney, A. (1993, June) Successful Inclusion of Special Needs Learners in the Primary Program. Presented for West Kentucky Educational Coop. Murray, Kentucky

Hart, S. \& Haney, A. ( 1993, June) Developing Brain Compatible Classrooms Where All Children Can Learn, Presented for Central Kentucky Education Cooperative, Lexington, Kentucky

Hart, S. \& Haney, A. (1993, June) Megaskills: A Dynamic Tool for Developing KERA Goals 3 and 4. Presented for Central Kentucky Education Cooperative, Lexington, Kentucky

Hart, S. \& Haney, A. (1993, July) A Kentucky Primary School: A Speech Language Pathologist’s Role. Presented for Ohio Valley Educational Cooperative, La Grange, Kentucky

Hart, S. \& Haney, A. (1993, June, August) How To Collaborate For Successful Inclusion Of Special Needs Learners. Presented for Early Childhood Regional Primary Institute (Murray State University - June 1993 and Lexington Kentucky - August 1993) 
Hart, S. \& Haney, A. (1993, August) Consultation/Collaboration Strategies for Regular and Special Educators. Presented for Central Kentucky Education Cooperative, Lexington, Kentucky

Hart, S. \& Haney, A. (1993, August) How To Collaborate For Successful Inclusion Of Special Needs Learners. Presented for Yates Elementary School, Lexington, Kentucky

\section{THESIS COMMITTEES}

Seiner, Leigh Ann (1999). Teaching Meaningful Vocabulary: The Effect of Using Music and Movement In The Classroom., thesis committee member

Gregory, Carrie (2001). Communication Abilities of a Six year Old Bilingual Child, undergraduate honors thesis, advisor

Schaaf, Stephanie (2007) Creating Communicative Contexts for Phonological Intervention: A Single Subject Study, thesis committee member

\section{PROFESSIONAL CERTIFICATIONS}

The Certificate of Clinical Competence in Speech-Language Pathology (American Speech-Language-Hearing Association)

Licensed Speech-Language Pathologist, Kentucky Board of Speech-Language Pathology and Audiology

\section{PROFESSIONAL ASSOCIATION MEMBERSHIPS}

American Speech-Language-Hearing Association (ASHA), Member

Kentucky Speech-Language Hearing Association (KSHA), Member

\section{PROFESSIONAL SERVICE}

Kentucky Eligibility Guidelines (KEG) Trainer

Kentucky Speech Language Hearing Association, Executive Board

\section{SELECTED UNIVERSITY SERVICE}

University - Roads Scholars Program, Team Captain 1998-99

College - Member of Field Experience Committee, 1998; Teacher educator member of Kentucky Teacher Internship Program (KTIP) teams

Department - Undergraduate advisor, 1997 to present 